\title{
Recent Advances in Chemistry of Unsymmetrical Phosphorus-Based Pincer Nickel Complexes: From Design to Catalytic Applications
}

\author{
Zufar N. Gafurov 1,*, Artyom O. Kantyukov ${ }^{1,2}$, Alexey A. Kagilev ${ }^{1,2}$, Alina A. Kagileva ${ }^{1,2}$, I1'yas F. Sakhapov ${ }^{1}$, \\ Ilya K. Mikhailov ${ }^{2}$ and Dmitry G. Yakhvarov $1,2, *$ (D) \\ 1 FRC Kazan Scientific Center, Arbuzov Institute of Organic and Physical Chemistry, Russian Academy of \\ Sciences, 420088 Kazan, Russia; kant.art@mail.ru (A.O.K.); al-kagilev@mail.ru (A.A.K.); \\ vtb241997@mail.ru (A.A.K.); sakhapovilyas@mail.ru (I.F.S.) \\ 2 Alexander Butlerov Institute of Chemistry, Kazan Federal University, 420008 Kazan, Russia; \\ tiimhailovilya@gmail.com \\ * Correspondence: zufargo@gmail.com (Z.N.G.); yakhvar@iopc.ru (D.G.Y.); Tel.: +7-(843)-2732253 (D.G.Y.)
}

\section{check for}

updates

Citation: Gafurov, Z.N.; Kantyukov, A.O.; Kagilev, A.A.; Kagileva, A.A.; Sakhapov, I.F.; Mikhailov, I.K.;

Yakhvarov, D.G. Recent Advances in Chemistry of Unsymmetrical Phosphorus-Based Pincer Nickel Complexes: From Design to Catalytic Applications. Molecules 2021, 26, 4063 https://doi.org/10.3390/molecules 26134063

Academic Editor: Yves Canac

Received: 27 May 2021

Accepted: 29 June 2021

Published: 2 July 2021

Publisher's Note: MDPI stays neutral with regard to jurisdictional claims in published maps and institutional affiliations.

Copyright: (c) 2021 by the authors. Licensee MDPI, Basel, Switzerland. This article is an open access article distributed under the terms and conditions of the Creative Commons Attribution (CC BY) license (https:// creativecommons.org/licenses/by/ $4.0 /)$

\begin{abstract}
Pincer complexes play an important role in organometallic chemistry; in particular, their use as homogeneous catalysts for organic transformations has increased dramatically in recent years. The high catalytic activity of such bis-cyclometallic complexes is associated with the easy tunability of their properties. Moreover, the phosphorus-based unsymmetrical pincers showed higher catalytic activity than the corresponding symmetrical analogues in several catalytic reactions. However, in modern literature, an increasing interest in the development of catalysts based on non-precious metals is observed. For example, nickel, which is an affordable and sustainable analogue of platinum and palladium, known for its low toxicity, has attracted increasing attention in the catalytic chemistry of transition metals in recent years. Thus, this mini-review is devoted to the recent advances in the chemistry of unsymmetrical phosphorus-based pincer nickel complexes, including the ligand design, the synthesis of nickel complexes and their catalytic applications.
\end{abstract}

Keywords: pincer ligands; unsymmetrical ligands; nickel complexes; PCN and POCN complexes; NNP and PNP complexes; NHC complexes; catalysts

\section{Introduction}

The control of the properties of metal complexes by varying the nature of the ligand to obtain highly efficient catalytic systems and materials with useful properties is one of the main tasks of modern organometallic and inorganic chemistry. Fine-tuning of the steric and electronic parameters of the formed metal complexes can be realized by chelation by binding the ligand to the metal through two or more bonds, which leads to a dramatic change in the properties of metal complexes such as stability and reactivity [1,2].

The introduction of a direct metal-carbon bond in chelate systems leads to the formation of an organometallic complex with a metal cycle, providing additional stabilization of this bond [3-19]. Pincer ligands are tridentate and typically bind to a metal in a meridional fashion, forming complexes of general formula $\left[\mathrm{M}\left(\mathrm{E}^{1} \mathrm{YE}^{2}\right) \mathrm{L}_{\mathrm{m}}\right] \mathrm{X}_{\mathrm{n}}$ (Figure 1), where $\mathrm{E}^{1}$ and $\mathrm{E}^{2}$ are typically a neutral two-electron donor group (such as amine or phosphine group), while $\mathrm{Y}$ is usually represented by an anionic carbon atom of a 2,6-disubstituted aryl moiety or, less often, pyridine group; $X$ and $L$ are counterions and auxiliary ligands, respectively; $M$ is metal [20]. Pincer complexes play an important role in organometallic chemistry mainly due to their versatility, arising from the numerous possibilities to adjust the ligand environment, as well as due to their high thermal stability, which is mainly attributed to the rigidity of the pincer framework [2]. In particular, their use as homogeneous catalysts for organic transformations has increased dramatically in recent years [1,3,4,12-15]. The high catalytic activity of such bis-cyclometallic complexes is associated with the easy tunability 
of their properties [8]. PCP-type nickel complexes have been reported as the first example of nickel pincer systems [21], followed by NCN pincer nickel complexes [22,23]; this success promoted the development of the chemistry of pincer ligands as a whole. These two types of ligands show different influence of the properties of the formed nickel complexes. For example, the use of an NCN pincer ligand enabled the stabilization of nickel (III) complexes, while PCP pincer nickel complexes engaged in the activation of small molecules. These early pincer ligands were symmetric with respect to ligand "arms" [21,24-34].

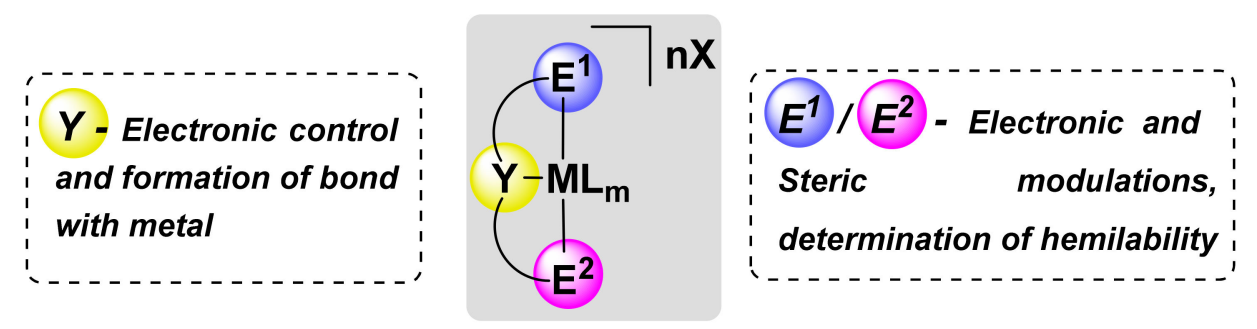

Figure 1. General formula of pincer-type complexes, where $E^{1}$ and $E^{2}$ are a neutral two-electron donor group, $\mathrm{Y}$ is usually represented by an anionic carbon atom of a 2,6-disubstituted aryl moiety, $\mathrm{X}$ and $\mathrm{L}$ are counterions and auxiliary ligands, and $\mathrm{M}$ is metal, $\mathrm{m}$ and $\mathrm{n}-$ number of auxiliary ligands and counterions respectively.

However an increasing interest in the development of nickel complexes based on unsymmetrical phosphorus containing pincer ligands (PCN, POCN, PNN, PCO, PCS, etc.) is observed in modern literature [35-44].

Thus, metal complexes based on pincer ligands have established themselves as highly effective catalysts for such processes as the formation of a new carbon-carbon bond (Heck, Suzuki-Miyaura reactions), hydrogenation of aryl and alkyl ketones, alkane dehydrogenation, hydrosilylation, oligo- and polymerization of unsaturated hydrocarbons and others [8]; moreover, unsymmetrical pincer complexes showed higher catalytic activity than their symmetrical analogues [45-48]. Thus, Milshtein and colleagues described the better catalytic activity of unsymmetrical ruthenium pincer complexes for the dehydrogenation of primary alcohols to esters and hydrogen [49] and hydrogenation of esters to alcohols [40,50]. Gebbink, Szabó et al. showed higher TOF values for the unsymmetrical palladium PCS complex compared to PCP and SCS complexes in aldol reactions [44]. Huang and colleagues reported that the benzoquinoline-based iridium PCN complex catalyzes the alkene hydrogenation reaction more efficiently than the PCP counterpart [51]. Shubina et al. demonstrated the superior catalytic activity of the $\mathrm{PCN}$ pincer complex of iridium containing a pyrazole N-donor compared to the PCP complex in the dehydrogenation of amine boranes [52].

The chemistry of pincer compounds, including their catalytic use, is described in detail in a number of works $[3,13-15,28,53-63]$. Most of them are devoted to the complexes based on metals such as ruthenium, rhodium, iridium, palladium and platinum. However, in modern literature, there is an increasing interest in the development of catalysts based on non-precious metals. For example, nickel, which is a more affordable low-cost and high-natural-abundance analogue of platinum and palladium, has attracted increasing attention in the catalytic chemistry of transition metals in recent years [1,64-73]. Thus, this mini-review is devoted to the recent advances in the chemistry of unsymmetrical phosphorus-based pincer nickel complexes, including the ligand design, the synthesis of nickel complexes and their catalytic applications. 


\section{Synthesis of Nickel Pincer Complexes}

The methods most widely used for the synthesis of nickel pincer complexes include: cyclometalation with activation of $\mathrm{C}-\mathrm{H}$ bond, oxidative addition and transmetalation (Scheme 1). Obviously, cyclometalation is the most convenient method since it does not require an additional prefunctionalization of the ligand and avoids using low-stable and flammable precursors [1].
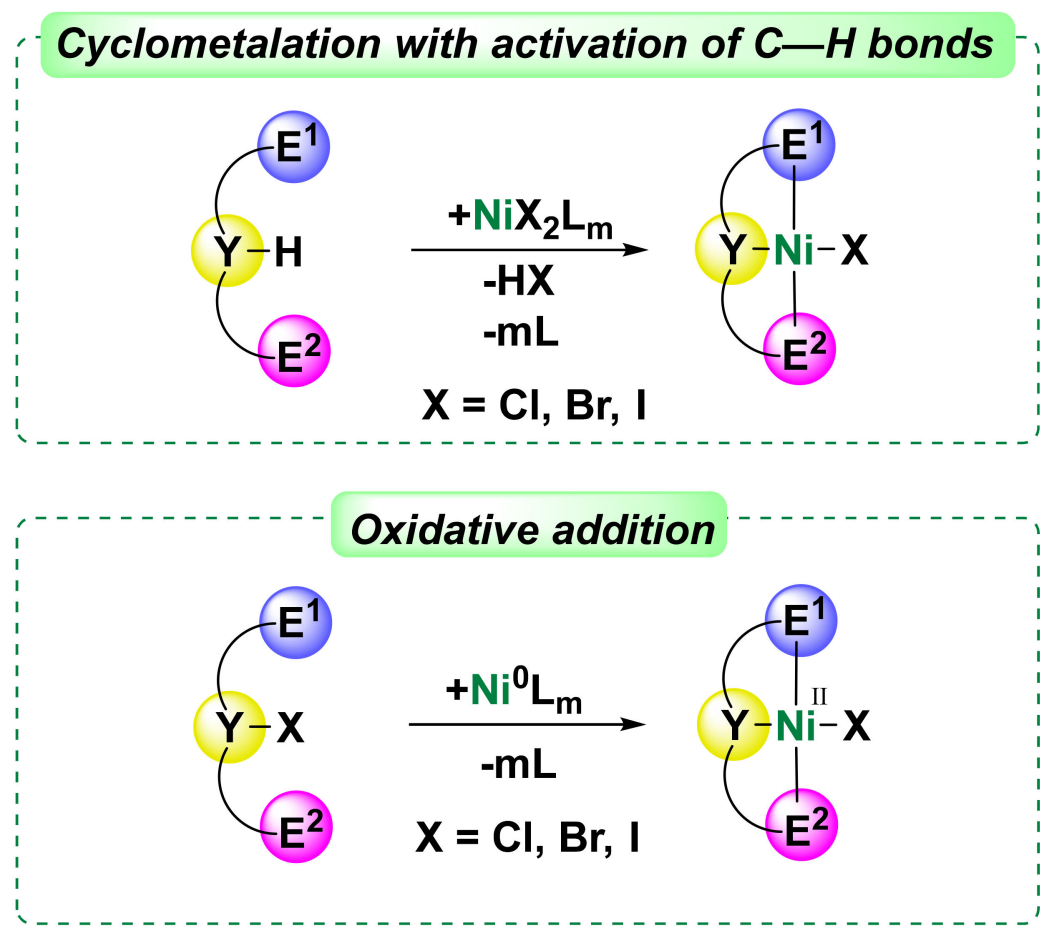

\section{Transmetalation}

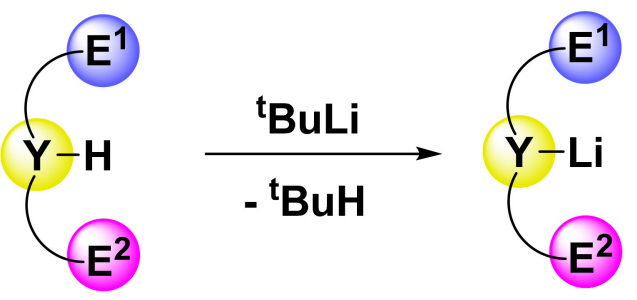

$$
\text { For } E^{1}=E^{2}=N\left(R^{2}\right)_{2}
$$

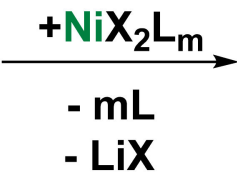

$$
\mathrm{X}=\mathrm{Cl}, \mathrm{Br}
$$

Scheme 1. The methods used for the synthesis of nickel pincer complexes [1].

PCP-containing metallacycles are the most common representatives of nickel pincer complexes. The first example of a PCP nickel complex is $\{2,6$-Bis[(di-tert-butylphosphino) methyl]phenyl\}chloronickel (1), obtained in 1976 [21], followed by NCN pincer nickel complexes $\mathbf{2 a}$ and $\mathbf{2 b}$ (Scheme 2) [22,23,74,75]. 


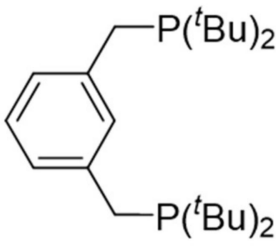<smiles>CO[C@@H](O)[C@@H](O)C#N</smiles><smiles>CN(C)Cc1cccc(CN(C)C)c1Br</smiles><smiles>N#CCOC(=O)OCc1ccccc1</smiles>
$40{ }^{\circ} \mathrm{C} \rightarrow$ r.t.

\section{1) ${ }^{n} \mathrm{BuLi}$ \\ Hexane}

r.t.<smiles></smiles>

1, $54 \%$<smiles>CN(C)[N+]1(Br)c2cccc(c2)CN1C</smiles>

2a, $71 \%$

2) $\underset{\mathrm{THF}}{\mathrm{Ni}\left(\mathrm{PMe}_{3}\right) \mathrm{Cl}_{2}}$

r.t.

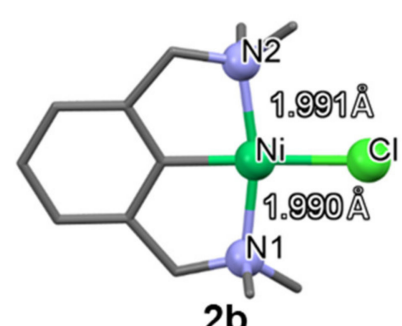

$2 b$

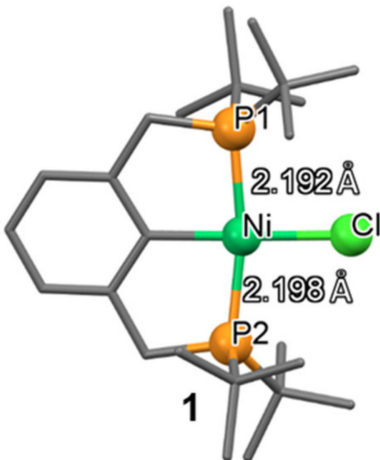<smiles>CN1CN2c3cccc(c31)[N+]2(Cl)N(C)C</smiles>

$2 b$

moderate yield

Scheme 2. Synthesis of symmetrical PCP and NCN pincer nickel complexes $\mathbf{1}$ and $\mathbf{2 a} \mathbf{a}, \mathbf{2} \mathbf{b}[22,23,74,75]$.

Based on the differences in the electronic and steric properties of the PCP- and NCNtype ligands, the preparation of the corresponding nickel complexes is based on different strategies. Nickel PCP complexes can be obtained by direct $\mathrm{C}-\mathrm{H}$ bond activation of the corresponding PCP ligand, while the use of $\mathrm{Ni}(0)$ precursor $\left[\mathrm{Ni}(\mathrm{COD})_{2}\right]$ or the preliminary lithiation of the NCN ligand followed by the replacement of lithium with nickel is a necessary condition for obtaining nickel NCN complexes. Important differences between these types of complexes are manifested in both stoichiometric and catalytic reactions. For example, the use of the pincer NCN ligands made it possible to stabilize and isolate corresponding nickel (III) species and significantly increase the catalytic activity of divalent nickel halide complexes in the addition of polyhalogenated hydrocarbons to olefins (Kharasch addition) [76], while PCP nickel complexes are involved in the activation of small molecules due to the strong coordination of the ligand (Figure 2) [30,33,77]. Thus, various symmetric pincer nickel complexes were synthesized and used in homogeneous catalysis. 


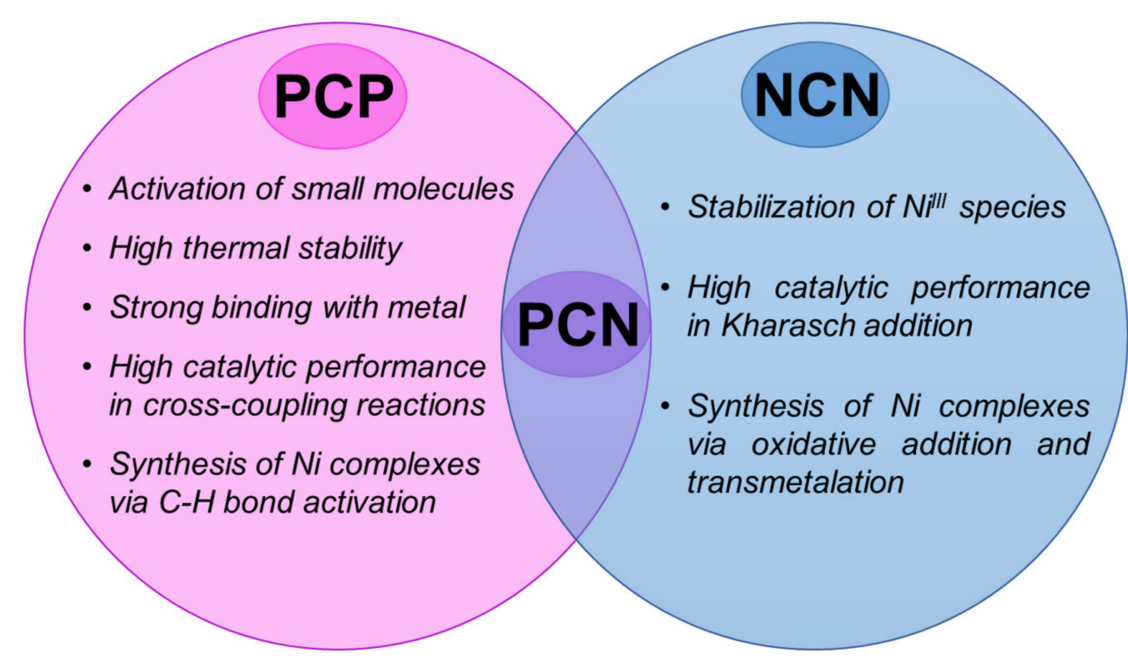

Figure 2. Properties of the nickel complexes formed by different types of pincer ligands.

\section{POCN Complexes}

Unsymmetrical nickel pincer complexes are less studied, and one of the first examples was represented by the POCN-type phosphinite amine ligands (complexes 3a-3c in Scheme 3; see Table A1 in Appendix A for selected bond lengths $(\AA)$ of unsymmetrical nickel pincer complexes presented in this paper) described by Zargarian and Miller [78-81]. It is interesting to note that, unlike their symmetric NCN analogues, these complexes can be obtained by direct metalation with activation of the $\mathrm{C}-\mathrm{H}$ bond, and, unlike PCP analogues, they can be oxidized with bromine to form stable nickel (III) complexes (complexes 4a-4c in Scheme 3). Thus, POCN nickel complexes combine the unique properties of both classes of ligands. However, the synthesis of unsymmetrical pincer ligands is more complex and requires multiple steps (Scheme 3).<smiles>O=Cc1cccc(O)c1</smiles><smiles>[R20]NCc1cccc(O[Pb])c1</smiles>

i) $\mathrm{HNR}_{2}, \mathrm{NaBH}_{4}, \mathrm{MeOH},-5{ }^{\circ} \mathrm{C}, 2 \mathrm{~h}$;

ii) $\left({ }^{(} \mathrm{Pr}\right)_{2} \mathrm{PCl}, \mathrm{Et}_{3} \mathrm{~N}, \mathrm{THF}, 0-5{ }^{\circ} \mathrm{C}, 1 \mathrm{~h}$.

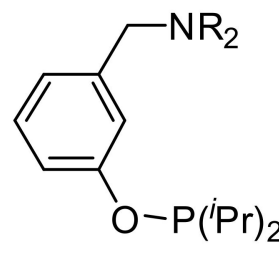

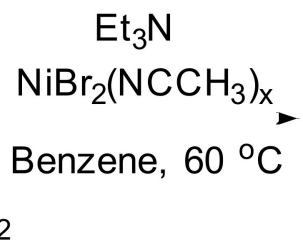

$3 a, 77 \% ; 3 \mathbf{b}, 84 \% ; 3 \mathbf{c}, 91 \%$<smiles>[R2]N1Cc2cccc3c2N1[P+]3([R])Br</smiles><smiles>CCOCC</smiles>

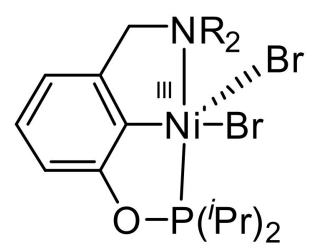

$4 a, 96 \% ; 4 \mathbf{b}, 80 \% ; 4 c, 95 \%$

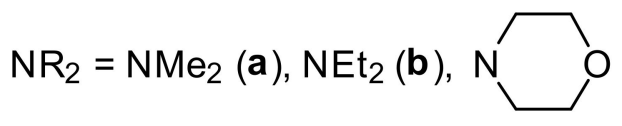

Scheme 3. Cont. 


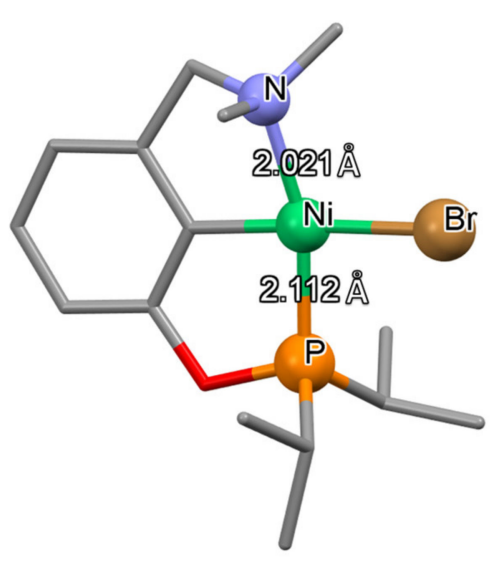

$3 a$

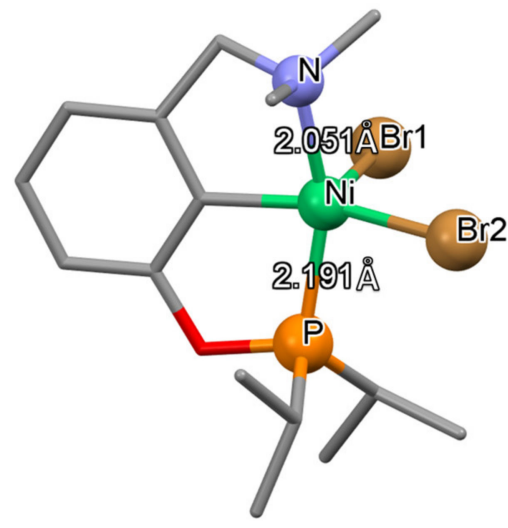

$4 a$

Scheme 3. Synthesis of unsymmetrical POCN pincer nickel complexes $\mathbf{3 a}-\mathbf{3 c}$ and $\mathbf{4 a} \mathbf{a}-\mathbf{4}$ [78-81].

The presence of bulky substituents at the phosphorus atom can increase the stability of the resulting nickel complexes and allow their catalytically active forms to be isolated. Therefore, the same authors obtained a complex containing a secondary amine in its structure (complex 5 in Figure 3). This complex is capable of dimerization with the formation of binuclear complex 6, which turned out to be an active catalyst in the processes of functionalization of acrylonitrile in alcoholic media [79].

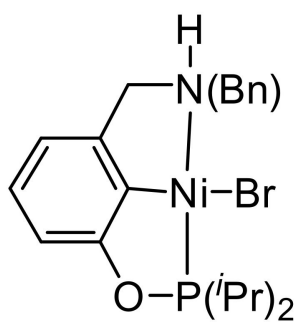

5

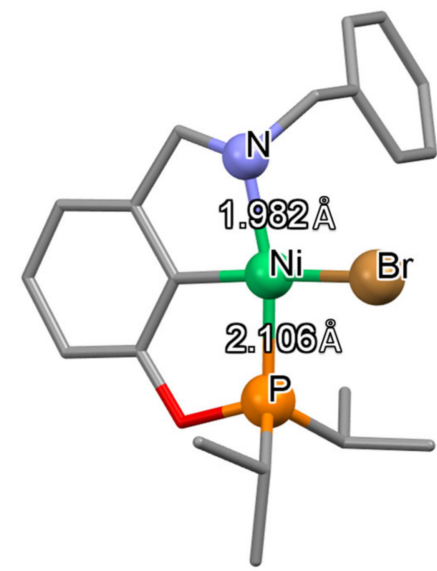

5

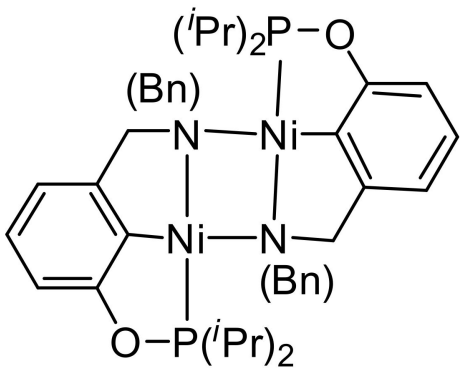

6

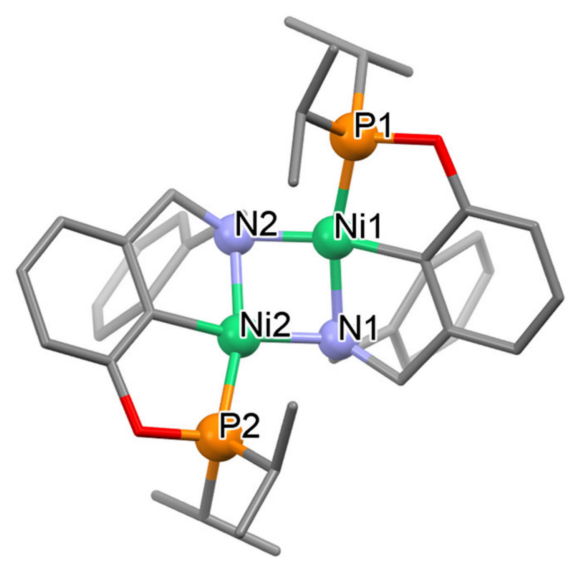

6

Figure 3. Structure of unsymmetrical POCN pincer nickel complexes 5 and 6 [79]. 
Since then, many other nickel complexes containing unsymmetrical POCN ligands have been described [82], including various substituted analogues of complex 3a, such as compound 7 (Figure 4) [80]. Optically active species are also known, for example, a complex containing the imidazole fragment (8 and $\mathbf{9}$ ) (Figure 4), which is successfully used in the asymmetric Suzuki-Miyaura cross-coupling reaction [83-86], as well as complex 10 [87], containing diisopropylphosphinite and imine fragments, which can be oxidized with bromine or $N$-bromosuccinimide to complex 11 (Figure 4). It is interesting to note that complex 12 also obtained by Zargarian and co-workers, containing the diphenylphosphinite fragment, undergoes two-electron oxidation of the phosphinite fragment with the formation of complex 13 upon interaction with bromine (Figure 4). Thus, we can conclude that the choice of the P-substituent is very important for the stabilization of Ni (III) particles [87].<smiles>[R20]Cc1cccc2c1N(Br)P([PH3+])O2</smiles>

7<smiles></smiles>

8

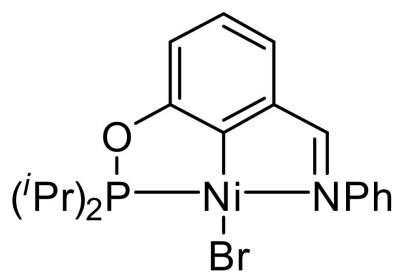

10<smiles>Pc1cccc2c1[PH](Br)(c1ccccc1)N=C2</smiles>

12<smiles>[R20]#N</smiles>

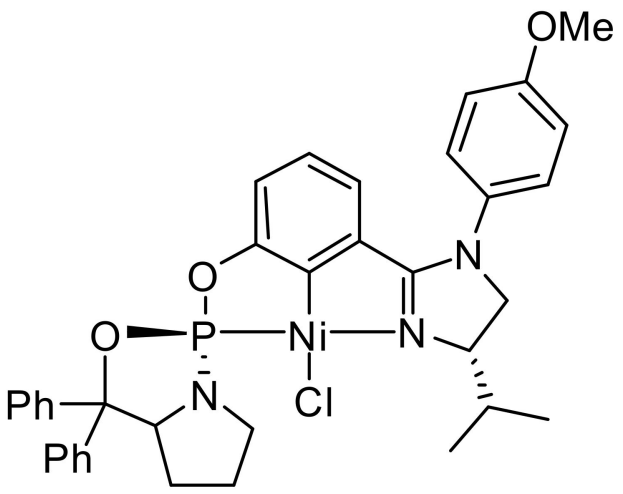

9

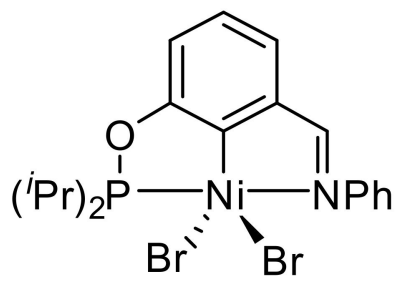

11<smiles>O=P(O)(Br)N(Br)Oc1cccc(/C=N/[OH+]c2ccccc2)c1</smiles>

13

Figure 4. Structure of unsymmetrical POCN pincer nickel complexes 7-13 [80,83-87]. 


\section{PCN Complexes}

Phosphorus-based complexes such as PCN-type systems are particularly intriguing since, unlike their symmetric NCN analogues, their nickel complexes can be obtained by direct cyclometalation with activation of the $\mathrm{C}-\mathrm{H}$ bond, and, unlike $\mathrm{PCP}$ analogues, they can stabilize nickel (III) species. Thus, PCN nickel complexes combine the unique properties of both classes of N- and P-based ligands [88-94]. In such species, the difference in the trans effect between the two different donor arms provides the hemilability of the ligand since the group with the weaker trans effect $(\mathrm{N})$ is more likely to dissociate from the metal center, which leads to a vacant coordination site at the metal center and thus can allow for effective coordination and transformation of substrate molecules in the homogeneous catalysis conditions [95].

Recently, Moussa and co-authors reported the synthesis of PCN complexes of nickel with ditertbutylphosphine and dimethylamine fragments (Scheme 4) [96]. It is interesting to note that the cyclometalation of this PCN ligand with anhydrous nickel chloride in toluene in the presence of 4-dimethylaminopyridine (DMAP) leads to the formation of complex 14a with $63 \%$ yield, while this reaction in THF in the presence of triethylamine allows complex 14a to be obtained in $86.5 \%$ yield. Such a low yield of compound 14a in the first case is associated with the formation of a paramagnetic complex $\mathbf{1 5}$ as a byproduct. Triethylamine is a stronger base than DMAP, which avoids protonation of the amine fragment of the $\mathrm{PCN}$ ligand with acid $(\mathrm{HCl})$, formed during the reaction. The bromide analogue $14 \mathbf{b}$ was obtained by a similar method with a yield of $96 \%$.

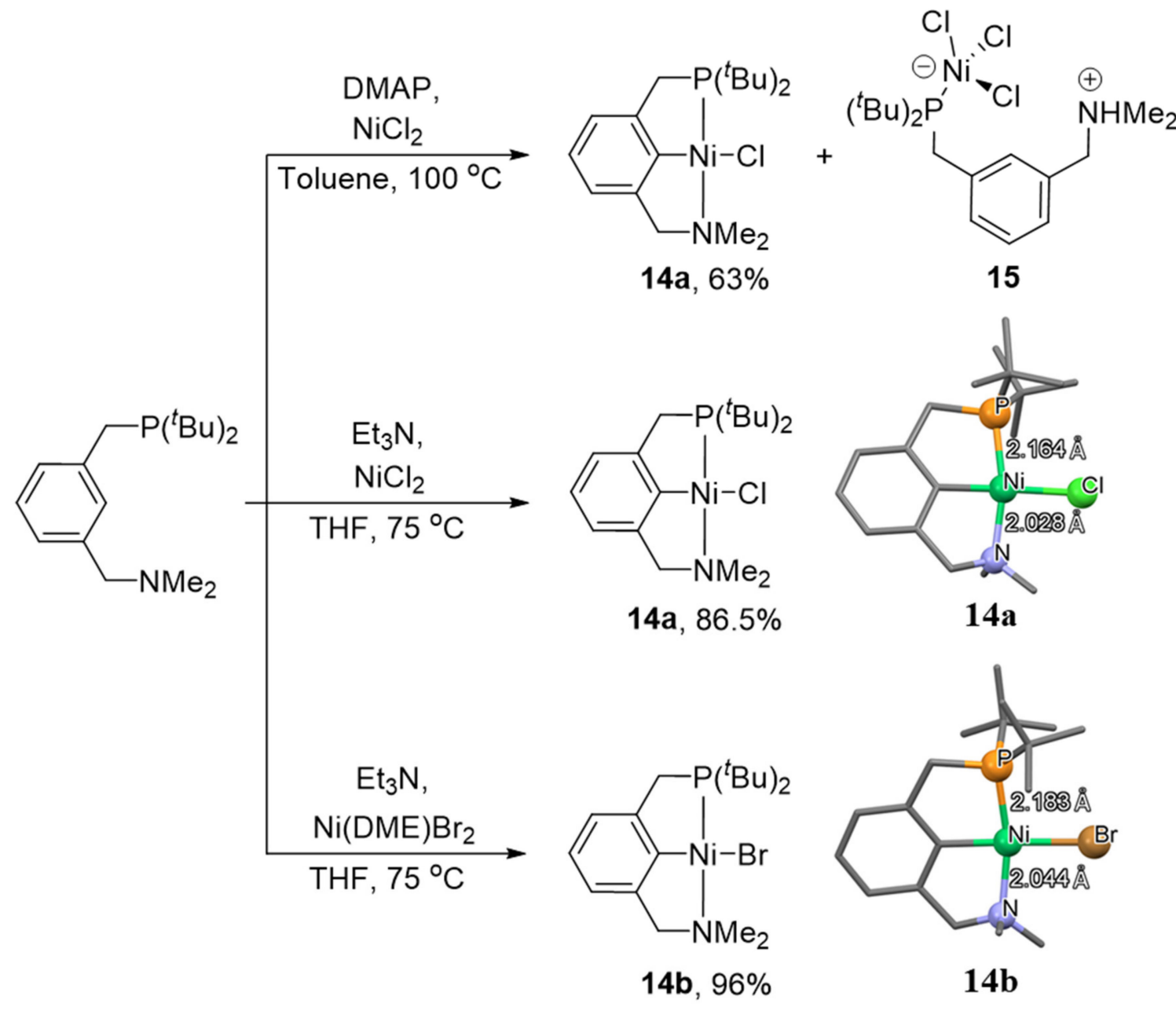

Scheme 4. Synthesis of unsymmetrical PCN pincer nickel complexes 14a, 14b and non-pincer complex 15 [96]. 
Interestingly, the P-Ni bond in 14a is significantly shorter, than the corresponding bond in its symmetrical PCP analogue (complex 1); at the same time, the N-Ni bond is found to be much longer than in symmetrical NCN complex $\mathbf{2 b}$ (Table 1). These differences are due to the strong trans influence of the phosphine moiety, and they determine hemilability.

Table 1. Selected bond lengths ( $\AA$ ) of symmetrical nickel PCP and NCN pincer complexes $\mathbf{1}, \mathbf{2 b}$ and unsymmetrical PCN complex 14a.

\begin{tabular}{cccc}
\hline \multirow{2}{*}{ Complex } & \multicolumn{2}{c}{ Selected Bond Lengths $(\AA)$} & Reference \\
\cline { 2 - 3 } & $\mathbf{P}-\mathbf{N i}$ & $\mathbf{N}-\mathbf{N i}$ & \\
\hline $\mathbf{1}$ & $2.195^{\mathrm{a}}$ & & {$[74]$} \\
$\mathbf{2 b}$ & & $1.990^{\mathrm{a}}$ & {$[75]$} \\
$\mathbf{1 4 a}$ & 2.164 & 2.028 & {$[96]$} \\
\hline
\end{tabular}

a Average of two distances.

On the cyclic voltammograms of complexes $14 a$ and $14 b$ in dichloromethane, irreversible oxidation peaks at $E_{1 / 2}=0.837$ and $0.797 \mathrm{~V}$ for $\mathbf{1 4} \mathbf{a}$ and $\mathbf{1 4} \mathbf{b}$, respectively, are observed [96]. These oxidation potentials are lower than the corresponding values for complexes of nickel with POCN ligands (around $1.0 \mathrm{~V}$ ), which is associated with a higher donor ability of PCN ligand. Thus, PCN nickel (III) complexes can be easily obtained by oxidation of the corresponding nickel (II) complexes. Indeed, the interaction of complexes 14a and $14 \mathrm{~b}$ with anhydrous salts of $\mathrm{CuX}_{2}(\mathrm{X}=\mathrm{Cl}, \mathrm{Br})$ in dichloromethane leads to the formation of the corresponding $\mathrm{Ni}(\mathrm{III})$ complexes 16a and 16b (Scheme 5) [96]. Both of the obtained complexes in the crystal display distorted square-pyramidal coordination geometries around nickel with a halide in the apical position.

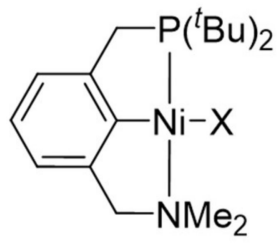

$14 a, 14 b$

$\mathrm{X}=\mathrm{Cl}(\mathbf{a})$

$\mathrm{X}=\mathrm{Br}(\mathbf{b})$

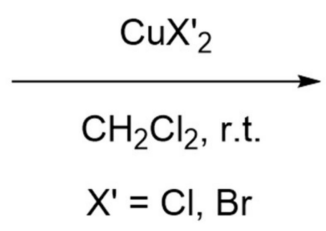

16a, $93 \% ; 16 b, 71,8 \%$

$$
\begin{aligned}
& X=X^{\prime}=\mathrm{Cl}(\mathbf{a}) \\
& X=X^{\prime}=\mathrm{Br}(\mathbf{b})
\end{aligned}
$$

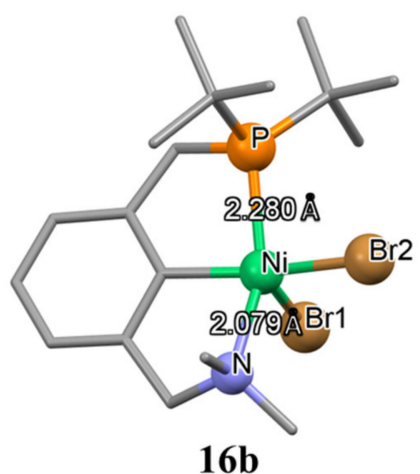

$16 \mathrm{~b}$

Scheme 5. Synthesis of unsymmetrical PCN pincer nickel (III) complexes 16a and 16b [96].

It is well known that trivalent nickel complexes are important intermediates of the Kharasch addition reaction [97]. Therefore, NCN nickel complexes are efficient for this process, while the aromatic PCP nickel pincer analogues are not suitable as catalysts in this reaction mainly because they do not produce the corresponding Ni(III) species. PCN complexes 14a and $14 \mathrm{~b}$ were tested in this process, showing higher catalytic activity in the process of addition of $\mathrm{CCl}_{4}$ to styrene than their POCN analogues; however, they turned out to be less active than NCN nickel complexes. Thus, the catalytic efficiency of nickel pincer complexes in the Kharasch addition reaction appears in the following order: $\mathrm{NCN}>$ $\mathrm{POC}_{\mathrm{sp} 3} \mathrm{OP}>\mathrm{PCN}>\mathrm{POCN}[78]$.

It is also worth noting that the interaction of $14 a$ and $14 b$ with Grignard reagents yielded the first examples of alkyl and aryl-nickel complexes based on an unsymmetrical aromatic pincer ligand $\mathbf{1 7 a}$ and $\mathbf{1 7 b}$ (Scheme 6) [96]. 


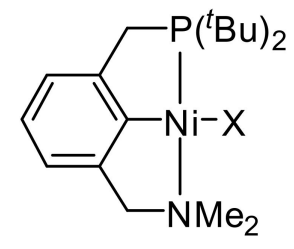

$14 a, 14 b$

$\mathrm{X}=\mathrm{Cl}(\mathbf{a}), \mathrm{Br}(\mathbf{b})$

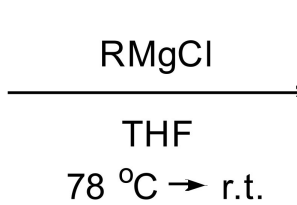

$17 a, 89 \% ; 17 b, 90 \%$

$\mathrm{R}=\mathrm{Me}(\mathbf{a}), \mathrm{Ph}(\mathbf{b})$<smiles>[R]C12CN(CC)c3c(cccc31)CN2CCCC</smiles>

Scheme 6. Synthesis of unsymmetrical PCN pincer alkyl and aryl-nickel complexes 17a and 17b [96].

Later, Moussa and co-authors presented the synthesis of an unsymmetrical PCN pincer complex of nickel bearing tertbutyl groups on the phosphorus atom and isopropyl groups on the nitrogen donor atom (complex 18 in Scheme 7) [98]. The corresponding methyl complex 19 was also obtained from 18 through a transmetalation reaction with $\mathrm{MeMgCl}$. Complex 19 demonstrated a high reactivity in a carboxylation of a $\mathrm{Ni}-\mathrm{C}$ bond using $\mathrm{CO}_{2}$ with the formation of acetate complex 20.

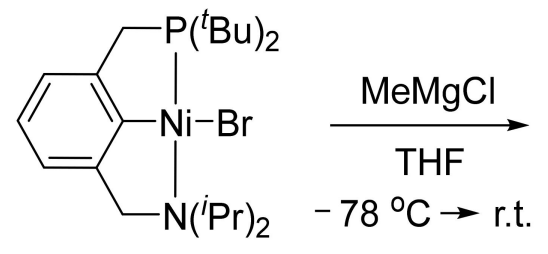

$18,56 \%$

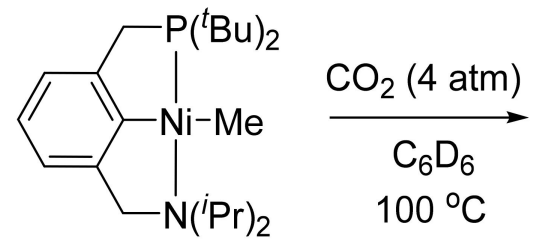

$19,85 \%$

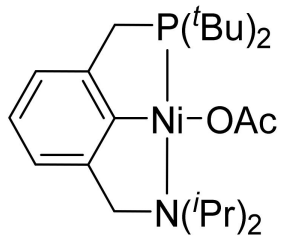

$20,44 \%$

Scheme 7. Synthesis of unsymmetrical PCN pincer nickel complexes 19 and 20 [98].

In 2019, Luconi et al. demonstrated a synthesis of PCN nickel complexes containing ditertbutylphosphine and pyrazolyl fragments and different halogens in the structure $(\mathrm{F}, \mathrm{Cl}$, $\mathrm{Br}$, I; see Scheme 8) [88]. The electrochemical properties of the obtained complexes 21a-21d were investigated using cyclic voltammetry and in situ EPR spectroelectrochemistry.
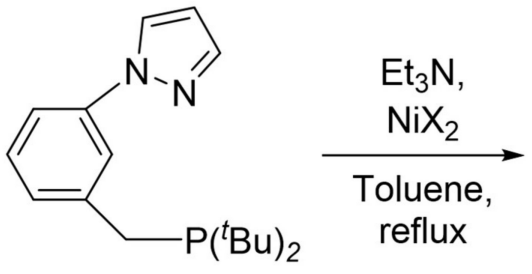

\footnotetext{
21
}<smiles>[X][N+]1(C)Cc2cccc3c2N1[N+]31CCC1</smiles>

21b, 96\%; 21c, 98\%; 21d, 92\%
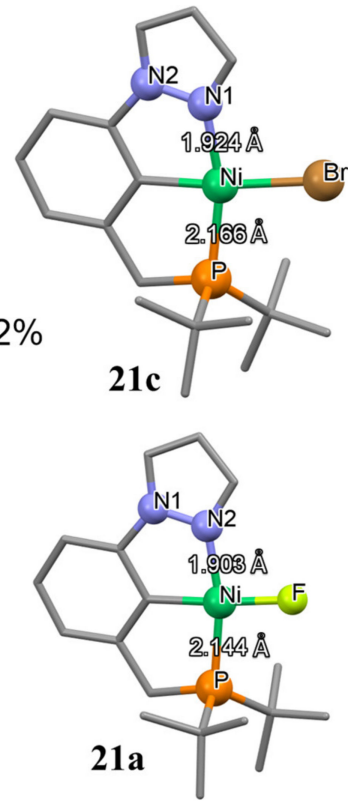<smiles>CCCCN1c2c(cccc2-n2cccn2)CP1Cl</smiles>

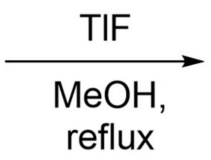<smiles>CCCC[PH]1(F)c2ccccc2-c2cccn21</smiles>

21a, $85 \%$ 
Authors found that the complexes exhibit different behaviors during electro-oxidation. Thus, complexes 21a and 21d during the electro-oxidation process (proceeding at $E_{1 / 2}=0.44$ and $0.29 \mathrm{~V}$ for $21 \mathrm{a}$ and $21 \mathrm{~d}$, respectively) form halogen-free species of nickel (III), while chloride and bromide complexes $21 \mathbf{b}$ and $21 \mathrm{c}\left(\mathrm{E}_{1 / 2}=0.79\right.$ and $0.83 \mathrm{~V}$, respectively) change the square-planar geometry of the molecule to a distorted tetrahedron, preserving the halogen atom to the coordination sphere of nickel (Scheme 9), as evidenced by the hyperfine interactions on their EPR spectra [88].

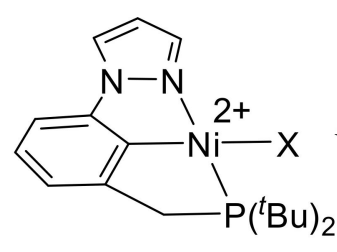<smiles>C=CC=C</smiles>

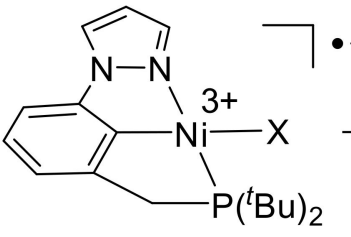

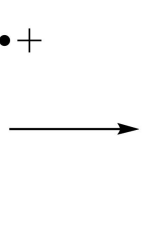

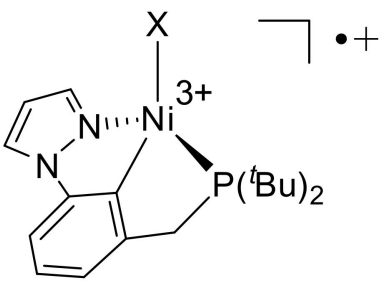

$X=\mathrm{Cl}(\mathbf{2 1 b}), \mathrm{Br}(\mathbf{2 1 c})$

Scheme 9. Electrochemical oxidation of unsymmetrical pyrazole PCN pincer nickel complexes 21b and 21c [88].

Authors have also found that the high nucleophilicity of the fluoride ligand in 21a leads to halogen bonding with the electrophilic iodine atom in iodopentafluorobenzene $\left(\mathrm{C}_{6} \mathrm{~F}_{5} \mathrm{I}\right)$. However, the halogen-bonding capability is weaker than that of the symmetrical analogue $\left({ }^{\mathrm{tBu}} \mathrm{PCP}\right) \mathrm{NiF}\left[{ }^{\mathrm{tBu}} \mathrm{PCP}=2,6-\mathrm{C}_{6} \mathrm{H}_{3}\left(\mathrm{CH}_{2} \mathrm{P}^{t} \mathrm{Bu}_{2}\right)_{2}\right]$, and it is featured by a positive $\Delta \mathrm{S}^{\circ}$ value because of a higher degree of aggregation in solution [88,99].

Interestingly, the oxidation of complexes $21 b$ and $21 c$ with anhydrous $\mathrm{CuX}_{2}$ salts $(\mathrm{X}=\mathrm{Cl}, \mathrm{Br}$ ) did not lead to stable $\mathrm{Ni}(\mathrm{III})$ species, which were observed only in situ by EPR spectroscopy [89]. The presence of the aromatic pyrazole ligand as a weaker sigma donor compared with an aliphatic $-\mathrm{NR}_{2}$ group (complexes such $\mathbf{3 a}-\mathbf{3 c}, \mathbf{9}, \mathbf{1 4 a}$ and $\mathbf{1 4 b}$ ) is detrimental for the stabilization of the electron-poorer $\mathrm{Ni}(\mathrm{III})$ complexes.

The interaction of chloride complex $\mathbf{2 1 b}$ with an excess of sodium borohydride led to the formation of the relatively robust borohydride complex 22 (Scheme 10) [89], which was isolated and characterized by $\mathrm{X}$-ray diffraction. Interestingly, the reaction of symmetrical ( $\left.{ }^{\mathrm{tBu}} \mathrm{PCP}\right) \mathrm{NiCl}$ with $\mathrm{NaBH}_{4}$ generates $\left({ }^{\mathrm{tBu}} \mathrm{PCP}\right) \mathrm{NiH}$ as the isolable product with ( $\left.{ }^{\mathrm{tBu}} \mathrm{PCP}\right) \mathrm{Ni}\left(\mathrm{BH}_{4}\right)$ observed as intermediate in solution by NMR spectroscopy [99] and only later was isolated by Enthaler and co-workers [100].<smiles></smiles>

21b

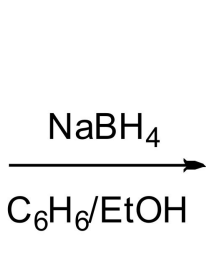

22, $71 \%$

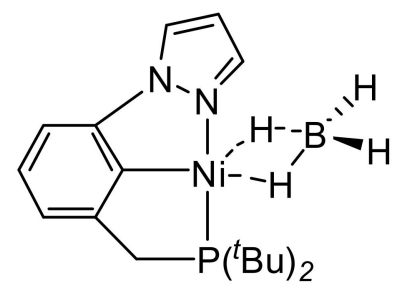

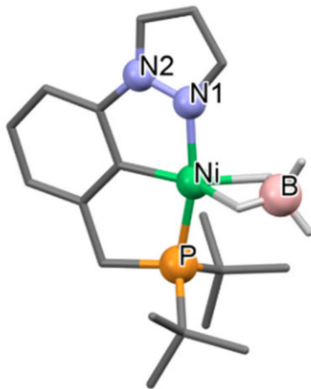

Scheme 10. Synthesis of unsymmetrical pyrazole PCN pincer nickel borohydride complex 22 [89].

The nickel complexes 21a-21d preactivated by MMAO have shown moderate activity in the ethylene oligomerization process leading to even-numbered olefins, predominantly $\mathrm{C}_{4}-\mathrm{C}_{10}$ fractions. To the best of our knowledge, this is the first example of application of PCN nickel complexes on the ethylene oligomerization reaction [101-106].

It also should be mentioned that Luconi and co-authors demonstrated the synthesis of unusual benzothiazole-based unsymmetrical pincer nickel complexes 23a, 23b and 24 (Scheme 11) [107]. The reaction of the corresponding benzothiazole-based pincer ligand with nickel dibromide in toluene in the presence of $\mathrm{Et}_{3} \mathrm{~N}$ as a base leads to the bromide 
complex 23a. Fluoride analogue $\mathbf{2 3 b}$ was obtained by treatment of 23a with silver fluoride in toluene (Scheme 11). The ionic aquo complex 24 was synthesized through bromide abstraction from 23a with a silver tetrafluoroborate in THF. The water molecule came from the $\mathrm{AgBF}_{4}$ or from THF. The N atom in the thiazole ring is a stronger donor, therefore no sulfur coordination was ever observed. Interestingly, binding of ligand to a metal ion generates coordination rings of different sizes: a five-membered cycle on the phosphine arm and a six-membered cycle on the benzothiazole arm. Moreover, the oxo-bridge induces a distortion of the ligand, which is not lying on the P-Ni-N plane (Figure 5).

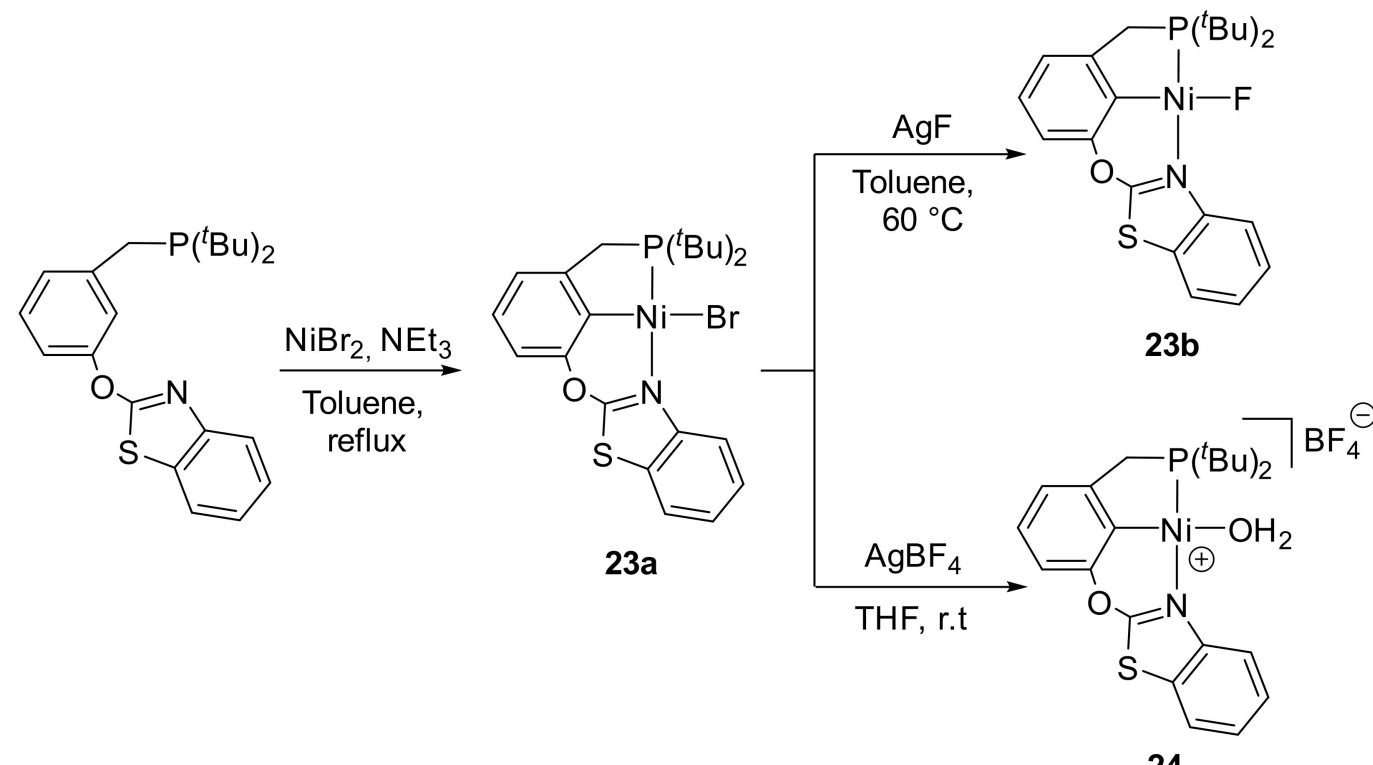

24

Scheme 11. Synthesis of benzothiazole-based unsymmetrical PCN pincer nickel complexes 23a, 23b and 24 [107].

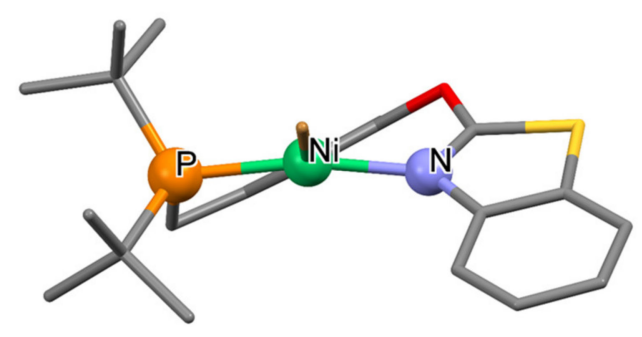

23a

Figure 5. Crystal structure of the benzothiazole-based PCN pincer nickel bromide 23a [107].

Table 2 represents the comparison of P-Ni and N-Ni bond distances of analogous PCN nickel pincers with different $\mathrm{N}$-donor groups (dimethylamine for 14a, pyrazole for 21c and benzothiazole for 23a). The corresponding distances of 21c and 23a are almost equal due to the similar basicity of $\mathrm{N}$ atom in the thiazole and pyrazole rings ( $p K_{a}$ of the conjugate acid 2.50 vs. 2.48 for thiazole and pyrazole, respectively), while a higher $p K_{a}$ value of the dimethylamine (10.73) indicates stronger basicity. Since lower $p K_{a}$ values of electron-poor pyrazole and benzothiazole groups indicate their weaker $\sigma$-donor ability, these groups more likely dissociate from the metal center, yielding more pronounced hemilability, which leads 
to higher catalytic activity of related complexes in various catalytic processes compared to dimethylamine-containing analogues.

Table 2. Selected bond lengths ( $\mathrm{A})$ of unsymmetrical nickel PCN pincer complexes, containing dimethylamine (14a), pyrazole (21c) or benzothiazole (23a) groups.

\begin{tabular}{cccc}
\hline \multirow{2}{*}{ Complex } & \multicolumn{2}{c}{ Selected Bond Lengths $(\AA)$} & Reference \\
\cline { 2 - 3 } & P-Ni & N-Ni & \\
\hline 14a & 2.183 & 2.044 & {$[96]$} \\
21c & 2.166 & 1.924 & {$[88]$} \\
23a & 2.169 & 1.955 & {$[107]$} \\
\hline
\end{tabular}

Interestingly, complexes 23a and $\mathbf{2 3 b}$ preactivated by MMAO demonstrated high catalytic activity in ethylene oligomerization (up to $200 \times 10^{3} \mathrm{~mol}_{\mathrm{C} 2 \mathrm{H} 4} \cdot \mathrm{mol}_{\mathrm{Ni}}{ }^{-1} \cdot \mathrm{h}^{-1}$ ) with the formation of even-numbered olefins (mainly $\mathrm{C}_{4}-\mathrm{C}_{10}$ fractions) as products. The comparison of their performance with the results obtained for more rigid pyrazole-based analogues 21a and 21c demonstrates a positive effect of the flexibility modification of the ligand [108].

Recently, Zargarian and co-workers demonstrated the synthesis of unsymmetrical pincer $\mathrm{Ni}-\mathrm{C}_{\mathrm{sp}}{ }^{3}$ complexes 25a-25f containing two metallacycles of different sizes: a sixmembered cycle on the phosphine side and a four-membered cycle on the amine side (Scheme 12). The synthetic methodology presented in this study is based on the reactivity of phosphinite derived from 2-vinylphenol. Starting phosphinite, nickel (II) precursor and a base $\left(\mathrm{Et}_{3} \mathrm{~N}\right)$ in THF at room temperature produce the target complexes. The solid-state structure of the complexes was established by XRD analyses, which revealed that the Ni-P bond is typically longer than the corresponding Ni-N bond (Figure 6). Interestingly, authors observed isomerization of these complexes due to the hemilability of the N-Ni coordination bond, which may provide the basis for the future rational design of new active systems, since this hemilability generates a vacant coordination site, which is a prerequisite for the obtainment of an active catalyst. Moreover, CV experiments revealed that these complexes undergo facile one-electron oxidation due to the impact of a $\mathrm{C}_{\mathrm{sp}}{ }^{3}-\mathrm{Ni}$ moiety [109].

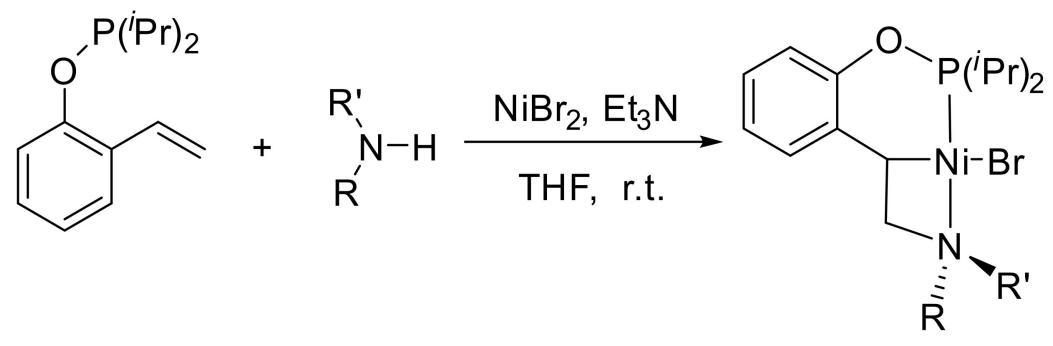

25a, 63\%; 25b, 70\%; 25c, 62\%; 25d, 65\%; 25e, 64\%; 25f, 63\%

$$
\begin{gathered}
\mathrm{NR}\left(\mathrm{R}^{\prime}\right)=\mathrm{NH}\left({ }^{\prime} \mathrm{Pr}\right),(\mathbf{2 5 a}) ; \mathrm{N} \text {-morpholyl,(25b); } \\
\mathrm{NPh}(\mathrm{Et}),(\mathbf{2 5 c}) ; \mathrm{NH}(\mathrm{Ph}),(\mathbf{2 5 d}) ; \mathrm{NH}(\mathrm{Cy}),(\mathbf{2 5 e}) ; \mathrm{NH}\left({ }^{(} \mathrm{Bu}\right),(\mathbf{2 5 f})
\end{gathered}
$$

Scheme 12. Synthesis of unsymmetrical $\mathrm{PC}_{\mathrm{sp}}{ }^{3} \mathrm{~N}$ nickel pincer complexes 25a-25f [109]. 


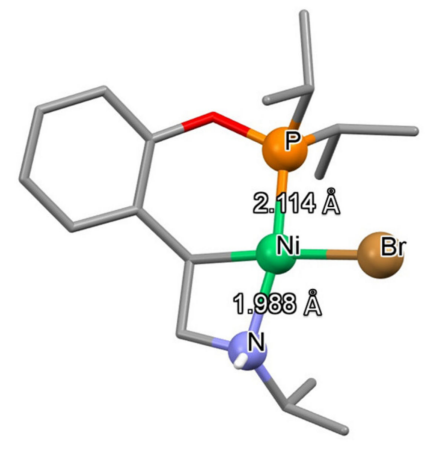

$25 a$

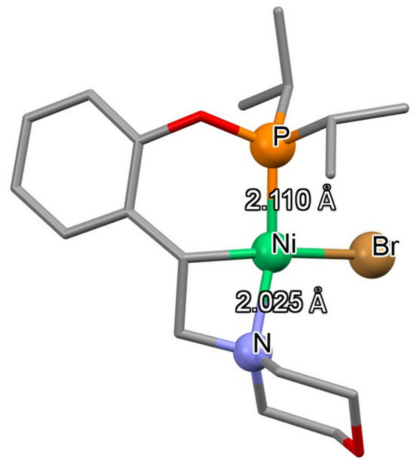

25b

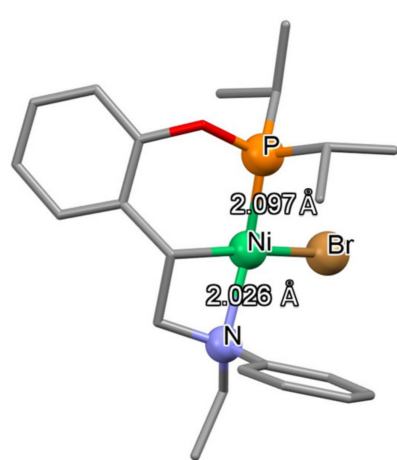

$25 c$

Figure 6. Crystal structures of the unsymmetrical $\mathrm{PC}_{\mathrm{sp}}{ }^{3} \mathrm{~N}$ nickel pincer complexes 25a, 25b, 25c [109].

\section{NNP Complexes}

The other important class of phosphorus and nitrogen containing unsymmetrical pincer nickel systems is NNP complexes. The combination of pincer-type ligands with a nickel ion has attracted much attention to create effective cross-coupling catalysts in recent decades. Mostly, aryl chlorides, bromides and iodides are used as electrophiles in these processes $[110,111]$, while the activation of aryl fluorides using nickel catalysts is still a challenge in synthetic chemistry [112,113]. In 2019, Yamaguchi and co-workers described the synthesis of $\beta$-aminoketonato- and $\beta$-diketiminato-based unsymmetrical pincer complexes 26-28 (Scheme 13), whose catalytic performances in the cross-coupling of aryl chlorides with aryl Grignard reagents [114] and in the highly Markovnikov-selective hydroboration of vinylarenes using bis(pinacolato)diboron have been investigated [115]. It was found that the presence of the phosphorus group in complex 27 brings to remarkable catalytic activity in the cross-coupling process over the phosphorus-free analogues, while the $\beta$-diketiminato framework increases the energy level of the HOMO of the complex 28, according to the DFT study, making the system electronically more favorable. However, NNN complex 28 is not an effective catalyst for cross-coupling reactions. Later, in 2019, the working group combined these features introducing a phosphorus donor into the $\beta$-diketiminato framework to create a sterically and electronically favorable environment at the Ni center (complex 29), which was prepared by the reaction of the nickel (II) precursor $\left.\left[\mathrm{NiCl}_{2} \text { (2,4-lutidine }\right)_{2}\right]$ with the lithiated NNP ligand and effectively facilitated the crosscoupling of aryl fluorides with aryl Grignard reagents (Table 3) [116].

Table 3. Comparison of the catalytic performances of the unsymmetrical nickel pincer complexes 26-29 for the cross-coupling of aryl fluorides with aryl Grignard reagents. Adapted from [116].

\begin{tabular}{|c|c|c|c|c|}
\hline Entry & Catalyst & $\mathbf{R}^{1}$ & $\mathbf{R}^{2}$ & Yield (\%) \\
\hline 1 & 26 & $\mathrm{H}$ & $\mathrm{Me}$ & 17 \\
\hline 2 & 27 & $\mathrm{H}$ & $\mathrm{Me}$ & 66 \\
\hline 3 & 28 & $\mathrm{H}$ & $\mathrm{Me}$ & 9 \\
\hline 4 & 29 & $\mathrm{H}$ & $\mathrm{Me}$ & 67 \\
\hline 5 & 27 & $\mathrm{Me}$ & $\mathrm{H}$ & 44 \\
\hline 6 & 29 & $\mathrm{Me}$ & $\mathrm{H}$ & 52 \\
\hline
\end{tabular}


<smiles></smiles>

26, $99 \%$<smiles></smiles>

27, $97 \%$

1) ${ }^{n} \mathrm{BuLi}$

2) $\left[\mathrm{NiCl}_{2}(2,4 \text {-lutidine })_{2}\right]$

$\mathrm{NH}$<smiles>CC(/C=C(/C)NCCP)=Nc1c(C)cc(C)cc1C</smiles>

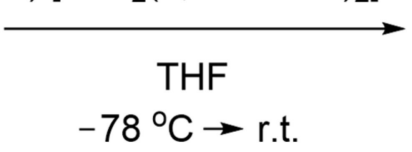<smiles></smiles>

28, $92 \%$<smiles></smiles>

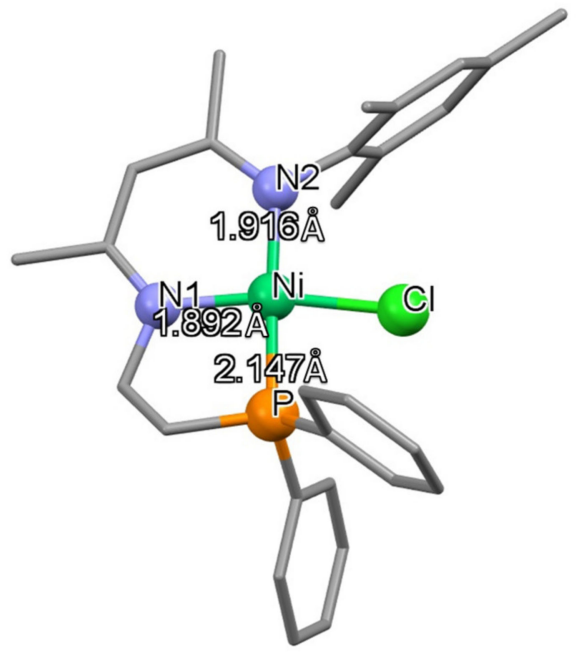

29

$29,83 \%$

Scheme 13. Structure of unsymmetrical pincer nickel complexes 26-28 and synthesis of unsymmetrical NNP pincer nickel complex $29[114,116]$.

The reaction was carried out with $1.0 \mathrm{mmol}$ of fluoroarene and $1.2 \mathrm{mmol}$ of arylmagnesium bromide in the presence of a Ni (II) complex $(0.05 \mathrm{mmol})$ in THF $(5 \mathrm{~mL})$ at room temperature for $6 \mathrm{~h}$ [116].

Shortly afterward, the synthesis of the first pyrrole-based unsymmetrical NNP pincer complexes of nickel (30a-30c) containing diphenylphosphine and pyrazole fragments was presented (Scheme 14) [117]. 1:1 reaction between $\mathrm{NNP}$ ligand and $\left[\mathrm{NiCl}_{2}(\mathrm{DME})\right]$ or $\mathrm{NiX}_{2}$ $(\mathrm{X}=\mathrm{Br}, \mathrm{I})$ in acetonitrile in the presence of $\mathrm{NEt}_{3}$ under reflux conditions afforded the pincer nickel complexes 30a-30c with good yields. The pyrrole-based pincers are well known to stabilize a variety of nickel complexes [118-120]. Authors compared the efficiencies of complexes 30a-30c in catalyzing norbornene to polynorbornene with efficiencies of their symmetrical analogues-PNP complexes 32a-32c (Scheme 14) [121]—which were synthesized by the reaction between PNP pincer ligand and $\left[\mathrm{Ni}(\mathrm{OAc})_{2}\right] \cdot 4 \mathrm{H}_{2} \mathrm{O}$ with the formation of 31, which further treated with an excess of $\mathrm{LiCl}$ or $\mathrm{LiBr}$ or $\mathrm{KI}$ in acetone/water at room temperature to give the corresponding halide ion substituted Ni complexes 32a-32c.

Interestingly, according to X-ray diffraction analysis the Ni-P distance in 30b is 2.1613 $\AA$, while for 30c, it is $2.1647 \AA$, which are shorter than the distances found in their symmetrical PNP analogues $32 \mathrm{~b}$ and $32 \mathrm{c}$, indicating the strong trans effect of the $\mathrm{P}$ atom in comparison to the $\mathrm{N}$ atom (Figure 7). Moreover, the pyrrolide $\mathrm{N}-\mathrm{Ni}$ distances in $30 \mathrm{~b}$ and 30c (1.886 $\AA$ and $1.847 \AA$, correspondingly) are shorter than the amide $\mathrm{N}-\mathrm{Ni}$ distances found in the analogous pincer nickel (II) complexes: $1.924 \AA$ in $\left[\mathrm{NiCl}\left\{\mathrm{N}\left(\mathrm{SiMe}_{2} \mathrm{CH}_{2} \mathrm{PPh}_{2}\right)_{2}\right\}\right]$ [122] and 1.895/1.912 $\AA$ in $\left[\mathrm{NiX}\left\{\mathrm{N}\left(o-\mathrm{C}_{6} \mathrm{H}_{4} \mathrm{PPh}_{2}\right)_{2}\right\}\right](\mathrm{X}=\mathrm{Cl}, \mathrm{Br})$ [110], which indicate the strong bond formed by the pyrrolide $\mathrm{N}$ atom. 
<smiles>CCN(C)CCNCCn1nc(C)cc1C</smiles>

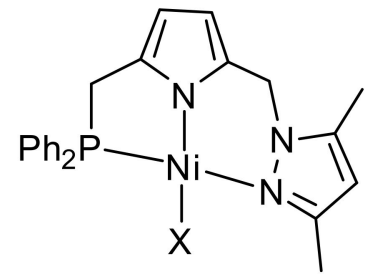

30a, $54 \% ; 30 b, 46 \% ; 30 c, 46 \%$

$$
\mathrm{X}=\mathrm{Cl}(\mathbf{a}), \mathrm{Br}(\mathbf{b}), \mathrm{I}(\mathbf{c})
$$

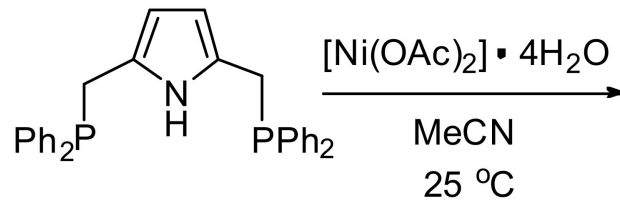

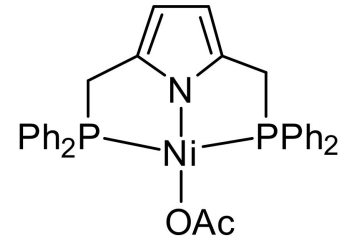

31

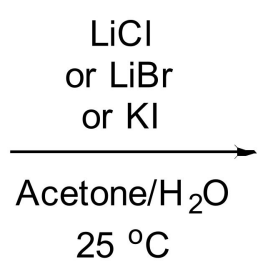<smiles>[X]C1(P)Cc2ccc(n2P)CP1c1ccccc1</smiles>

32a, $89 \%$; 32b, $80 \%$; 32c, $85 \%$.

$\mathrm{X}=\mathrm{Cl}(\mathbf{a}), \mathrm{Br}(\mathbf{b}), \mathrm{I}(\mathbf{c})$

Scheme 14. Synthesis of unsymmetrical NNP pincer nickel complexes 30a-30c and its symmetrical PNP analogues 32a32c $[117,121]$.

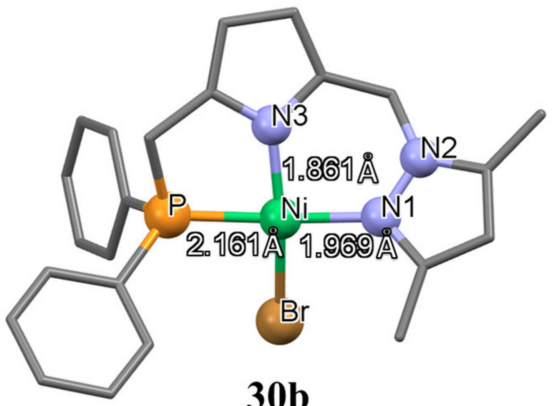

30b

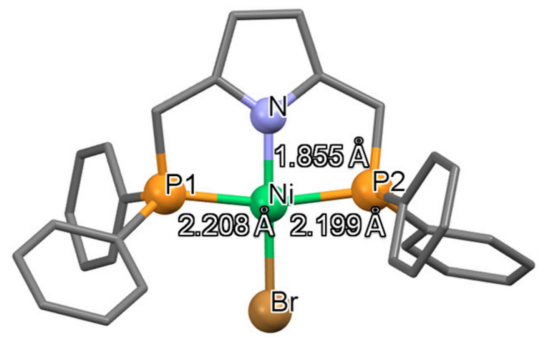

32b
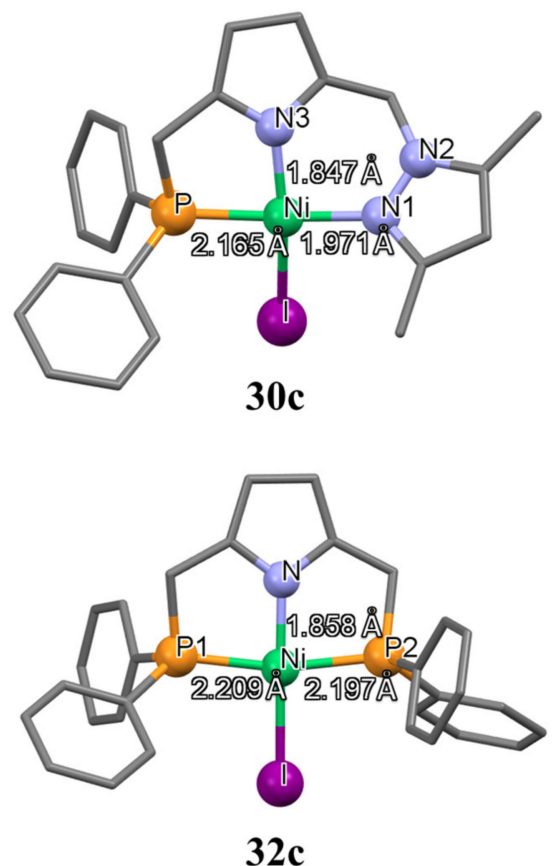

Figure 7. Structures of complexes 30b, 30c [117], 32b and 32c [121].

The authors carried out a systematic study of the polymerization of norbornene using symmetric (32a-32c) and unsymmetrical (30a-30c) pyrrole-based complexes. Nickel pincer NNP complexes in the presence of MMAO or $\mathrm{EtAlCl}_{2}$ showed high yields and high activities (in the range of $10^{7} \mathrm{~g}$ of PNB mol${ }^{-1} \mathrm{~h}^{-1}$ ). Meanwhile, symmetric PNP complexes, on the contrary, turned out to be ineffective catalysts in this process, suggesting that with an increase in the number of $\mathrm{N}$ donors, the yield and activity of the catalytic system increase, following the order PNN > PNP (Table 4). 
Table 4. Comparison of the catalytic performances of the unsymmetrical PNN and PNP nickel pincer complexes 30a-30c and 32a-32c for the catalytic polymerization of norbornene.

\begin{tabular}{|c|c|c|c|}
\hline Entry & Catalyst ( $\mu \mathrm{mol})$ & Yield (\%) & Activity $\left(10^{5}\right)^{a}$ \\
\hline 1 & $30 a(1.0)$ & 64 & 760 \\
\hline 2 & $32 \mathrm{a}(1.0)$ & 16 & 190 \\
\hline 3 & $30 \mathrm{~b}(1.0)$ & 81 & 970 \\
\hline 4 & $32 b(1.0)$ & 24 & 280 \\
\hline 5 & $30 c(1.0)$ & 75 & 90 \\
\hline 6 & $32 c(1.0)$ & 34 & 410 \\
\hline
\end{tabular}

a In units of $\mathrm{g}$ of PNB (polynorbornene) $\mathrm{mol}^{-1} \mathrm{~h}^{-1}$. Reactions were carried out with $2 \mathrm{~g}$ of norbornene in $5 \mathrm{~mL}$ of $\mathrm{CH}_{2} \mathrm{Cl}_{2}$ with [MMAO]/[cat.] = 1000 at room temperature for $1 \mathrm{~min}$ [117].

It is interesting to note that nickel complexes 33a-33d with diarylamido-based unsymmetrical pincer ligands containing a chiral oxazoline ring (Scheme 15) showed much lower activity during the catalytic polymerization of norbornene in the presence of $\mathrm{MAO}$ (in the range $0.12-1.5 \times 10^{5} \mathrm{~g}$ of PNB mol ${ }^{-1} \mathrm{~h}^{-1}$ ) [123]. Meanwhile, the analogous palladium complexes exhibited relatively higher activities (in the range of $4 \times 10^{6} \mathrm{~g}$ of $\mathrm{PNB} \mathrm{mol}^{-1} \mathrm{~h}^{-1}$ ). However, it has been demonstrated that the steric hindrance and electronic effect of the ligands have a significant influence on the complexes and the consequent catalytic properties (the activity increase, following the order $33 \mathbf{c}<33 \mathbf{b}<33 \mathbf{d}<33 \mathbf{a}$, see Table 5).<smiles>[R]c1ccc(Nc2ccc([R])cc2C2=NC([R])CO2)c(P)c1</smiles>

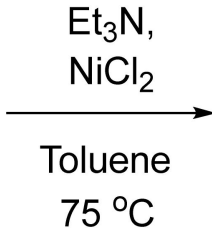

$75^{\circ} \mathrm{C}$<smiles>[R]c1ccc(N2c3ccc([R])cc3C3=[N+](C([R])CO3)N2P)c(P)c1</smiles>

33a-33d, high yield

$$
\begin{aligned}
& R=B n, R^{1}=H(\mathbf{a}), M e(b) \\
& R=P h, R^{1}=H(\mathbf{c}), M e(d)
\end{aligned}
$$

Scheme 15. Synthesis of unsymmetrical NNP pincer nickel complexes 33a-33d [123].

Table 5. Comparison of the catalytic performances of the unsymmetrical NNP nickel pincer complexes 33a-33d for the catalytic polymerization of norbornene [123].

\begin{tabular}{ccccc}
\hline Entry & Catalyst $(\mu \mathbf{m o l})$ & Time $(\mathbf{m i n})$ & Yield (\%) & Activity $\left(\mathbf{1 0}^{\mathbf{5}}\right)^{\mathbf{a}}$ \\
\hline 1 & 33a (1.5) & 60 & 22 & 1.5 \\
2 & 33b (1.5) & 270 & 9 & 0.12 \\
3 & 33c (1.5) & 720 & 22 & 0.14 \\
4 & 33d (1.5) & 300 & 14 & 0.19
\end{tabular}

${ }^{a}$ In units of g of PNB (polynorbornene) $\mathrm{mol}^{-1} \mathrm{~h}^{-1}$. Reactions were carried out with $1 \mathrm{~g}$ of norbornene in $10 \mathrm{~mL}$ of toluene with $[\mathrm{MAO}] /$ [cat.] $=7000$ at room temperature.

Recently, Gardinier and Wang demonstrated synthesis of unsymmetrical PNN pincer nickel complexes 34a-34c with pyrazolyl and diphenylphosphino donor groups (Scheme 16) [124]. These complexes were tested in hydrodehalogenation reactions of 1-bromooctane and different aryl halides in using sodium borohydride as a hydride source and as a base. 34a derivative showed the best catalytic performance that correlates with its electron donor properties [125]. 
<smiles>[X]c1ccc(Nc2ccccc2P)c(-n2cccn2)c1</smiles>

$$
\begin{gathered}
\left(\mathrm{NEt}_{4}\right)(\mathrm{OH}), \\
\stackrel{\mathrm{NiCl}_{2} \cdot 6 \mathrm{H}_{2} \mathrm{O}}{\longrightarrow}
\end{gathered}
$$$$
\text { r.t. }
$$<smiles>[X]c1ccc(N(c2ccccc2P)[n+]2cccn2-c2ccccc2)c(Cl)c1</smiles>

34a, 94\%; 34b, 91\%; 34c, 94\%

$$
\mathrm{X}=\mathrm{MeO}(\mathbf{a}), \mathrm{Me}(\mathbf{b}), \mathrm{CF}_{3}(\mathbf{c})
$$

Scheme 16. Synthesis of unsymmetrical NNP pincer nickel complexes 34a-34c [124].

One of the latest published cationic unsymmetrical pincer complexes of nickel was synthesized by the reaction of anhydrous $\mathrm{NiCl}_{2}$ with 1.2 equivalents of the Milstein's NNP ligand in THF (Scheme 17) [126,127]. In 35, the Ni-N(pyridyl) distance (1.876 $⿱$ ) is shorter than the $\mathrm{Ni}-\mathrm{N}$ (amine) bond length (2.014 $\AA$ ). The complex was tested as a catalyst precursor for the hydrogenation of $\mathrm{CO}_{2}$ to formamide in anhydrous DMSO as a solvent; however, no catalytic activity was observed in the presence of morpholine or dimethylamine as substrates under the applied reaction conditions.

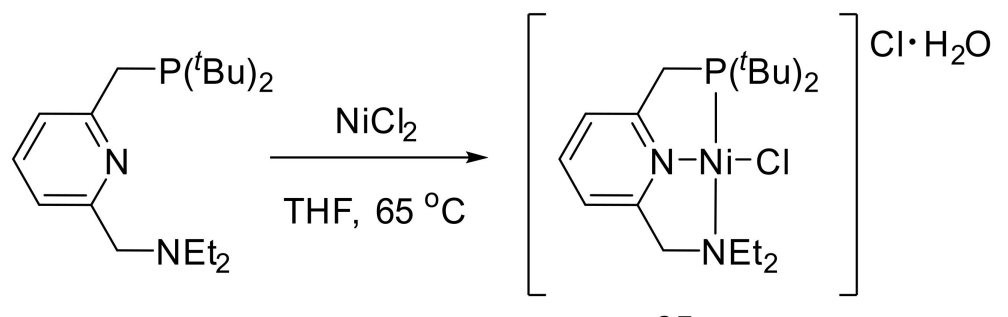

$35,70 \%$

Scheme 17. Synthesis of unsymmetrical PNN pincer nickel complex 35 [126,127].

Analogously to 14a, the Ni-P bond in 35 is significantly shorter than the corresponding bond in its symmetrical PNP analogue [128]; at the same time, the Ni-N(amine) bond of 35 is much longer than in the symmetrical NNN complex (Figure 8) [129]. These differences are due to the strong trans influence of the phosphine moiety, and they determine hemilability (see Table A1 in Appendix A for selected bond lengths $(\AA)$ of unsymmetrical nickel pincer complexes presented in this paper).

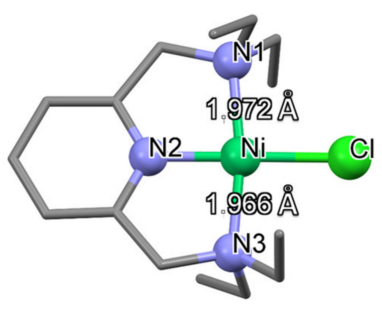

[Ni(NNN)Cl]

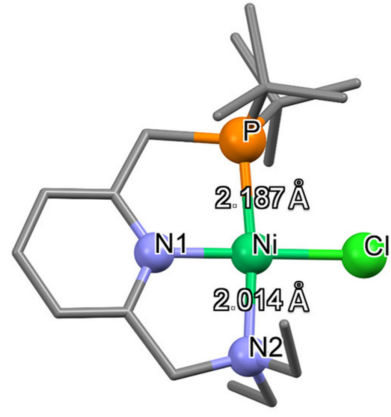

35

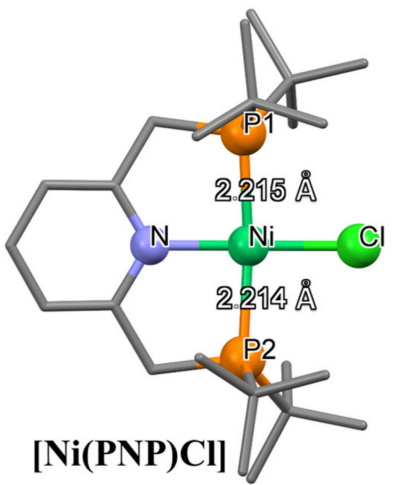

$[\mathrm{Ni}(\mathrm{PNP}) \mathrm{Cl}]$

Figure 8. Crystal structures of the cations of nickel NNN and PNP pincers and complex 35 [126-129].

\section{PNP' Complexes}

The unsymmetrical ${ }^{\mathrm{R}} \mathrm{PNP} \mathrm{R}^{\prime}$ pincer hydride nickel complexes (36a-36c) containing various substituents at the phosphorus atom $\left(R=P h, R^{\prime}={ }^{i} P r, C y\right)$ are also known in the 
literature. These complexes can be obtained by direct interaction of the corresponding ${ }^{\mathrm{R}} \mathrm{PNP}^{\mathrm{R}^{\prime}}$ ligand with the zero-valent metal precursor $\mathrm{Ni}(\mathrm{COD})_{2}$ with a yield of $84-89 \%$ (Scheme 18) [130,131].

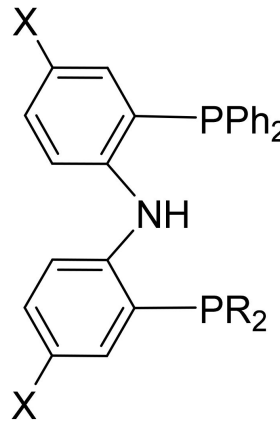

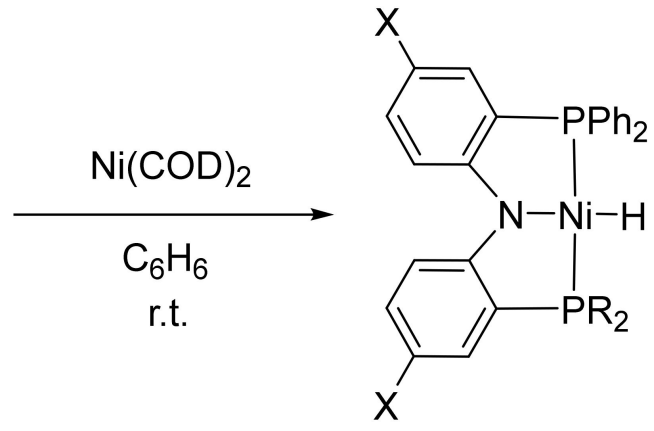

36a, 89\%; 36b, 84\%; 36c, 87\%

$$
\begin{aligned}
& X=H, R={ }^{i} \operatorname{Pr}(36 a) \\
& X=M e, R={ }^{i} \operatorname{Pr}(36 b), \text { Cy (36c) }
\end{aligned}
$$

Scheme 18. Synthesis of unsymmetrical PNP pincer nickel complexes 36a, 36b and 36c [130,131].

It was found that these complexes are capable of activating small molecules, such as $\mathrm{O}_{2}, \mathrm{CO}$, olefins and some others [130-133]. The reaction includes the insertion of the substrate into the Ni-H bond. For example, complex 36a reacts with olefins such as ethylene, 1-hexene, norbornene and styrene to generate complexes $37 \mathrm{a}-\mathbf{3 7 c}, \mathbf{3 8}$ as thermally stable solids (Scheme 19) [131]. In contrast to the selective 1,2-insertion found for 1-hexene, styrene inserts into the $\mathrm{Ni}-\mathrm{H}$ bond of 36a in an exclusively 2,1-manner. In addition, 36a reacts with electronically activated olefins such as methyl acrylate affording product 39.

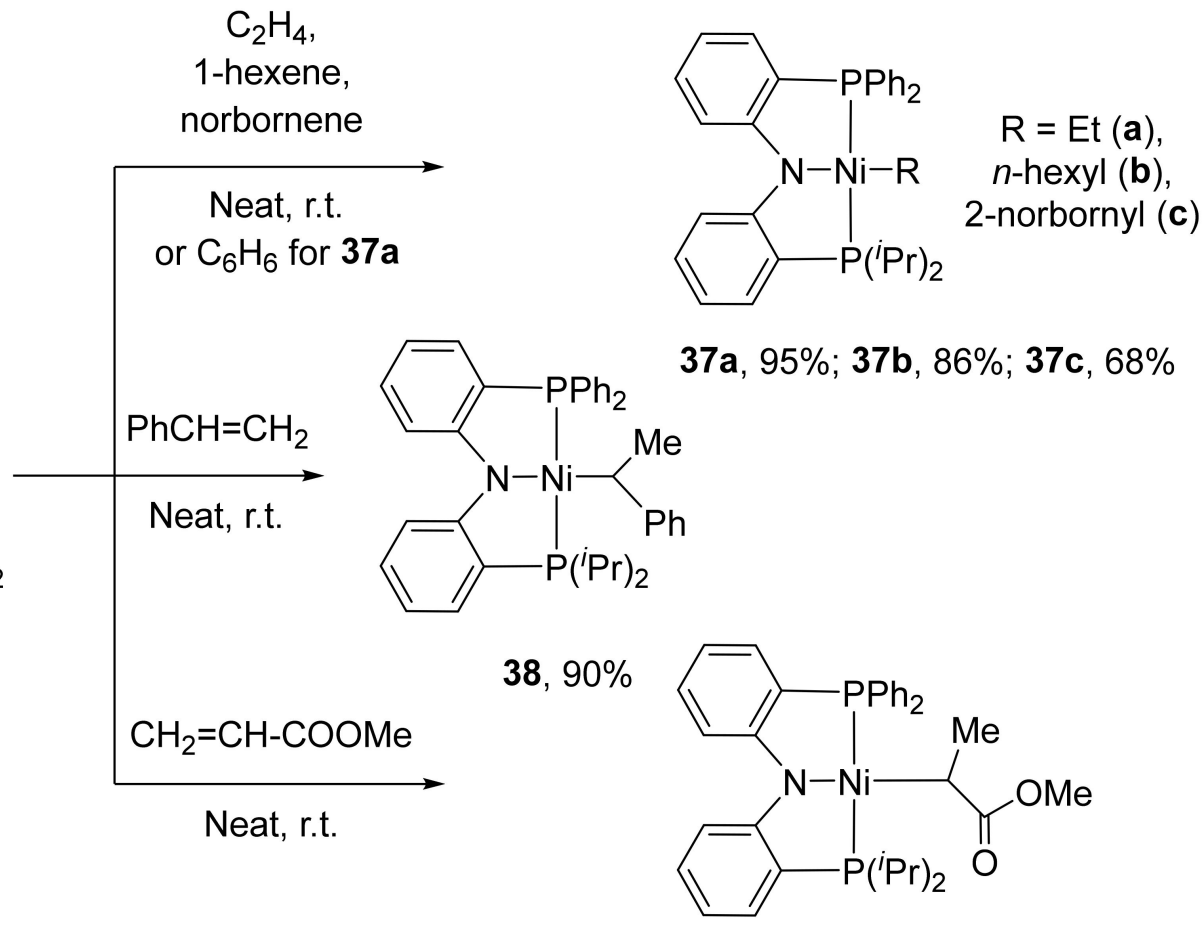

$39,84 \%$

Scheme 19. Cont. 

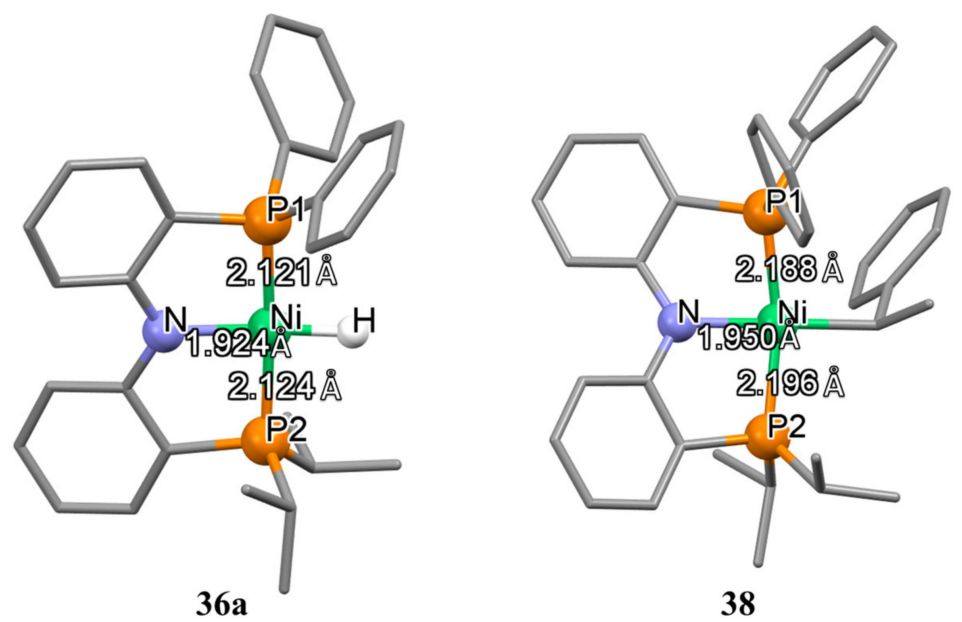

Scheme 19. Synthesis of unsymmetrical PNP pincer alkyl-nickel complexes 37a-37c, 38 and 39 [131].

It should be noted that authors described the reactivity of obtained complexes $37 \mathrm{a}-37 \mathrm{c}$ toward carbon monoxide. It was found, that migratory insertion of $\mathrm{CO}$ into the $\mathrm{Ni}-\mathrm{R}$ bonds affords $\mathrm{Ni}(\mathrm{II})$-acyl derivatives 40a-40c (Scheme 20) [133].

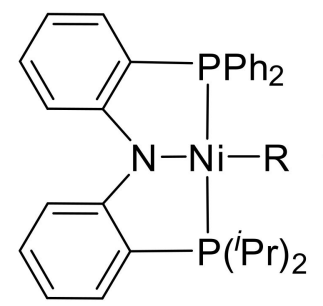

$37 a-37 c$

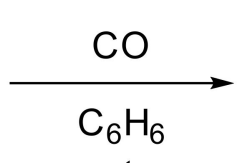

r.t.<smiles>[R][PH2+]N1c2ccccc2-c2ccccc2N1C([R])=O</smiles>

$40 a, 92 \% ; 40 b, 82 \% ; 40 c, 81 \%$

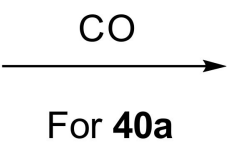

$$
\mathrm{R}=\mathrm{Et}(\mathbf{a}) \text {, }
$$$$
n \text {-hexyl (b), }
$$

2-norbornyl (c)

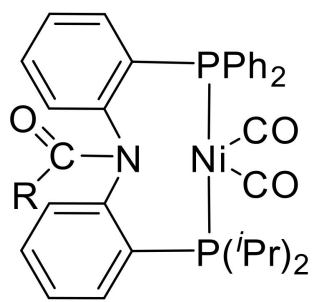

$41,70 \%$
$\mathrm{R}=\mathrm{Et}(\mathbf{a})$,
$n$-hexyl (b),
2-norbornyl (c)

Scheme 20. Insertion of carbon monoxide into the Ni-R bonds of 37a-37c [133].

Interestingly, further carbonylation of acyl compound 40a leads to generation of nickel zero complex 41 as a result of the $\mathrm{C}-\mathrm{N}$ bond-forming reductive elimination whereas no reaction occurs for $40 \mathrm{~b}$ and $36 \mathrm{c}$ under similar conditions. At the same time, in the presence of carbon monoxide, hydride complex 34 undergoes exclusively $\mathrm{N}-\mathrm{H}$ bond-forming reductive elimination to generate zero-valent nickel dicarbonyl derivatives.

\section{7. $\mathrm{N}$-Heterocyclic Carbene Complexes}

$\mathrm{N}$-Heterocyclic carbenes (NHCs) are isolobal with electron-rich phosphines and they are often considered as phosphine ligand alternatives [134]; therefore, unsymmetrical pincer nickel complexes bearing NHC groups are also discussed herein. These carbenes show low toxicity and strong $\sigma$-donating properties easily tunable by varying the substituents at the nitrogen atom and known to exert electronic and steric effects. Due to these unique properties, NHCs are a versatile and indispensable class of ligands applied in coordination chemistry and homogeneous catalysis by transition metal complexes. Consequently, NHCbased $\mathrm{C}$ donors have been commonly employed in symmetrical-type ligands. NHCcontaining unsymmetrical pincer-type ligands have also been reported by adding different donors to the pincer architectures.

As a very good example of unsymmetrical pincer complexes of nickel with NHCmoiety, Sun and co-workers reported the preparation and characterization of the CNN- 
pincer complex 42a-42c (Scheme 21) [135]. Complexes were synthesized via the lithiation of related pincer ligands and transmetalation by $\mathrm{Ni}(\mathrm{DME}) \mathrm{Br}_{2}$ precursor.
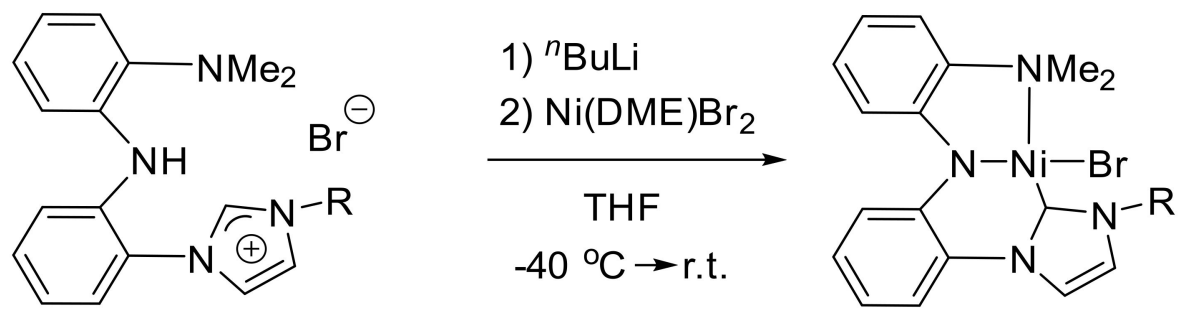

42a, $87 \% ; 4 \mathbf{4 2 b}, 80 \% ; 42 c, 80 \%$
$\mathrm{R}={ }^{i} \operatorname{Pr}(\mathbf{a}),{ }^{n} \mathrm{Bu}(\mathbf{b}), \mathrm{Bn}(\mathbf{c})$

Scheme 21. Synthesis of unsymmetrical NHC pincer nickel complexes 42a-42c [135].

Obtained complexes showed high catalytic activity in Kumada cross-coupling reactions of aryl chlorides or dichlorides with aryl Grignard reagents under mild conditions as well as in Sonogashira coupling reactions of aliphatic halides with terminal alkynes [136].

It has also been confirmed that the hydrogenation of nickel halides $42 \mathrm{a}-42 \mathrm{c}$ in the presence of $(\mathrm{EtO})_{3} \mathrm{SiH}$ and $\mathrm{NaO}^{t} \mathrm{Bu}$ as a base leads to the formation of hydrido nickel complexes 43a-43c (Scheme 22) [137]. According to the X-ray diffraction analysis of 42a and $43 \mathrm{~b}$, the $\mathrm{Ni}-\mathrm{N}$ (amine) bond distance is remarkably longer than the $\mathrm{Ni}-\mathrm{N}$ (amide) due to the strong trans influence of the carbon atom of the NHC coordination moiety. Complex 43a exhibited high catalytic activity in the hydrodehalogenation of organic halides.<smiles>[R]N1C=CN2c3ccccc3N(c3ccccc3N(C)C)C12Br</smiles>

42a-42c

$\mathrm{R}={ }^{i} \operatorname{Pr}(\mathbf{a}),{ }^{n} \mathrm{Bu}(\mathbf{b}), \mathrm{Bn}(\mathbf{c})$

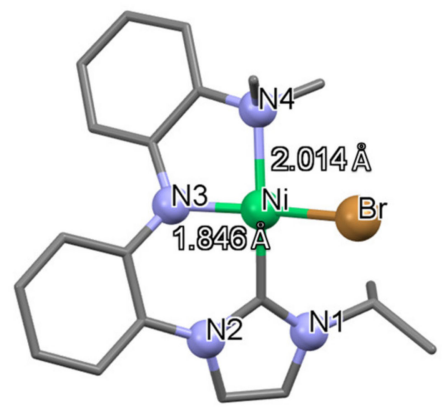

$42 \mathrm{a}$

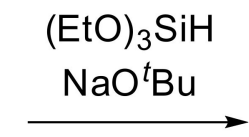

Toluene, $80^{\circ} \mathrm{C}$<smiles>[R]N1C=CN2c3ccccc3N(c3ccccc3N(C)C)[C@@H]12</smiles>

43a, 64\%; 43b, 47\%; 43c, 55\% $\mathrm{R}={ }^{i} \operatorname{Pr}(\mathbf{a}),{ }^{n} \mathrm{Bu}(\mathbf{b}), \mathrm{Bn}(\mathbf{c})$

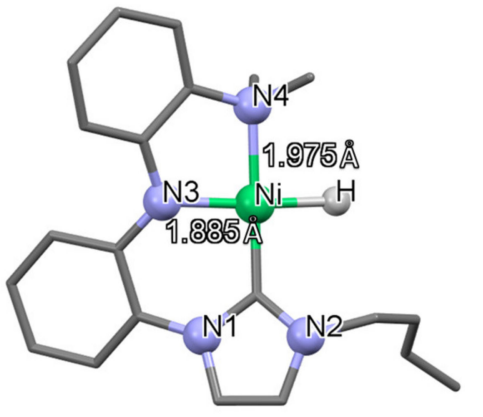

$43 b$

Scheme 22. Synthesis of unsymmetrical NHC pincer nickel hydride complexes 43a-43c [137].

Later, authors introduced a pyrrolidine group, instead of a dimethyl amino group to the pincer ligand structure and synthesized complexes $44 \mathbf{a}$ and $44 \mathbf{b}$ by the direct cyclometalation of the corresponding ligand precursor in the presence of $\mathrm{Et}_{3} \mathrm{~N}$ (Scheme 23) [138]. 
Interestingly, the yields of $44 \mathbf{a}$ and $44 \mathbf{b}$ were higher ( 85 and $90 \%$, respectively) than the yields of $\mathbf{4 2} \mathbf{a}$ and $\mathbf{4 2 b}(80-87 \%)$.

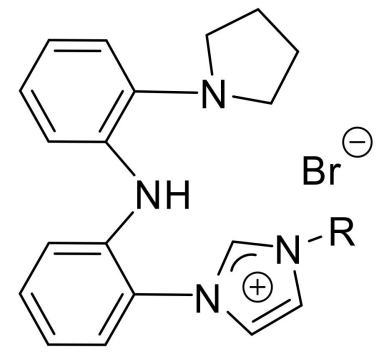

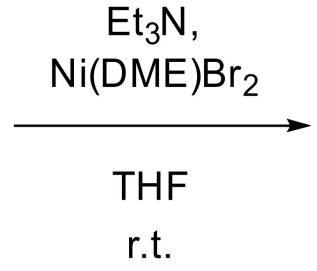

$44 a, 85 \% ; 44 b, 90 \%$

$$
\mathrm{R}={ }^{i} \operatorname{Pr}(\mathbf{a}),{ }^{n} \mathrm{Bu}(\mathbf{b})
$$

Scheme 23. Synthesis of unsymmetrical NHC pincer nickel complexes $44 \mathbf{a}$ and $\mathbf{4 4 b}$ [138].

Complexes 42a, 42b, 44a and 44b were examined in transfer hydrogenation of ketones in the presence of a base $\left(\mathrm{NaO}^{t} \mathrm{Bu}\right.$ or $\left.\mathrm{KO}^{t} \mathrm{Bu}\right)$. The results show that the catalytic activity follows the order $4 \mathbf{4} a>42 a>44 b>42 b$ for acetophenone hydrogenation. Authors considered that the strong electron-donating properties of the pyrrolidine and iso-propyl group in complex 44a made the metal center electron-rich. Authors also proposed the hydrido nickel complex to be the intermediate of this process, whose electron-rich property would increase the activity of the $\mathrm{Ni}-\mathrm{H}$ bond. Thus, hydrido complex 43a was tested as the catalyst to explore the mechanism of the interaction. Indeed, it was found that complexes $\mathbf{4 2 a}, \mathbf{4 2 b}$, $44 a$ and $44 \mathbf{b}$ were catalyst precursors, which generate the corresponding catalytically active hydrido complexes.

It is also interesting to note the synthesis of the NHC pincer complexes of nickel with both unsymmetrical and chiral properties. The cyclometalation was carried out via direct $\mathrm{C}-\mathrm{H}$ bond activation in the presence of $\mathrm{NaOAc}$ to form corresponding complexes $45 \mathrm{a}-\mathbf{4 5 f}$ (Scheme 24) [139]. However, the yields of $\mathbf{4 5 a}-\mathbf{4 5 f}$ were in the range of $15-27 \%$, and they did not find their place in catalysis yet. However, their palladium analogues showed moderate stereoselectivities in the asymmetric Friedel-Crafts alkylation.<smiles></smiles><smiles>[R]C1CNC2=C1N1N3C4N([R])C=CN4C=C(C2)[N+]13Cl</smiles>

45a, 23\%; 45b, 18\%; 45c, 27\%; 45d, $24 \% ; 45 e, 21 \% ; 45 f, 15 \%$

$$
\begin{aligned}
& \mathrm{R}^{1}={ }^{i} \mathrm{Pr}, \mathrm{R}^{2}=\mathrm{Et}(\mathbf{a}), \mathrm{Bn}(\mathbf{b}), \\
& \mathrm{R}^{1}=\mathrm{Bn}, \mathrm{R}^{2}=\mathrm{Et}(\mathbf{c}), \mathrm{Bn}(\mathbf{d}), \\
& \mathrm{R}^{1}={ }^{t} \mathrm{Bu}, \mathrm{R}^{2}=\mathrm{Et}(\mathbf{e}), \mathrm{Bn}(\mathbf{f}),
\end{aligned}
$$

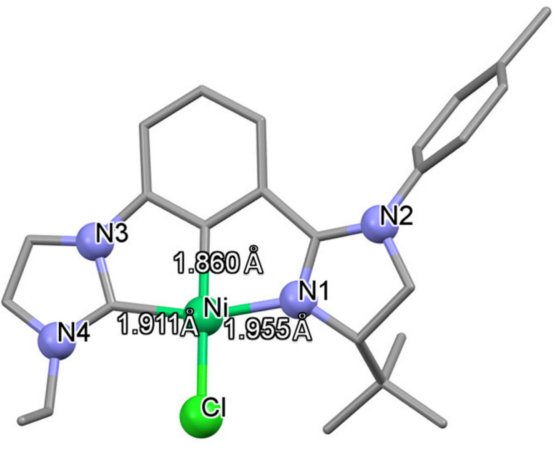

$45 \mathrm{e}$

Scheme 24. Synthesis of unsymmetrical NHC pincer nickel complexes 45a-45f [139].

It is also worth mentioning the unsymmetrical nickel complex with NHC-triazole arms, synthesized by the reaction of a ligand precursor with $\mathrm{Ag}_{2} \mathrm{O}$ with in situ formation 
of a silver NHC complex, which was transmetalated by $\left[\mathrm{NiCl}_{2}\left(\mathrm{PPh}_{3}\right)_{2}\right]$ to provide desired complex 46 (Scheme 25) with 32\% yield [140]. Complex 46 was found to be highly active in the Suzuki-Miyaura cross-coupling reactions of aryl bromides or aryl iodides with phenylboronic acid at $110^{\circ} \mathrm{C}$.
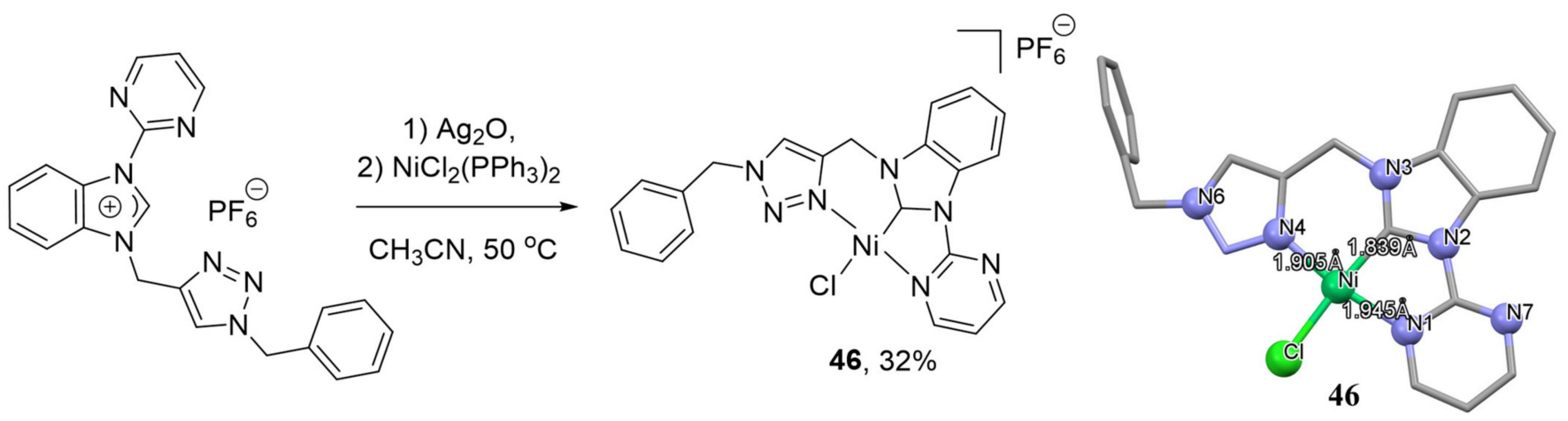

Scheme 25. Synthesis of unsymmetrical NHC pincer nickel complex 46 [140].

The electrochemical generation of NHC containing unsymmetrical pincer nickel complex $\mathbf{4 7}$ has been described by some of us (Scheme 26) [141,142]. It was found that cathodic reduction of the imidazolium salt (LHBr in Scheme 26) in the presence of nickel (II) ions leads to the formation of $N$-heterocyclic carbene complexes of nickel (II) with the molecular hydrogen as the only byproduct. Interestingly, the imidazolium salt plays a role of both NHC source and electrolyte, while the source of nickel ions is the nickel plate.

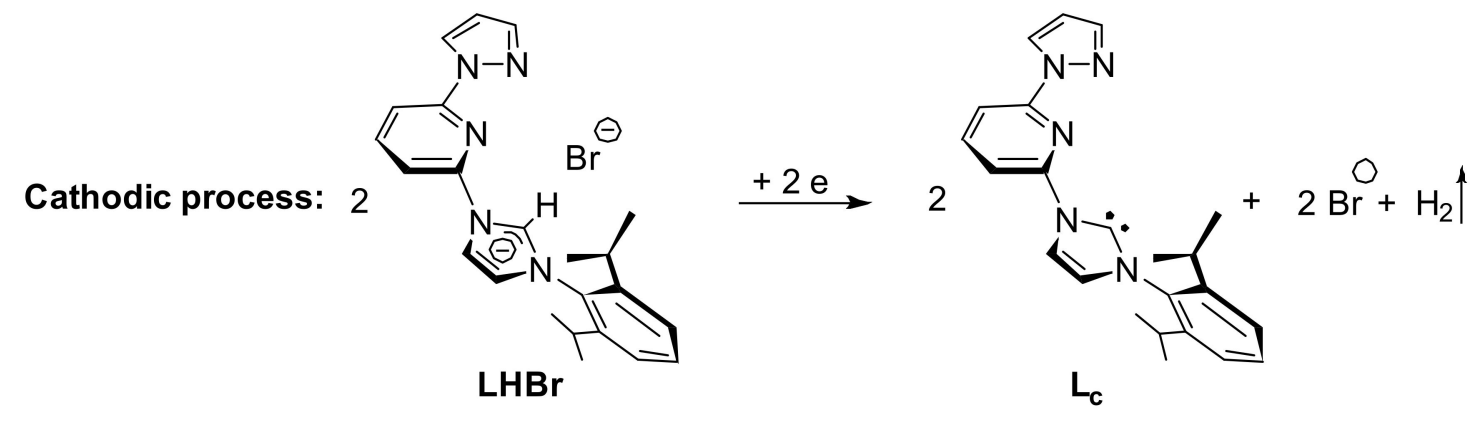

Anodic process: $\quad \mathrm{Ni}^{0} \stackrel{-2 \mathrm{e}}{\longrightarrow} \mathrm{Ni}^{2+}$

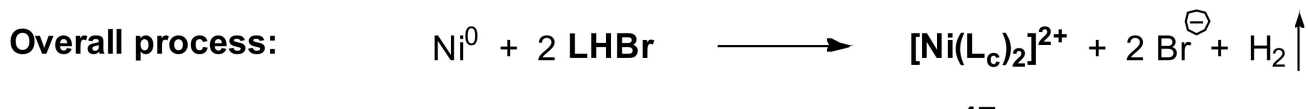

47

Scheme 26. Electrochemical generation of unsymmetrical NHC pincer nickel complex 47 [141].

Vabre et al. demonstrated the synthesis of nickel complexes with PIMCOP, PIMIOCOP and NHCCOP ligands (Scheme 27) [143]. PIMCOP complex 48 was obtained by nickelation of an unsymmetrical meta-phenylene-based ligand bearing phosphinite and imidazolophosphine groups. $N$-methylation of the latter generates a new PIMIOCOP complex 49 with NHC moiety, which can be converted subsequently into NHCCOP complex 50 (Scheme 27). Interestingly, the Ni-P distance in 50 is much longer (2.145 $\AA$ ) compared to the related Ni-P bond of 48 and 49 (2.132 and $2.133 \AA$ ). These indicate the much stronger trans influence of the NHC moiety compared to the phosphine group. 


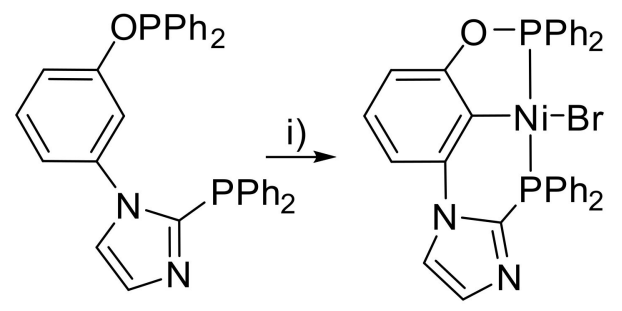

48, $78 \%$<smiles>Cn1cc[n+]([O-])c1-c1cccc2c1N(c1ccccc1)[P+](c1ccccc1)O2</smiles>

$49,97 \%$<smiles></smiles>

50, $39 \%$

i) $\left\{\left({ }^{i} \mathrm{PrCN}\right) \mathrm{NiBr}_{2}\right\}_{n}, \mathrm{NEt}_{3}$, THF, r.t.; ii) $\mathrm{MeOTf}, \mathrm{CH}_{2} \mathrm{Cl}_{2}$, r.t.; iii) $\left[\mathrm{Et}_{4} \mathrm{~N}\right] \mathrm{Cl}, \mathrm{MeCN}, 60{ }^{\circ} \mathrm{C}$

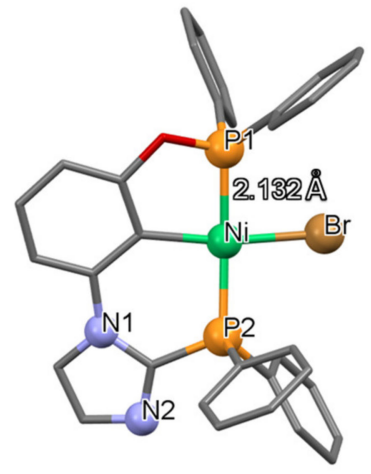

48

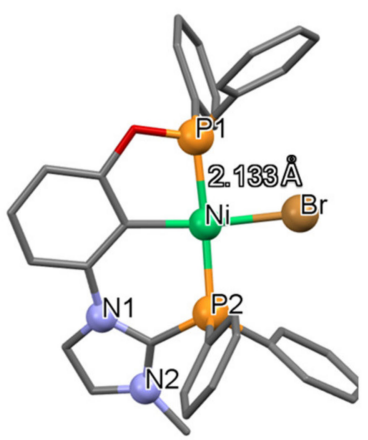

49

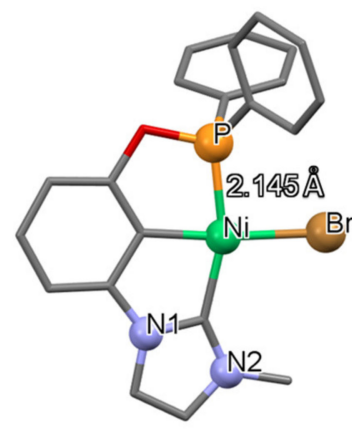

50

Scheme 27. Synthesis of unsymmetrical pincer nickel complexes 48-50 [143].

\section{Other Types of Complexes}

Other types of unsymmetrical pincer nickel complexes are also known in the literature. For example, phosphinito-thiophosphinito PSCOP complex 51 (Scheme 28), which was obtained by cyclometalation of the related ligand by $\mathrm{NiCl}_{2}$ [144]. The X-ray diffraction analysis showed that the nickel center is located in a slightly distorted square-planar geometry. PSCOP complex $\mathbf{5 1}$ demonstrated a good catalytic activity and selectivity in C-S couplings of iodobenzene with different disulfides.<smiles>Oc1cccc(S)c1</smiles><smiles></smiles><smiles>c1ccc(PSc2ccccc2)cc1</smiles><smiles>[Mg][Mg][Mg]</smiles><smiles>Cl[N+]12c3ccccc3P1Oc1cccc3[pH]n2c13</smiles>

$51,91 \%$

Scheme 28. Synthesis of sulfur-containing unsymmetrical PSCOP pincer nickel complex 51 [144].

Other sulfur-containing nickel complexes are SCS-type pincers. Interestingly, SCSligand-based nickel pincer nucleotide (lactate racemase) is the first enzyme known to contain a pincer metal complex as a cofactor [145]. This enzyme converts L-lactic acid into D-lactic acid. The mechanisms of this transformation have been studied using DFT calculations. The most probable pathway for proton-coupled hydride transfer involves the intermediate formation of an unsymmetrical complex [146]. Inspired by the structures of the active site of lactate racemase, similar scorpion-like SCS nickel complexes were proposed, and their potentials for catalytic hydrogenation of $\mathrm{CO}_{2}$ [147] and for the asymmetric transfer hydrogenation of 1-acetonaphthone (the phosphorus-based complexes $\mathbf{5 2} \mathbf{a}-\mathbf{5 2} \mathbf{d}$ in Figure 9) [148] were computationally predicted. 
<smiles>[R]PS[N+]1(C)SSC(=O)c2c[n+](CCc3c[nH]cn3)cc([R])c21</smiles>

\section{2a-52d}

$$
\mathrm{R}=\mathrm{Ph}(\mathbf{a}), \mathrm{Me}(\mathbf{b}), \mathrm{Et}(\mathbf{c}),{ }^{t} \mathrm{Bu}(\mathbf{d})
$$

Figure 9. Structure of phosphorus-based SCS unsymmetrical pincer nickel complexes 52a-52d [148].

It is also interesting to mention the phosphinite PONNOP expanded pincer ligand, which undergoes an unexpected rearrangement in the presence of nickel (II) species to form an unusual PONNP complex 53 (Scheme 29) [149]. Interestingly, the reaction of the PONNOP ligand with copper chloride did not lead to the rearrangement but to a binuclear PONNOP copper complex. The performed DFT calculations confirmed that PONNOP and PONNP free ligand isomers are similar in energy and have a high barrier for their interconversion. However, authors concluded that the $\mathrm{P}$ atom, which migrates from $\mathrm{O}$ to $\mathrm{N}$, is bound to the transition metal atom, which provides the additional stabilization of the transition state to enable the isomerization toward the more stable PONNP pincer motif.

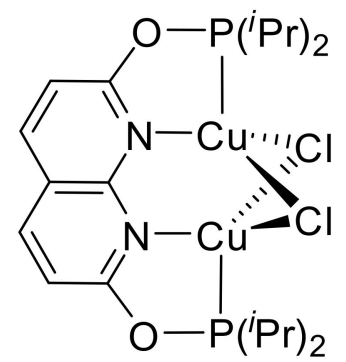

(PONNOP) $\mathrm{Cu}_{2} \mathrm{Cl}_{2}, 77 \%$

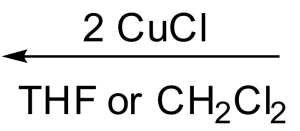

r.t.<smiles>Oc1ccc2ccc(OP)nc2n1</smiles><smiles></smiles>

$53,89 \%$

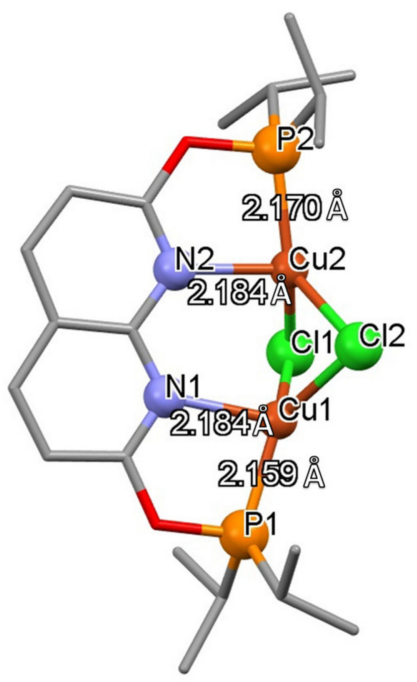

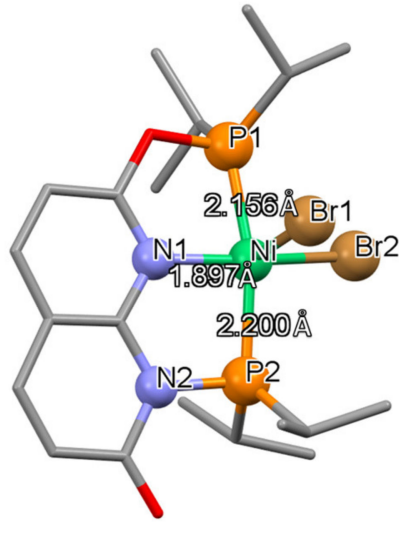

53

$(\mathrm{PONNOP}) \mathrm{Cu}_{2} \mathrm{Cl}_{2}$

Scheme 29. Synthesis of unsymmetrical PONNP pincer nickel complex 53 and its PONNOP copper analogue [149]. 
More recently, the synthesis of a series of unsymmetrical Ni(II)-POCOP pincer complexes (54a-54c) derived from 1,7-naphthalenediol were described (Scheme 30) [150]. The molecular structures of two complexes were determined by single-crystal X-ray diffraction analysis. Interestingly, the Ni-P distances were almost identical, despite the size of the metallocycle. For example, for $\mathbf{5 4 a}$, the M-P ${ }^{1}$ bond length was $2.1340 \AA$, while that for the $\mathrm{M}-\mathrm{P}^{2}$ distance was slightly longer $(2.1417 \AA)$. These complexes were examined as catalysts in Suzuki-Miyaura C-C cross-coupling reactions. However, the results are not as good as those obtained with their analogous POCOP pincer derivatives of 1,3-naphtalene diol [151]. Complex 54c, bearing a more sterically demanding $-\mathrm{PPh}_{2}$ group, was the most efficient catalyst of the series, reaching $53 \%$ yield of the biphenyl product.<smiles>[R2]Oc1ccc2cccc(OP[R2])c2c1</smiles>

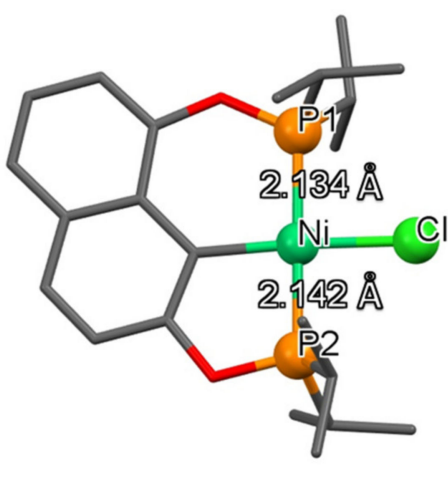

$54 a$

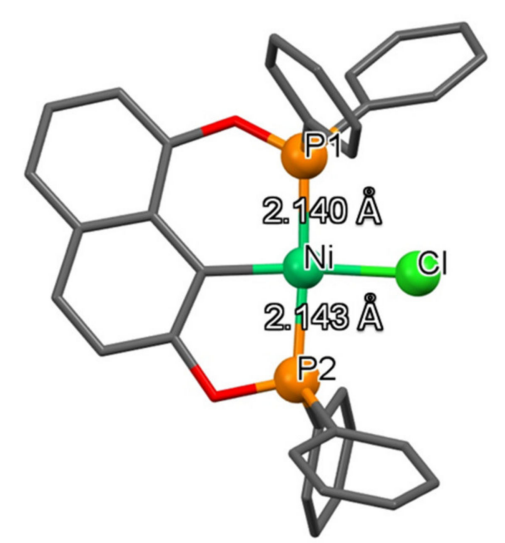

$54 c$

Scheme 30. Synthesis of unsymmetrical POCOP pincer nickel complexes 54a, 54b and 54c [150].

Very recently, Wang et al. demonstrated the synthesis of unsymmetrical $\mathrm{PCP}^{\prime}$ pincer nickel complexes bearing a phosphine-phosphinite ligand with a stereogenic carbon center [152]. The corresponding enantiopure nickel complexes $55 \mathbf{a}$ and $\mathbf{5 5} \mathbf{b}$ were obtained via a convenient one-pot three-step reaction (Scheme 31). Moreover, the authors showed the possibility of the replacement of the chloride ligand in $55 \mathbf{b}$ by the action of silver agents $\mathrm{AgOAc}$ or $\mathrm{AgBF}_{4}$ with the formation of a neutral complex $56 \mathrm{~b}$ or a cationic complex $57 \mathrm{~b}$ (Scheme 31). The crystal structures of complexes $\mathbf{5 5 a}$ and $\mathbf{5 6} \mathbf{b}$ were determined by X-ray diffraction analysis (Figure 10), which revealed that, in 55a, atoms of phosphorus lie on the same plane defined by the $\left[\mathrm{PCP}^{\prime} \mathrm{Cl}\right]$ atoms. Meanwhile, 3,5-methyl substituents and -OAc group in $\mathbf{5 6 b}$ lead to the distortion of the ligand in which the phosphine moiety is not located in the same plane $\left[\mathrm{PCP}^{\prime} \mathrm{Cl}\right]$. 


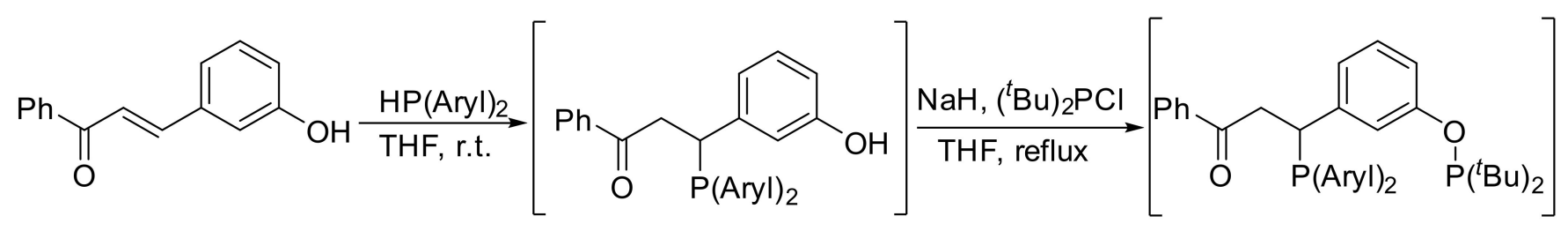

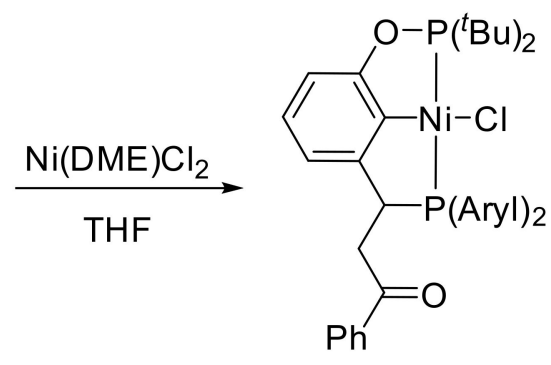

55a, $42 \%$; $55 \mathrm{~b}, 45 \%$

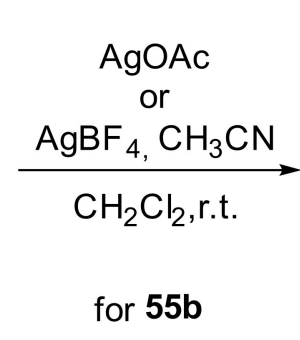

$\mathrm{Ph}$

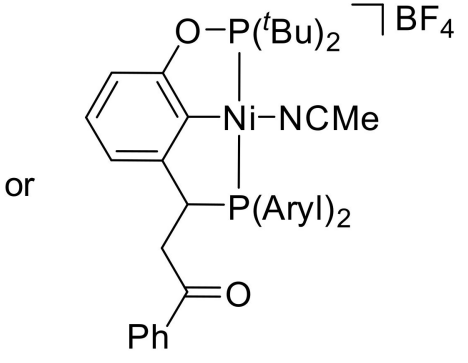

57b, $97 \%$<smiles>Cc1cc(C)cc(C)c1</smiles>

Scheme 31. Synthesis of unsymmetrical PCP' nickel pincer complexes 55a, 55b, 56b and 57b [152].

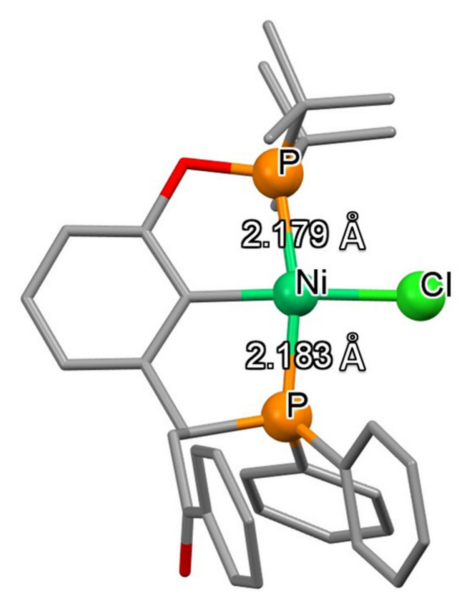

$55 a$

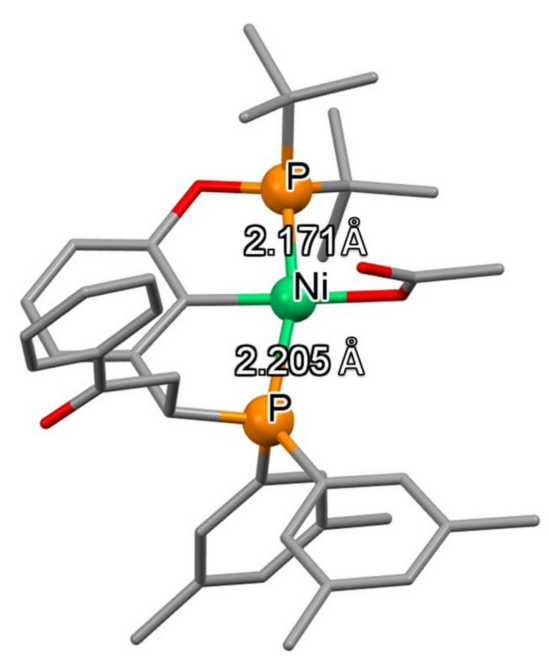

$56 b$

Figure 10. The structures of the unsymmetrical $\mathrm{PCP}^{\prime}$ nickel pincer complexes 55a, 56b [152].

Authors applied these newly developed nickel pincer complexes for the highly enantioselective catalytic synthesis of P-stereogenic secondary phosphine-boranes by asymmetric addition of primary phosphine to electron-deficient alkenes. The resulting products may be easily converted into useful chiral phosphine ligands for asymmetric transformations. Interestingly, the nickel-based catalysts demonstrated the improved enantio- and diastereoselectivity to $94 \%$ ee and 13:1 dr (for complex 55b, entry 2) compared to palladium-based analogues (59\% ee with low dr). While Ni-OAc complex $56 \mathbf{b}$ exhibited similar catalytic activity compared to $\mathbf{5 5 \mathbf { b }}$ (entry 3 , Table 6 ), in contrast, the cationic complex $\mathbf{5 7 \mathbf { b }}$ did not catalyze the reaction at all (entry 4, Table 6). Moreover, authors revealed that $\mathrm{CH}_{2} \mathrm{Cl}_{2}$ as a solvent and temperature of $-40^{\circ} \mathrm{C}$ is the best combination (entries 8-11, Table 6) compared 
to other conditions (entries 5-7, Table 6). Control experiments confirmed that both the catalyst and the base were necessary for product formation (entries 10 and 11, Table 6).

Table 6. Catalytic synthesis of P-stereogenic secondary phosphine-boranes with unsymmetrical $\mathrm{PCP}^{\prime}$ nickel pincer complexes $55 \mathrm{a}, 55 \mathrm{~b}, 56 \mathrm{~b}$ and $56 \mathrm{~b}$.

\begin{tabular}{|c|c|c|c|c|c|}
\hline$\prod_{0}$ & + & $\mathrm{H}_{2} \mathrm{PPh}$ & $\begin{array}{l}\text { 1) cataly } \\
\mathrm{KOAc} \\
\text { solvent, } \\
\text { 2) } \begin{array}{l}\mathrm{BH}_{3} \cdot 5 \\
\text { react }\end{array}\end{array}$ & $\begin{array}{l}1 \mathrm{~mol} \%) \\
\mathrm{mol} \%) \\
\mathrm{np}, 12 \mathrm{~h} \\
\underset{2,0.5 \mathrm{~h},}{\mathrm{temp}}\end{array}$ & $\mathrm{H}^{-\mathrm{P}}-\mathrm{BH}_{3}$ \\
\hline Entry & Catalyst $^{a}$ & Solvent & $\mathrm{T}\left({ }^{\circ} \mathrm{C}\right)$ & Yield $(\%)^{b} / d^{c}{ }^{c}$ & $\begin{array}{l}\text { ee of the Major and } \\
\text { Minor Product (\%) }\end{array}$ \\
\hline 1 & $55 a$ & $\mathrm{CH}_{2} \mathrm{Cl}_{2}$ & -60 & $75(5: 1)$ & $70 / 24$ \\
\hline 2 & $55 \mathrm{~b}$ & $\mathrm{CH}_{2} \mathrm{Cl}_{2}$ & -60 & $80(13: 1)$ & 94/- \\
\hline $3^{e}$ & $56 \mathrm{~b}$ & $\mathrm{CH}_{2} \mathrm{Cl}_{2}$ & -60 & $78(13: 1)$ & 94/- \\
\hline $4^{e}$ & $57 \mathrm{~b}$ & $\mathrm{CH}_{2} \mathrm{Cl}_{2}$ & -60 & 0 & n.a. \\
\hline 5 & $55 \mathrm{~b}$ & $\mathrm{MeOH}$ & -60 & $70(2: 1)$ & $40 / 32$ \\
\hline 6 & $55 \mathrm{~b}$ & $\mathrm{CHCl}_{3}$ & -60 & $60(4: 1)$ & $89 / 56$ \\
\hline 7 & $55 \mathrm{~b}$ & THF & -60 & $18(1: 1)$ & $44 / 17$ \\
\hline 8 & $55 \mathrm{~b}$ & $\mathrm{CH}_{2} \mathrm{Cl}_{2}$ & -40 & $82(13: 1)$ & $94 /-$ \\
\hline 9 & $55 \mathrm{~b}$ & $\mathrm{CH}_{2} \mathrm{Cl}_{2}$ & -20 & $82(12: 1)$ & $90 /-$ \\
\hline $10^{\mathrm{e}}$ & $55 \mathrm{~b}$ & $\mathrm{CH}_{2} \mathrm{Cl}_{2}$ & -40 & 0 & n.a. \\
\hline 11 & none & $\mathrm{CH}_{2} \mathrm{Cl}_{2}$ & -40 & 0 & n.a. \\
\hline
\end{tabular}

According to the proposed by the authors catalytic cycle for $\mathbf{5 5 b}$, catalyzed synthesis of secondary phosphine-boranes includes the formation of Ni-OAc (56b) complex by the ligand exchange reaction, followed by the transphosphination step between diphenylphosphine and formed complex, which leads to a nickel phosphide intermediate. Then, the nucleophilic phosphorus addition to the $\beta$-position of enone affords a nickel phosphine complex, which, finally, reacts with HOAc, formed at the transphosphination step, and releases the product as well as regenerates the active catalyst.

\section{Conclusions}

In summary, the chemistry of unsymmetrical P-based nickel pincer complexes is young and started its way only in 2008, which is 32 years later after the synthesis of the first symmetrical nickel pincer complex (Figure 11). However, the number of publications in this area has increased dramatically in recent years. Research gains new unprecedented complexes with unexpected properties in the past few years. The development in this field seems to be very promising $[109,124,125,153,154]$. 


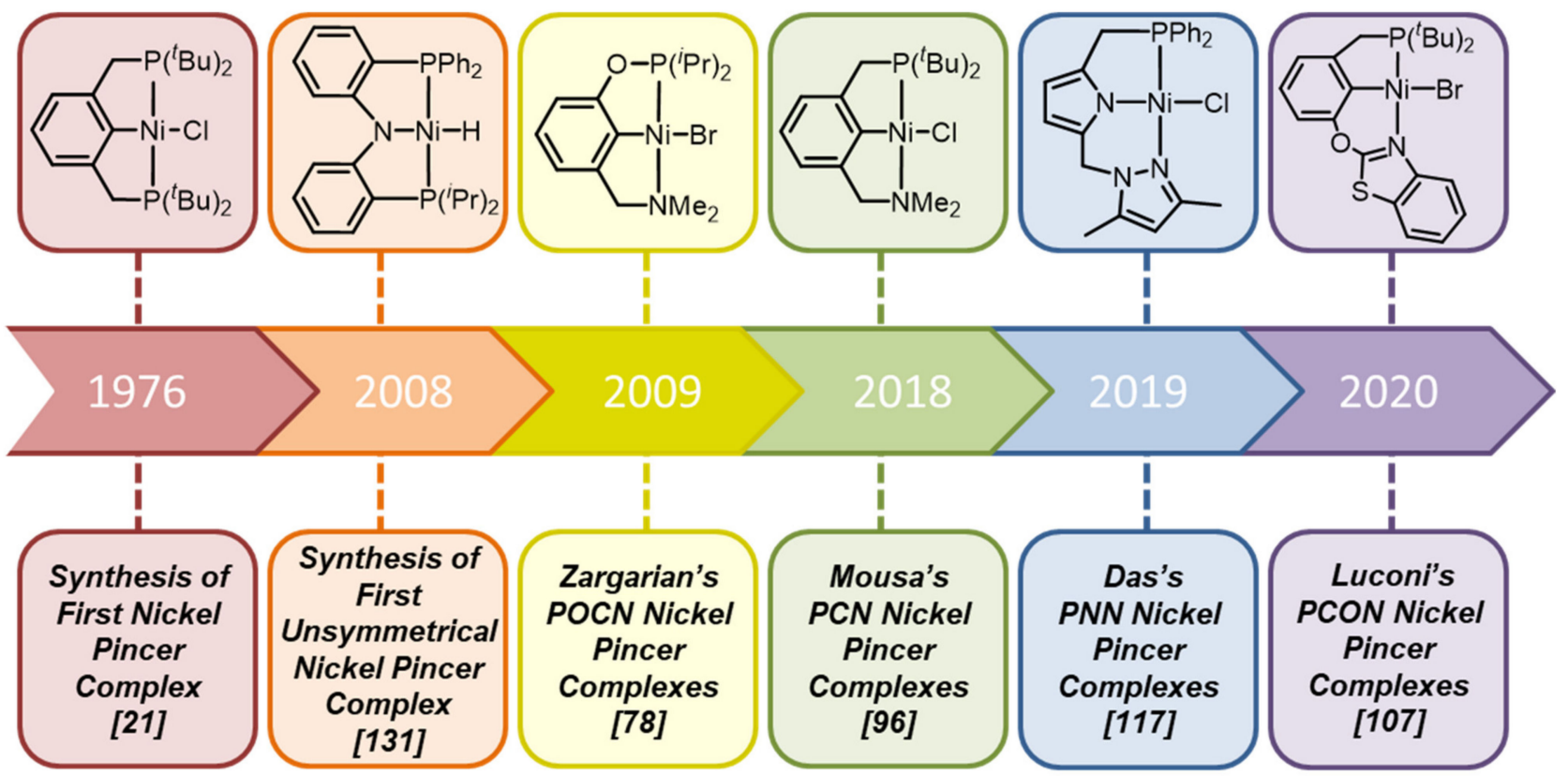

Figure 11. Historical timeline for unsymmetrical pincer nickel complexes.

As follows from the review, unlike their symmetric NCN analogues, unsymmetrical PCN complexes can be obtained by direct metalation with activation of the C-H bond, and, unlike PCP analogues, they can be oxidized with bromine to form stable nickel (III) complexes. Thus, unsymmetrical $\mathrm{P}$ - and $\mathrm{N}$ - based nickel complexes combine the unique properties of both classes of ligands. Moreover, POCN complexes turned out to be active catalysts in the processes of functionalization of acrylonitrile and asymmetric SuzukiMiyaura cross-coupling reaction, while the catalytic efficiency of nickel pincer complexes in the Kharasch addition follows the order: $\mathrm{NCN}>\mathrm{POC}_{\mathrm{sp} 3} \mathrm{OP}>\mathrm{PCN}>\mathrm{POCN}$. The utilization of the PCN scaffold can be efficient for the ethylene oligomerization process. The catalytic efficiency of nickel pincer complexes in the cross-coupling of aryl fluorides with aryl Grignard reagents follows the order: NNP > ONP > ONN > NNN, demonstrating the importance of the presence of the $\mathrm{P}$ atom in ligand design. Meanwhile, the asymmetry in NNP scaffold causes higher catalytic activity in the polymerization of norbornene compared to symmetrical PNP analogues. Unsymmetrical PNP' nickel hydrides react with olefins such as ethylene, 1-hexene and norbornene and styrene to generate corresponding Ni-R derivatives. Meanwhile, NHC-based analogues of P-based nickel pincers turned out to be active catalysts in Kumada, Sonogashira and Suzuki-Miyaura cross-coupling reactions, as well as in asymmetric Friedel-Crafts alkylation and transfer hydrogenation of ketones. Unsymmetrical $\mathrm{PCP}^{\prime}$ scaffold is particularly interesting since complexes based on it have been successfully applied for highly enantioselective catalytic synthesis of P-stereogenic secondary phosphine-boranes.

The steric and electronic effects of ligands have a significant effect on the catalytic properties of the complexes formed by them. Therefore, the design of the ligand frameworks and their combination with the metal play crucial roles in the development of highly active catalysts. In this context, the use of such donor atoms as phosphorus and nitrogen for the development of pincer ligands and nickel complexes, which have the unique properties in both stoichiometric and catalytic reactions, is a very promising task of modern organometallic chemistry. In such species, the difference in the trans effect between the two different donor arms provides the hemilability of the ligand since the group with the weaker trans effect $(\mathrm{N})$ is more likely to dissociate from the metal center, which leads to a vacant coordination site at the metal center and thus can allow for effective coordination and transformation of substrate molecules in the homogeneous catalysis conditions. Thus, phosphorus- and nitrogen-based pincer nickel complexes demonstrated high activities in 
such processes as the formation of a new carbon-carbon bond (Heck, Suzuki-Miyaura reactions), hydrogenation of aryl and alkyl ketones, alkane dehydrogenation, carboxylation, hydrosilylation, oligo- and polymerization of unsaturated hydrocarbons and others; moreover, unsymmetrical pincer complexes showed higher catalytic activity than their symmetrical analogues. However, to improve the catalytic activity of the complexes bearing unsymmetrical pincer ligands, the strategies for regulating hemilability of coordination site and flexibility of ligand backbone need to be deeply explored.

Author Contributions: Conceptualization and methodology, Z.N.G. and D.G.Y.; writing-original draft preparation, Z.N.G., A.O.K., A.A.K. (Alexey A. Kagilev), A.A.K. (Alina A. Kagileva), I.K.M. and I.F.S.; writing-review and editing, Z.N.G., A.O.K. and D.G.Y. All authors have read and agreed to the published version of the manuscript.

Funding: This research activity was funded by the Russian Foundation for Basic Research, grant number 19-33-90288, and the Government assignment for FRC Kazan Scientific Center of RAS.

Institutional Review Board Statement: Not applicable.

Informed Consent Statement: Not applicable.

Data Availability Statement: Not applicable.

Acknowledgments: Z.N.G. and D.G.Y. acknowledge the financial support from the Russian Foundation for Basic Research, grant number 19-33-90288. The authors are thankful to the Government assignment for FRC Kazan Scientific Center of RAS for the financial support of this research related to the synthesis of nickel pincers that was performed by Z.N.G., A.O.K., Alexey A.K., Alina A.K., I.F.S. and D.G.Y. at the Arbuzov Institute of Organic and Physical Chemistry of FRC Kazan Scientific Center of RAS, and the other part of the work related to the investigation of the catalytic activity of the reported complexes was done in Alexander Butlerov Institute of Chemistry of Kazan Federal University by A.O.K., Alexey A.K., Alina A.K., I.K.M. and D.G.Y.

Conflicts of Interest: The authors declare no conflict of interest.

Sample Availability: Samples of the compounds presented in this review are not available from the authors.

$\begin{array}{ll}\text { Abbreviations } \\ \text { COD } & \text { cycloocta-1,5-diene } \\ \text { DMAP } & \text { 4-dimethylaminopyridine } \\ \text { CV } & \text { cyclic voltammograms } \\ \text { DME } & \text { dimethyl ether } \\ \text { DMSO } & \text { dimethyl sulfoxide } \\ \text { EPR } & \text { electron paramagnetic resonance } \\ \text { HPLC } & \text { high-performance liquid chromatography } \\ \text { MAO } & \text { methylaluminoxane } \\ \text { MMAO } & \text { modified methylaluminoxane } \\ \text { NMR } & \text { nuclear magnetic resonance } \\ \text { THF } & \text { tetrahydrofuran } \\ \text { TOF } & \text { turnover frequency } \\ \text { XRD } & \text { X-ray diffraction }\end{array}$




\section{Appendix A}

Table A1. Selected bond lengths ( $(\AA)$ of unsymmetrical nickel pincer complexes presented in this review.

\begin{tabular}{|c|c|c|c|c|c|}
\hline \multirow{3}{*}{ Complex } & \multicolumn{4}{|c|}{ Selected Bond Lengths (Å) } & \multirow{3}{*}{ Reference } \\
\hline & \multicolumn{4}{|c|}{ POCN Complexes } & \\
\hline & $P-N i$ & $N-N i$ & $\mathrm{C}-\mathrm{Ni}$ & $\mathrm{X}-\mathrm{Ni}$ & \\
\hline $3 a$ & 2.112 & 2.021 & 1.859 & 2.341 & [78] \\
\hline $3 b$ & 2.109 & 2.025 & 1.856 & 2.361 & [78] \\
\hline $3 c$ & 2.111 & 2.043 & 1.853 & 2.332 & [78] \\
\hline $4 a$ & 2.191 & 2.051 & 1.897 & $2.371 / 2.435$ & [78] \\
\hline $4 b$ & 2.208 & 2.069 & 1.891 & $2.369 / 2.464$ & [78] \\
\hline $4 c$ & 2.201 & 2.072 & 1.883 & $2.367 / 2.434$ & [78] \\
\hline 5 & 2.106 & 1.982 & 1.855 & 2.344 & [79] \\
\hline 6 & 2.122 & $1.997 / 2.001$ & 1.864 & & [79] \\
\hline 7 & 2.104 & 2.030 & 1.854 & 2.345 & [80] \\
\hline 8 & 2.115 & 1.948 & 1.869 & 2.211 & [83] \\
\hline 9 & 2.093 & 1.900 & 1.851 & 2.217 & [85] \\
\hline 10 & 2.107 & 2.003 & 1.851 & 2.333 & [87] \\
\hline 11 & 2.198 & 2.012 & 1.902 & $2.357 / 2.447$ & [87] \\
\hline \multirow[t]{3}{*}{12} & 2.110 & 1.994 & 1.856 & 2.336 & [87] \\
\hline & \multicolumn{4}{|c|}{ PCN complexes } & \\
\hline & $P-N i$ & $N-N i$ & $\mathrm{C}-\mathrm{Ni}$ & $\mathrm{X}-\mathrm{Ni}$ & \\
\hline $14 a$ & 2.164 & 3.199 & 1.880 & 2.233 & [96] \\
\hline $14 b$ & 2.183 & 2.044 & 1.892 & 2.282 & [96] \\
\hline $16 a$ & 2.267 & 2.072 & 1.928 & $2.250 / 2.289$ & [96] \\
\hline $16 b$ & 2.280 & 2.079 & 1.927 & $2.382 / 2.443$ & [96] \\
\hline $17 \mathbf{a}$ & 2.130 & 2.039 & 1.902 & $1.983(\mathrm{C}-\mathrm{Ni})$ & [96] \\
\hline $17 b$ & 2.158 & 2.046 & 1.915 & 1.950 (C-Ni) & [96] \\
\hline 18 & 2.171 & 2.081 & 1.881 & 1.394 & [98] \\
\hline 19 & 2.130 & 2.121 & 1.905 & $1.981(\mathrm{C}-\mathrm{Ni})$ & [98] \\
\hline $21 a$ & 2.144 & 1.903 & 1.857 & 1.872 & [88] \\
\hline $21 b$ & 2.168 & 1.919 & 1.885 & 2.232 & [88] \\
\hline $21 c$ & 2.166 & 1.924 & 1.880 & 2.363 & [88] \\
\hline $21 d$ & 2.173 & 1.922 & 1.875 & 2.559 & [88] \\
\hline 22 & 2.186 & 1.932 & 1.886 & $2.252(\mathrm{~B}-\mathrm{Ni})$ & [89] \\
\hline $23 a$ & 2.169 & 1.955 & 1.889 & 2.378 & [107] \\
\hline $23 b$ & 2.143 & 1.941 & 1.885 & 1.854 & [107] \\
\hline 24 & 2.169 & 1.939 & 1.867 & $1.968(\mathrm{O}-\mathrm{Ni})$ & [107] \\
\hline $25 a$ & 2.114 & 1.988 & 1.943 & 2.373 & [109] \\
\hline $25 b$ & 2.110 & 2.025 & 1.944 & 2.352 & [109] \\
\hline $25 c$ & 2.097 & 2.026 & 1.942 & 2.353 & [109] \\
\hline $25 d$ & 2.106 & 1.989 & 1.938 & 2.361 & [109] \\
\hline $25 e$ & 2.113 & 1.984 & 1.951 & 2.386 & [109] \\
\hline \multirow[t]{3}{*}{$25 f$} & 2.121 & 2.008 & 1.942 & 2.375 & [109] \\
\hline & \multicolumn{4}{|c|}{ NNP complexes } & \\
\hline & $P-N i$ & $N-N i$ & $N^{\prime}-N i$ & $X-N i$ & \\
\hline 29 & 2.147 & 1.916 & 1.892 & 2.195 & [116] \\
\hline $30 \mathrm{~b}$ & 2.161 & 1.969 & 1.861 & 2.321 & [117] \\
\hline $30 c$ & 2.165 & 1.971 & 1.847 & 1.847 & [117] \\
\hline $34 a$ & 2.129 & 1.941 & 1.899 & 2.182 & [124] \\
\hline $34 b$ & 2.142 & 1.931 & 1.890 & 2.181 & [124] \\
\hline $34 c$ & 2.123 & 1.940 & 1.912 & 2.172 & [124] \\
\hline 35 & 2.187 & 2.014 & 1.876 & 2.159 & [126] \\
\hline
\end{tabular}


Table A1. Cont.

\begin{tabular}{|c|c|c|c|c|c|}
\hline \multirow{3}{*}{ Complex } & \multicolumn{4}{|c|}{ Selected Bond Lengths (Å) } & \multirow{2}{*}{ Reference } \\
\hline & \multicolumn{4}{|c|}{ PNP' complexes } & \\
\hline & $P-N i$ & $P^{\prime}-N i$ & $N-N i$ & $Y-N i$ & \\
\hline $36 a$ & 2.121 & 2.124 & 1.924 & $1.509(\mathrm{H}-\mathrm{Ni})$ & [131] \\
\hline $36 b$ & 2.135 & 2.134 & 1.921 & $1.949(\mathrm{H}-\mathrm{Ni})$ & [130] \\
\hline $37 b$ & 2.154 & 2.198 & 1.961 & $1.980(\mathrm{C}-\mathrm{Ni})$ & [131] \\
\hline $37 c$ & 2.194 & 2.201 & 1.975 & $1.973(\mathrm{C}-\mathrm{Ni})$ & [131] \\
\hline 38 & 2.188 & 2.196 & 1.950 & $1.996(\mathrm{C}-\mathrm{Ni})$ & [131] \\
\hline $40 b$ & 2.168 & 2.170 & 1.967 & $1.873(\mathrm{C}-\mathrm{Ni})$ & [133] \\
\hline \multirow[t]{3}{*}{$40 c$} & 2.178 & 2.190 & 1.974 & $1.886(\mathrm{C}-\mathrm{Ni})$ & [133] \\
\hline & \multicolumn{4}{|c|}{ N-Heterocyclic carbene complexes } & \\
\hline & $\mathrm{C}-\mathrm{Ni}$ & $\mathrm{N}-\mathrm{Ni}$ & $N^{\prime}-N i$ & $\mathrm{X}-\mathrm{Ni}$ & \\
\hline $42 a$ & 1.881 & 1.846 & 2.014 & 2.327 & [135] \\
\hline \multirow[t]{2}{*}{$43 b$} & 1.828 & 1.885 & 1.975 & $1.786(\mathrm{H}-\mathrm{Ni})$ & [137] \\
\hline & $\mathrm{C}-\mathrm{Ni}$ & $C^{\prime}-N i$ & $N-N i$ & $\mathrm{Cl}-\mathrm{Ni}$ & \\
\hline \multirow[t]{2}{*}{$45 e$} & 1.911 & 1.860 & 1.955 & 2.215 & [139] \\
\hline & $\mathrm{C}-\mathrm{Ni}$ & $N-N i$ & $N^{\prime}-N i$ & $\mathrm{Cl}-\mathrm{Ni}$ & \\
\hline \multirow[t]{2}{*}{46} & 1.839 & 1.905 & 1.945 & 2.196 & {$[140]$} \\
\hline & $\mathrm{C}-\mathrm{Ni}$ & $\mathrm{P}-\mathrm{Ni}$ & $P^{\prime}-N i$ & $\mathrm{Br}-\mathrm{Ni}$ & \\
\hline 48 & 1.945 & 2.169 & 2.132 & 2.334 & [143] \\
\hline \multirow[t]{2}{*}{49} & 1.874 & 2.133 & 2.176 & 2.312 & [143] \\
\hline & $\mathrm{C}-\mathrm{Ni}$ & $P-N i$ & $\mathrm{C}^{\prime}-\mathrm{Ni}$ & $\mathrm{Br}-\mathrm{Ni}$ & \\
\hline \multirow[t]{3}{*}{50} & 1.874 & 2.145 & 1.945 & 2.352 & [143] \\
\hline & \multicolumn{4}{|c|}{ Other types of complexes } & \\
\hline & $\mathrm{P}-\mathrm{Ni}$ & $P^{\prime}-N i$ & $\mathrm{~N}-\mathrm{Ni}$ & $\mathrm{Br}-\mathrm{Ni}$ & \\
\hline \multirow[t]{2}{*}{53} & 2.156 & 2.200 & 1.897 & $2.785 / 2.320$ & [149] \\
\hline & $P-N i$ & $P^{\prime}-N i$ & $\mathrm{C}-\mathrm{Ni}$ & $\mathrm{Cl}-\mathrm{Ni}$ & \\
\hline $54 a$ & 2.134 & 2.142 & 1.932 & 2.216 & [150] \\
\hline $54 \mathrm{c}$ & 2.140 & 2.143 & 1.941 & 2.192 & [150] \\
\hline \multirow[t]{2}{*}{$55 a$} & 2.179 & 2.183 & 1.897 & 2.195 & [152] \\
\hline & $\mathrm{P}-\mathrm{Ni}$ & $P^{\prime}-N i$ & $\mathrm{C}-\mathrm{Ni}$ & $\mathrm{O}-\mathrm{Ni}$ & \\
\hline $56 b$ & 2.171 & 2.205 & 1.907 & 1.921 & [152] \\
\hline
\end{tabular}

\section{References}

1. Gafurov, Z.N.; Kagilev, A.A.; Kantyukov, A.O.; Balabaev, A.A.; Sinyashin, O.G.; Yakhvarov, D.G. Classification and synthesis of nickel pincer complexes. Russ. Chem. Bull. 2018, 67, 385-394. [CrossRef]

2. Arora, V.; Narjinari, H.; Nandi, P.G.; Kumar, A. Recent advances in pincer-nickel catalyzed reactions. Dalton Trans. 2021, 50, 3394-3428. [CrossRef] [PubMed]

3. Szabó, K.J.; Wendt, O.F. Pincer and Pincer-Type Complexes: Applications in Organic Synthesis and Catalysis; Wiley-VCH Verlag GmbH \& Co. KGaA: Weinheim, Germany, 2014; ISBN 9783527681303.

4. Van Koten, G. Organometallic Pincer Chemistry. In Topics in Organometallic Chemistry; Van Koten, G., Milstein, D., Eds.; Springer: Berlin/Heidelberg, Germany, 2013; Volume 40, ISBN 978-3-642-31080-5.

5. Asay, M.; Morales-Morales, D. Recent Advances on the Chemistry of POCOP-Nickel Pincer Compounds. In The Privileged Pincer-Metal Platform: Coordination Chemistry \& Applications; Springer: Berlin/Heidelberg, Germany, 2015; pp. $239-268$.

6. Gomez-Benitez, V.; Baldovino-Pantaleon, O.; Herrera-Álvarez, C.; Toscano, R.A.; Morales-Morales, D. High yield thiolation of iodobenzene catalyzed by the phosphinite nickel PCP pincer complex: $\left[\mathrm{NiCl}\left\{\mathrm{C}_{6} \mathrm{H}_{3}-2,6-\left(\mathrm{OPPh}_{2}\right)_{2}\right\}\right]$. Tetrahedron Lett. 2006, 47, 5059-5062. [CrossRef]

7. Valdés, H.; Rufino-Felipe, E.; Morales-Morales, D. Pincer complexes, leading characters in C-H bond activation processes. Synthesis and catalytic applications. J. Organomet. Chem. 2019, 898, 120864. [CrossRef] 
8. Albrecht, M.; van Koten, G. Platinum Group Organometallics Based on "Pincer" Complexes: Sensors, Switches, and Catalysts. Angew. Chem. Int. Ed. 2001, 40, 3750-3781. [CrossRef]

9. Parshall, G.W. Intramolecular aromatic substitution in transition metal complexes. Accounts Chem. Res. 1970, 3, 139-144. [CrossRef]

10. Dehand, J.; Pfeffer, M. Cyclometallated compounds. Coord. Chem. Rev. 1976, 18, 327-352. [CrossRef]

11. Shilov, A.E.; Shul'Pin, G.B. Activation of C-H Bonds by Metal Complexes. Chem. Rev. 1997, 97, 2879-2932. [CrossRef] [PubMed]

12. Niu, J.-L.; Hao, X.-Q.; Gong, J.-F.; Song, M.-P. Symmetrical and unsymmetrical pincer complexes with group 10 metals: Synthesis via aryl C-H activation and some catalytic applications. Dalton Trans. 2011, 40, 5135-5150. [CrossRef] [PubMed]

13. Benito-Garagorri, D.; Kirchner, K. Modularly Designed Transition Metal PNP and PCP Pincer Complexes based on Aminophosphines: Synthesis and Catalytic Applications. Accounts Chem. Res. 2008, 41, 201-213. [CrossRef] [PubMed]

14. And, M.E.V.D.B.; Milstein, D. Cyclometalated Phosphine-Based Pincer Complexes: Mechanistic Insight in Catalysis, Coordination, and Bond Activation. Chem. Rev. 2003, 103, 1759-1792. [CrossRef]

15. Singleton, J.T. The uses of pincer complexes in organic synthesis. Tetrahedron 2003, 59, 1837-1857. [CrossRef]

16. Valdés, H.; García-Eleno, M.A.; Canseco-Gonzalez, D.; Morales-Morales, D. Recent Advances in Catalysis with Transition-Metal Pincer Compounds. ChemCatChem 2018, 10, 3136-3172. [CrossRef]

17. Luconi, L.; Rossin, A.; Tuci, G.; Gafurov, Z.; Lyubov, D.M.; Trifonov, A.A.; Cicchi, S.; Ba, H.; Pham-Huu, C.; Yakhvarov, D.; et al. Benzoimidazole-Pyridylamido Zirconium and Hafnium Alkyl Complexes as Homogeneous Catalysts for Tandem Carbon Dioxide Hydrosilylation to Methane. ChemCatChem 2019, 11, 495-510. [CrossRef]

18. Morales-Morales, D. Pincer Compounds: Chemistry and Applications; Elsevier: Amsterdam, The Netherlands, 2018; ISBN 978-0-12812931-9.

19. Asay, M.; Morales-Morales, D. Non-symmetric pincer ligands: Complexes and applications in catalysis. Dalton Trans. 2015, 44, 17432-17447. [CrossRef]

20. Van Koten, G. Tuning the reactivity of metals held in a rigid ligand environment. Pure Appl. Chem. 1989, 61, 1681-1694. [CrossRef]

21. Moulton, C.J.; Shaw, B.L. Transition metal-carbon bonds. Part XLII. Complexes of nickel, palladium, platinum, rhodium and iridium with the tridentate ligand 2,6-bis[(di-t-butylphosphino)methyl]phenyl. J. Chem. Soc. Dalton Trans. 1976, 1020-1024. [CrossRef]

22. Grove, D.M.; Van Koten, G.; Zoet, R.; Murrall, N.W.; Welch, A.J. Unique stable organometallic nickel(III) complexes; syntheses and the molecular structure of $\left[\mathrm{Ni}\left[\mathrm{C}_{6} \mathrm{H}_{3}\left(\mathrm{CH}_{2} \mathrm{NMe}_{2}\right)_{2}-2,6\right] \mathrm{I}_{2}\right]$. J. Am. Chem. Soc. 1983, 105, 1379-1380. [CrossRef]

23. Grove, D.M.; Van Koten, G.; Ubbels, H.J.C.; Zoet, R.; Spek, A.L. Organonickel(II) complexes of the tridentate monoanionic ligand o,o'-bis[(dimethylamino)methylphenyl (N-C-N). Syntheses and the x-ray crystal structure of the stable nickel(II) formate [Ni(N-C-N)O $\mathrm{O}_{2} \mathrm{CH}$ ]. Organometallics 1984, 3, 1003-1009. [CrossRef]

24. Roddick, D.M. Tuning of PCP Pincer Ligand Electronic and Steric Properties. In Topics in Organometallic Chemistry; Springer: Berlin/Heidelberg, Germany, 2013; Volume 40, pp. 49-88, ISBN 9783642310805.

25. Pandarus, V.; Zargarian, D. New pincer-type diphosphinito (POCOP) complexes of Ni ${ }^{\mathrm{II}}$ and Ni ${ }^{\mathrm{III}}$. Chem. Commun. 2007, 978-980. [CrossRef]

26. Hebden, T.J.; John, A.J.S.; Gusev, D.G.; Kaminsky, W.; Goldberg, K.I.; Heinekey, D.M. Preparation of a Dihydrogen Complex of Cobalt. Angew. Chem. Int. Ed. 2010, 50, 1873-1876. [CrossRef]

27. Kundu, S.; Choliy, Y.; Zhuo, G.; Ahuja, R.; Emge, T.J.; Warmuth, R.; Brookhart, M.; Krogh-Jespersen, K.; Goldman, A.S. Rational Design and Synthesis of Highly Active Pincer-Iridium Catalysts for Alkane Dehydrogenation. Organometallics 2009, 28, 5432-5444. [CrossRef]

28. Leis, W.; Mayer, H.; Kaska, W. Cycloheptatrienyl, alkyl and aryl PCP-pincer complexes: Ligand backbone effects and metal reactivity. Coord. Chem. Rev. 2008, 252, 1787-1797. [CrossRef]

29. Jensen, C.M. Iridium PCP pincer complexes: Highly active and robust catalysts for novel homogeneous aliphatic dehydrogenations. Chem. Commun. 1999, 2443-2449. [CrossRef]

30. Schneider, S.; Meiners, J.; Askevold, B. Cooperative Aliphatic PNP Amido Pincer Ligands—Versatile Building Blocks for Coordination Chemistry and Catalysis. Eur. J. Inorg. Chem. 2012, 2012, 412-429. [CrossRef]

31. Milstein, D. Discovery of Environmentally Benign Catalytic Reactions of Alcohols Catalyzed by Pyridine-Based Pincer Ru Complexes, Based on Metal-Ligand Cooperation. Top. Catal. 2010, 53, 915-923. [CrossRef]

32. Timpa, S.D.; Pell, C.J.; Zhou, J.; Ozerov, O.V. Fate of Aryl/Amido Complexes of Rhodium(III) Supported by a POCOP Pincer Ligand: C-N Reductive Elimination, $\beta$-Hydrogen Elimination, and Relevance to Catalysis. Organometallics 2014, 33, $5254-5262$. [CrossRef]

33. Jonasson, K.J.; Wendt, O.F. Synthesis and Characterization of a Family of POCOP Pincer Complexes with Nickel: Reactivity Towards $\mathrm{CO}_{2}$ and Phenylacetylene. Chem.-A Eur. J. 2014, 20, 11894-11902. [CrossRef]

34. Lao, D.B.; Owens, A.C.E.; Heinekey, D.M.; Goldberg, K.I. Partial Deoxygenation of Glycerol Catalyzed by Iridium Pincer Complexes. ACS Catal. 2013, 3, 2391-2396. [CrossRef]

35. Luconi, L.; Klosin, J.; Smith, A.J.; Germain, S.; Schulz, E.; Hannedouche, J.; Giambastiani, G. Cationic Group-IV pincer-type complexes for polymerization and hydroamination catalysis. Dalton Trans. 2013, 42, 16056-16065. [CrossRef] 
36. Luconi, L.; Rossin, A.; Motta, A.; Tuci, G.; Giambastiani, G. Group IV Organometallic Compounds Based on Dianionic “Pincer" Ligands: Synthesis, Characterization, and Catalytic Activity in Intramolecular Hydroamination Reactions. Chem.-A Eur. J. 2013, 19, 4906-4921. [CrossRef]

37. Broöring, M.; Kleeberg, C.; Koöhler, S. Palladium(II) Complexes of Unsymmetrical CNN Pincer Ligands. Inorg. Chem. 2008, 47, 6404-6412. [CrossRef]

38. Balaraman, E.; Gunanathan, C.; Zhang, J.; Shimon, L.; Milstein, D. Efficient hydrogenation of organic carbonates, carbamates and formates indicates alternative routes to methanol based on $\mathrm{CO}_{2}$ and CO. Nat. Chem. 2011, 3, 609-614. [CrossRef]

39. Gnanaprakasam, B.; Milstein, D.; Boopathy, G. Synthesis of Amides from Esters and Amines with Liberation of $\mathrm{H}_{2}$ under Neutral Conditions. J. Am. Chem. Soc. 2011, 133, 1682-1685. [CrossRef]

40. Zhang, J.; Balaraman, E.; Leitus, G.; Milstein, D. Electron-Rich PNP- and PNN-Type Ruthenium(II) Hydrido Borohydride Pincer Complexes. Synthesis, Structure, and Catalytic Dehydrogenation of Alcohols and Hydrogenation of Esters. Organometallics 2011, 30, 5716-5724. [CrossRef]

41. Balaraman, E.; Gnanaprakasam, B.; Shimon, L.; Milstein, D. Direct Hydrogenation of Amides to Alcohols and Amines under Mild Conditions. J. Am. Chem. Soc. 2010, 132, 16756-16758. [CrossRef] [PubMed]

42. Fulmer, G.R.; Kaminsky, W.; Kemp, R.A.; Goldberg, K.I. Syntheses and Characterization of Palladium Complexes with a Hemilabile "PCO" Pincer Ligand. Organometallics 2011, 30, 1627-1636. [CrossRef]

43. Li, J.; Siegler, M.; Lutz, M.; Spek, A.L.; Gebbink, R.J.M.K.; Van Koten, G. PCN- and PCS-Pincer Palladium Complexes as Tandem Catalysts in Homoallylation Reactions. Adv. Synth. Catal. 2010, 352, 2474-2488. [CrossRef]

44. Gagliardo, M.; Selander, N.; Mehendale, N.C.; Van Koten, G.; Gebbink, R.J.M.K.; Szabó, K.J. Catalytic Performance of Symmetrical and Unsymmetrical Sulfur-Containing Pincer Complexes: Synthesis and Tandem Catalytic Activity of the First PCS-Pincer Palladium Complex. Chem.-A Eur. J. 2008, 14, 4800-4809. [CrossRef]

45. Mehendale, N.C.; Sietsma, J.R.A.; De Jong, K.P.; Van Walree, C.A.; Gebbink, R.J.M.K.; Van Koten, G. PCP- and SCS-Pincer Palladium Complexes Immobilized on Mesoporous Silica: Application in C-C Bond Formation Reactions. Adv. Synth. Catal. 2007, 349, 2619-2630. [CrossRef]

46. Zhang, X.; Suzuki, S.; Kozaki, M.; Okada, K. NCN Pincer-Pt Complexes Coordinated by (Nitronyl Nitroxide)-2-ide Radical Anion. J. Am. Chem. Soc. 2012, 134, 17866-17868. [CrossRef]

47. Inés, B.; SanMartin, R.; Churruca, F.; Domínguez, E.; Urtiaga, M.K.; Arriortua, M. A Nonsymmetric Pincer-Type Palladium Catalyst in Suzuki, Sonogashira, and Hiyama Couplings in Neat Water. Organometallics 2008, 27, 2833-2839. [CrossRef]

48. Gong, J.-F.; Zhang, Y.-H.; Song, M.-P.; Xu, C. New PCN and PCP Pincer Palladium(II) Complexes: Convenient Synthesis via Facile One-Pot Phosphorylation/Palladation Reaction and Structural Characterization. Organometallics 2007, 26, 6487-6492. [CrossRef]

49. Zhang, J.; Leitus, G.; Ben-David, Y.; Milstein, D. Facile Conversion of Alcohols into Esters and Dihydrogen Catalyzed by New Ruthenium Complexes. J. Am. Chem. Soc. 2005, 127, 10840-10841. [CrossRef] [PubMed]

50. Zhang, J.; Leitus, G.; Ben-David, Y.; Milstein, D. Efficient Homogeneous Catalytic Hydrogenation of Esters to Alcohols. Angew. Chem. Int. Ed. 2006, 45, 1113-1115. [CrossRef] [PubMed]

51. Wang, Y.; Huang, Z.; Leng, X.; Zhu, H.; Liu, G.; Huang, Z. Transfer Hydrogenation of Alkenes Using Ethanol Catalyzed by a NCP Pincer Iridium Complex: Scope and Mechanism. J. Am. Chem. Soc. 2018, 140, 4417-4429. [CrossRef]

52. Luconi, L.; Osipova, E.S.; Giambastiani, G.; Peruzzini, M.; Rossin, A.; Belkova, N.V.; Filippov, O.A.; Titova, E.M.; Pavlov, A.A.; Shubina, E.S. Amine Boranes Dehydrogenation Mediated by an Unsymmetrical Iridium Pincer Hydride: (PCN) vs (PCP) Improved Catalytic Performance. Organometallics 2018, 37, 3142-3153. [CrossRef]

53. Nishiyama, H. Synthesis and use of bisoxazolinyl-phenyl pincers. Chem. Soc. Rev. 2007, 36, 1133-1141. [CrossRef]

54. Pugh, D.; Danopoulos, A.A. Metal complexes with 'pincer'-type ligands incorporating N-heterocyclic carbene functionalities. Coord. Chem. Rev. 2007, 251, 610-641. [CrossRef]

55. Morales-Morales, D. Recent Applications of Phosphinite POCOP Pincer Complexes Towards Organic Transformations. Mini-Rev. Org. Chem. 2008, 5, 141-152. [CrossRef]

56. Nishiyama, H.; Ito, J.-I. Bis(oxazolinyl)phenyl transition-metal complexes: Asymmetric catalysis and some reactions of the metals. Chem. Commun. 2009, 46, 203-212. [CrossRef] [PubMed]

57. Choi, J.; MacArthur, A.; Brookhart, M.; Goldman, A. Dehydrogenation and Related Reactions Catalyzed by Iridium Pincer Complexes. Chem. Rev. 2011, 111, 1761-1779. [CrossRef] [PubMed]

58. Selander, N.; Szabó, K.J. Catalysis by Palladium Pincer Complexes. Chem. Rev. 2010, 111, 2048-2076. [CrossRef] [PubMed]

59. Morales-Morales, D.; Jensen, C.M. The Chemistry of Pincer Compounds; Elsevier BV: Amsterdam, The Netherlands, 2007; ISBN 9780444531384.

60. Gossage, R.A.; van de Kuil, L.A.; van Koten, G. Diaminoarylnickel(II) “Pincer” Complexes: Mechanistic Considerations in the Kharasch Addition Reaction, Controlled Polymerization, and Dendrimeric Transition Metal Catalysts. Accounts Chem. Res. 1998, 31, 423-431. [CrossRef]

61. Morales-Morales, D. Pincer Complexes: Applications in Catalysis. Rev. Soc. Quim. Mex. 2004, 48, 338-346. [CrossRef]

62. Peris, E.; Crabtree, R.H. Recent homogeneous catalytic applications of chelate and pincer N-heterocyclic carbenes. Coord. Chem. Rev. 2004, 248, 2239-2246. [CrossRef]

63. Liang, L.-C. Metal complexes of chelating diarylamido phosphine ligands. Coord. Chem. Rev. 2006, 250, 1152-1177. [CrossRef] 
64. Campora, J. Nickel-Carbon $\sigma$-Bonded Complexes. In Comprehensive Organometallic Chemistry III; Elsevier: Amsterdam, The Netherlands, 2007; Volume 8, pp. 27-132, ISBN 9780080450476.

65. Gafurov, Z.N.; Zueva, E.M.; Yakhvarov, D.G. Sustainable Synthesis, NMR and Computational Study of Isobutylmesitylphosphine. ChemistrySelect 2021, 6, 1833-1837. [CrossRef]

66. Yakhvarov, D.G.; Trofimova, E.A.; Rizvanov, I.K.; Fomina, O.S.; Sinyashin, O.G. Electrochemical synthesis and catalytic activity of organonickel sigma-complexes. Russ. J. Electrochem. 2011, 47, 1100-1110. [CrossRef]

67. Sakhapov, I.F.; Gafurov, Z.N.; Babaev, V.; Rizvanov, I.K.; Dobrynin, A.; Krivolapov, D.B.; Khayarov, K.R.; Sinyashin, O.G.; Yakhvarov, D.G. First example of organonickel complex bearing three cyclic substituents in the $\sigma$-bonded aromatic ring: Bromo[(2,2'-bipyridine)-2,4,6-tricyclohexylphenylnickel]. Mendeleev Commun. 2016, 26, 131-133. [CrossRef]

68. Sakhapov, I.F.; Gafurov, Z.N.; Babaev, V.M.; Kurmaz, V.A.; Mukhametbareev, R.R.; Rizvanov, I.K.; Sinyashin, O.G.; Yakhvarov, D.G. Electrochemical properties and reactivity of organonickel sigma-complex [NiBr(Mes)(bpy)] (Mes = 2,4,6-trimethylphenyl, bpy = 2,2'-bipyridine). Russ. J. Electrochem. 2015, 51, 1061-1068. [CrossRef]

69. Gafurov, Z.N.; Musin, L.; Sakhapov, I.F.; Babaev, V.; Musina, E.I.; Karasik, A.A.; Sinyashin, O.G.; Yakhvarov, D.G. The formation of secondary arylphosphines in the reaction of organonickel sigma-complex [NiBr(Mes)(bpy)], where Mes = 2,4,6-trimethylphenyl, bpy $=2,2$ '-bipyridine, with phenylphosphine. Phosphorus Sulfur Silicon Relat. Elem. 2016, 191, 1475-1477. [CrossRef]

70. Gafurov, Z.N.; Sinyashin, O.G.; Yakhvarov, D.G. Electrochemical methods for synthesis of organoelement compounds and functional materials. Pure Appl. Chem. 2017, 89, 1089-1103. [CrossRef]

71. Gafurov, Z.N.; Sakhapov, I.F.; Babaev, V.M.; Dobrynin, A.B.; Kurmaz, V.A.; Metlushka, K.E.; Rizvanov, I.K.; Shaikhutdinova, G.; Sinyashin, O.G.; Yakhvarov, D.G. Study of the reactivity of organonickel sigma-complexes towards nitriles. Russ. Chem. Bull. 2017, 66, 254-259. [CrossRef]

72. Gafurov, Z.N.; Kantyukov, A.O.; Kagilev, A.A.; Balabayev, A.A.; Sinyashin, O.G.; Yakhvarov, D.G. Nickel and palladium Nheterocyclic carbene complexes. Synthesis and application in cross-coupling reactions. Russ. Chem. Bull. 2017, 66, 1529-1535. [CrossRef]

73. Gafurov, Z.N.; Kagilev, A.A.; Kantyukov, A.O.; Sinyashin, O.G.; Yakhvarov, D.G. The role of organonickel reagents in organophosphorus chemistry. Coord. Chem. Rev. 2021, 438, 213889. [CrossRef]

74. Boro, B.J.; Dickie, D.A.; Goldberg, K.I.; Kemp, R.A. \{2,6-Bis[(di-tert-butylphosphino)methyl]phenyl\}chloridonickel(II). Acta Crystallogr. Sect. E Struct. Rep. Online 2008, 64, m1304. [CrossRef] [PubMed]

75. Castonguay, A.; Charbonneau, F.; Beauchamp, A.L.; Zargarian, D. \{2,6-Bis[(dimethylamino)methyl]phenyl-k 2N, C 1, N '\}chloronickel(II). Acta Crystallogr. Sect. E Struct. Rep. Online 2005, 61, 2240. [CrossRef]

76. $\quad$ van de Kuil, L.A.; Grove, D.M.; Gossage, R.A.; Zwikker, J.W.; Jenneskens, L.W.; Drenth, W.; van Koten, G. Mechanistic Aspects of the Kharasch Addition Reaction Catalyzed by Organonickel(II) Complexes Containing the Monoanionic Terdentate Aryldiamine Ligand System $\left[\mathrm{C}_{6} \mathrm{H}_{2}\left(\mathrm{CH}_{2} \mathrm{NMe}_{2}\right) 2-2,6-\mathrm{R}-4\right]$-. Organometallics 1997, 16, 4985-4994. [CrossRef]

77. Jonasson, K.J.; Mousa, A.H.; Wendt, O.F. Synthesis and characterisation of $\mathrm{POC}_{\mathrm{sp} 3} \mathrm{OP}$ supported Ni(II) hydroxo, hydroxycarbonyl and carbonate complexes. Polyhedron 2018, 143, 132-137. [CrossRef]

78. Spasyuk, D.M.; Zargarian, D.; van der Est, A. New POCN-Type Pincer Complexes of Nickel(II) and Nickel(III). Organometallics 2009, 28, 6531-6540. [CrossRef]

79. Spasyuk, D.M.; Zargarian, D. Monomeric and Dimeric Nickel Complexes Derived from a Pincer Ligand Featuring a Secondary Amine Donor Moiety. Inorg. Chem. 2010, 49, 6203-6213. [CrossRef]

80. Smith, J.; Miller, A.J.M. Connecting Neutral and Cationic Pathways in Nickel-Catalyzed Insertion of Benzaldehyde into a C-H Bond of Acetonitrile. Organometallics 2015, 34, 4669-4677. [CrossRef]

81. Smith, J.B.; Kerr, S.H.; White, P.S.; Miller, A.J.M. Thermodynamic Studies of Cation-Macrocycle Interactions in Nickel PincerCrown Ether Complexes Enable Switchable Ligation. Organometallics 2017, 36, 3094-3103. [CrossRef]

82. Spasyuk, D.M.; Gorelsky, S.I.; Van Der Est, A.; Zargarian, D. Characterization of Divalent and Trivalent Species Generated in the Chemical and Electrochemical Oxidation of a Dimeric Pincer Complex of Nickel. Inorg. Chem. 2011, 50, 2661-2674. [CrossRef]

83. Zhang, B.-S.; Wang, W.; Shao, D.-D.; Hao, X.-Q.; Gong, J.-F.; Song, M.-P. Unsymmetrical Chiral PCN Pincer Palladium(II) and Nickel(II) Complexes of (Imidazolinyl)aryl Phosphinite Ligands: Synthesis via Ligand C-H Activation, Crystal Structures, and Catalytic Studies. Organometallics 2010, 29, 2579-2587. [CrossRef]

84. Yang, M.-J.; Liu, Y.-J.; Gong, J.-F.; Song, M.-P. Unsymmetrical Chiral PCN Pincer Palladium(II) and Nickel(II) Complexes with ArylBased Aminophosphine-Imidazoline Ligands: Synthesis via Aryl C-H Activation and Asymmetric Addition of Diarylphosphines to Enones. Organometallics 2011, 30, 3793-3803. [CrossRef]

85. Niu, J.-L.; Chen, Q.-T.; Hao, X.-Q.; Zhao, Q.-X.; Gong, J.-F.; Song, M.-P. Diphenylprolinol-Derived Symmetrical and Unsymmetrical Chiral Pincer Palladium(II) and Nickel(II) Complexes: Synthesis via One-Pot Phosphorylation/Metalation Reaction and C-H Activation. Organometallics 2010, 29, 2148-2156. [CrossRef]

86. Xiang, Y.; Ge, Q.; Wu, S.; Zheng, X.; Yang, Z. Synthesis and application in asymmetric catalysis of P-stereogenic pincer-metal complexes. RSC Adv. 2020, 10, 9563-9578. [CrossRef]

87. Mougang-Soumé, B.; Belanger-Gariépy, F.; Zargarian, D. Synthesis, Characterization, and Oxidation of New POCN $\mathrm{Nimine}^{-T y p e}$ Pincer Complexes of Nickel. Organometallics 2014, 33, 5990-6002. [CrossRef] 
88. Luconi, L.; Garino, C.; Vioglio, P.C.; Gobetto, R.; Chierotti, M.R.; Yakhvarov, D.; Gafurov, Z.N.; Morozov, V.; Sakhapov, I.; Rossin, A.; et al. Halogen-Bonding Interactions and Electrochemical Properties of Unsymmetrical Pyrazole Pincer Ni ${ }^{\mathrm{II}} \mathrm{Halides}$ : A Peculiar Behavior of the Fluoride Complex (PCN)NiF. ACS Omega 2019, 4, 1118-1129. [CrossRef]

89. Gafurov, Z.N.; Bekmukhamedov, G.; Kagilev, A.A.; Kantyukov, A.O.; Sakhapov, I.F.; Mikhailov, I.K.; Khayarov, K.R.; Zaripov, R.B.; Islamov, D.R.; Usachev, K.S.; et al. Unsymmetrical pyrazole-based PCN pincer $\mathrm{Ni}^{\mathrm{II}}$ halides: Reactivity and catalytic activity in ethylene oligomerization. J. Organomet. Chem. 2020, 912, 121163. [CrossRef]

90. Hao, X.-Q.; Huang, J.-J.; Wang, T.; Lv, J.; Gong, J.-F.; Song, M.-P. PCN Pincer Palladium(II) Complex Catalyzed Enantioselective Hydrophosphination of Enones: Synthesis of Pyridine-Functionalized Chiral Phosphine Oxides as $\mathrm{NC}_{\mathrm{sp} 3} \mathrm{O}$ Pincer Preligands. J. Org. Chem. 2014, 79, 9512-9530. [CrossRef]

91. Khake, S.M.; Soni, V.; Gonnade, R.G.; Punji, B. Design and development of POCN-pincer palladium catalysts for C-H bond arylation of azoles with aryl iodides. Dalton Trans. 2014, 43, 16084-16096. [CrossRef]

92. Herbert, D.; Ozerov, O.V. Binuclear Palladium Complexes Supported by Bridged Pincer Ligands. Organometallics 2011, 30, 6641-6654. [CrossRef]

93. Moreno, I.; SanMartin, R.; Ines, B.; Herrero, M.; Domínguez, E. Recent Advances in the Use of Unsymmetrical Palladium Pincer Complexes. Curr. Org. Chem. 2009, 13, 878-895. [CrossRef]

94. Poverenov, E.; Leitus, G.; Shimon, L.J.W.; Milstein, D. C-Metalated Diazoalkane Complexes of Platinum Based on PCP- and PCN-Type Ligands. Organometallics 2005, 24, 5937-5944. [CrossRef]

95. Bailey, W.D.; Luconi, L.; Rossin, A.; Yakhvarov, D.; Flowers, S.E.; Kaminsky, W.; Kemp, R.A.; Giambastiani, G.; Goldberg, K.I. Pyrazole-Based PCN Pincer Complexes of Palladium(II): Mono- and Dinuclear Hydroxide Complexes and Ligand Rollover C-H Activation. Organometallics 2015, 34, 3998-4010. [CrossRef]

96. Mousa, A.H.; Bendix, J.; Wendt, O.F. Synthesis, Characterization, and Reactivity of PCN Pincer Nickel Complexes. Organometallics 2018, 37, 2581-2593. [CrossRef]

97. Grove, D.M.; Verschuuren, A.H.; van Koten, G.; van Beek, J.A. The homogeneously catalysed addition reaction of polyhalogenoalkanes to olefins by divalent arylnickel complexes: Comparative reactivity and some important mechanistic leads. $J$. Organomet. Chem. 1989, 372, C1-C6. [CrossRef]

98. Mousa, A.H.; Polukeev, A.V.; Hansson, J.; Wendt, O.F. Carboxylation of the Ni-Me Bond in an Electron-Rich Unsymmetrical PCN Pincer Nickel Complex. Organometallics 2020, 39, 1553-1560. [CrossRef]

99. Rossin, A.; Peruzzini, M.; Zanobini, F. Nickel(II) hydride and fluoride pincer complexes and their reactivity with Lewis acids BX3.L (X = H, L = thf; X = F, L = Et $\left.t_{2} \mathrm{O}\right)$. Dalton Trans. 2011, 40, 4447-4452. [CrossRef] [PubMed]

100. Enthaler, S.; Brück, A.; Kammer, A.; Junge, H.; Irran, E.; Gülak, S. Exploring the Reactivity of Nickel Pincer Complexes in the Decomposition of Formic Acid to $\mathrm{CO}_{2} / \mathrm{H}_{2}$ and the Hydrogenation of $\mathrm{NaHCO}_{3}$ to HCOONa. ChemCatChem 2014, 7, 65-69. [CrossRef]

101. Wang, L.; Sun, W.-H.; Han, L.; Yang, H.-J.; Hu, Y.; Jin, X. Late transition metal complexes bearing 2,9-bis(imino)-1,10phenanthrolinyl ligands: Synthesis, characterization and their ethylene activity. J. Organomet. Chem. 2002, 658, 62-70. [CrossRef]

102. Sun, W.-H.; Zhang, S.; Jie, S.; Zhang, W.; Li, Y.; Ma, H.; Chen, J.; Wedeking, K.; Fröhlich, R. Synthesis, characterization and ethylene oligomerization studies of nickel complexes bearing 2-imino-1,10-phenanthrolines. J. Organomet. Chem. 2006, 691, 4196-4203. [CrossRef]

103. Jie, S.; Zhang, S.; Sun, W.-H. 2-Arylimino-9-phenyl-1,10-phenanthrolinyl-iron, -cobalt and -nickel Complexes: Synthesis, Characterization and Ethylene Oligomerization Behavior. Eur. J. Inorg. Chem. 2007, 2007, 5584-5598. [CrossRef]

104. Hao, P.; Zhang, S.; Sun, W.-H.; Shi, Q.; Adewuyi, S.; Lu, X.; Li, P. Synthesis, Characterization and Ethylene Oligomerization Studies of Nickel Complexes Bearing 2-Benzimidazolylpyridine Derivatives. Organometallics 2007, 26, 2439-2446. [CrossRef]

105. Tang, X.; Sun, W.-H.; Gao, T.; Hou, J.; Chen, J.; Chen, W. Nickel(II) complexes bearing 2-ethylcarboxylate-6-iminopyridyl ligands: Synthesis, structures and their catalytic behavior for ethylene oligomerization and polymerization. J. Organomet. Chem. 2005, 690, 1570-1580. [CrossRef]

106. Liu, H.; Zhang, L.; Chen, L.; Redshaw, C.; Li, Y.; Sun, W.-H. Synthesis, characterization and ethylene oligomerization behavior of 2-benzoimidazol-8-ethoxyquinolylnickel dihalides. Dalton Trans. 2011, 40, 2614-2621. [CrossRef]

107. Luconi, L.; Tuci, G.; Gafurov, Z.N.; Mercuri, G.; Kagilev, A.A.; Pettinari, C.; Morozov, V.I.; Yakhvarov, D.G.; Rossin, A.; Giambastiani, G. Unsymmetrical nickel (PCN) pincer complexes with a benzothiazole side-arm: Synthesis, characterization and electrochemical properties. Inorg. Chim. Acta 2021, 517, 120182. [CrossRef]

108. Gafurov, Z.N.; Zueva, E.M.; Bekmukhamedov, G.E.; Kagilev, A.A.; Kantyukov, A.O.; Mikhailov, I.K.; Khayarov, K.R.; Petrova, M.M.; Dovzhenko, A.P.; Rossin, A.; et al. Benzothiazole- vs. pyrazole-based unsymmetrical (PCN) pincer complexes of nickel(II) as homogeneous catalysts in ethylene oligomerization. J. Organomet. Chem. 2021, 949, 121951. [CrossRef]

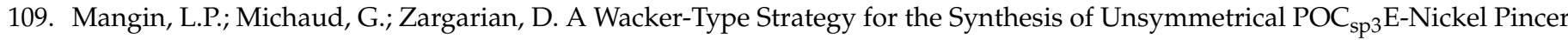
Complexes. Organometallics 2020, 39, 4006-4018. [CrossRef]

110. Liang, L.-C.; Chien, P.-S.; Lin, J.-M.; Huang, M.-H.; Huang, A.Y.-L.; Liao, J.-H. Amido Pincer Complexes of Nickel(II): Synthesis, Structure, and Reactivity. Organometallics 2006, 25, 1399-1411. [CrossRef]

111. Mastalir, M.; Kirchner, K. A triazine-based Ni(II) PNP pincer complex as catalyst for Kumada-Corriu and Negishi cross-coupling reactions. Monatshefte Chem. Chem. Mon. 2016, 148, 105-109. [CrossRef] [PubMed] 
112. Guo, W.-J.; Wang, Z.-X. Cross-Coupling of ArX with ArMgBr Catalyzed by N-Heterocyclic Carbene-Based Nickel Complexes. J. Org. Chem. 2013, 78, 1054-1061. [CrossRef] [PubMed]

113. Wu, D.; Wang, Z.-X. P,N,N-Pincer nickel-catalyzed cross-coupling of aryl fluorides and chlorides. Org. Biomol. Chem. 2014, 12, 6414-6424. [CrossRef] [PubMed]

114. Asano, E.; Hatayama, Y.; Kurisu, N.; Ohtani, A.; Hashimoto, T.; Kurihara, Y.; Ueda, K.; Ishihara, S.; Nagao, H.; Yamaguchi, Y. Acetylacetonato-based pincer-type nickel(II) complexes: Synthesis and catalysis in cross-couplings of aryl chlorides with aryl Grignard reagents. Dalton Trans. 2018, 47, 8003-8012. [CrossRef] [PubMed]

115. Hashimoto, T.; Shiota, K.; Yamaguchi, Y. Selective Synthesis of Secondary Alkylboronates: Markovnikov-Selective Hydroboration of Vinylarenes with Bis(pinacolato)diboron Catalyzed by a Nickel Pincer Complex. Org. Lett. 2020, 22, 4033-4037. [CrossRef] [PubMed]

116. Kurisu, N.; Asano, E.; Hatayama, Y.; Kurihara, Y.; Hashimoto, T.; Funatsu, K.; Ueda, K.; Yamaguchi, Y. A $\beta$-Diketiminato-Based Pincer-Type Nickel(II) Complex: Synthesis and Catalytic Performance in the Cross-Coupling of Aryl Fluorides with Aryl Grignard Reagents. Eur. J. Inorg. Chem. 2019, 2019, 126-133. [CrossRef]

117. Das, S.; Subramaniyan, V.; Mani, G. Nickel(II) and Palladium(II) Complexes Bearing an Unsymmetrical Pyrrole-Based PNN Pincer and Their Norbornene Polymerization Behaviors versus the Symmetrical NNN and PNP Pincers. Inorg. Chem. 2019, 58, 3444-3456. [CrossRef] [PubMed]

118. Grüger, N.; Wadepohl, H.; Gade, L.H. A readily accessible PNP pincer ligand with a pyrrole backbone and its $\mathrm{Ni}^{\mathrm{I} / \mathrm{II}}$ chemistry. Dalton Trans. 2012, 41, 14028-14030. [CrossRef] [PubMed]

119. Venkanna, G.T.; Ramos, T.V.M.; Arman, H.D.; Tonzetich, Z.J. Nickel(II) Complexes Containing a Pyrrole-Diphosphine Pincer Ligand. Inorg. Chem. 2012, 51, 12789-12795. [CrossRef] [PubMed]

120. Kessler, J.A.; Iluc, V.M. NI(II) phosphine and phosphide complexes supported by a PNP-pyrrole pincer ligand. Dalton Trans. 2017, 46, 12125-12131. [CrossRef] [PubMed]

121. Kumar, S.; Mani, G.; Mondal, S.; Chattaraj, P.K. Pyrrole-Based New Diphosphines: Pd and Ni Complexes Bearing the PNP Pincer Ligand. Inorg. Chem. 2012, 51, 12527-12539. [CrossRef]

122. Fryzuk, M.D.; MacNeil, P.A.; Rettig, S.J.; Secco, A.S.; Trotter, J. Tridentate amidophosphine derivatives of the nickel triad: Synthesis, characterization, and reactivity of nickel(II), palladium(II), and platinum(II) amide complexes. Organometallics 1982, 1, 918-930. [CrossRef]

123. Liu, H.; Yuan, H.; Shi, X. Synthesis of nickel and palladium complexes with diarylamido-based unsymmetrical pincer ligands and application for norbornene polymerization. Dalton Trans. 2018, 48, 609-617. [CrossRef]

124. Wang, D.; Gardinier, J.R. The Electronic Properties of Ni(PNN) Pincer Complexes Modulate Activity in Catalytic Hydrodehalogenation Reactions. Eur. J. Inorg. Chem. 2020, 2020, 4425-4434. [CrossRef]

125. Weidauer, M.; Irran, E.; Someya, C.I.; Haberberger, M.; Enthaler, S. Nickel-catalyzed hydrodehalogenation of aryl halides. J. Organomet. Chem. 2013, 729, 53-59. [CrossRef]

126. Affan, M.A.; Schatte, G.; Jessop, P.G. Formylation of Amines by $\mathrm{CO}_{2}$ Hydrogenation Using Preformed Co(II)/Nickel(II) Complexes. Inorg. Chem. 2020, 59, 14275-14279. [CrossRef] [PubMed]

127. Srimani, D.; Mukherjee, A.; Goldberg, A.F.G.; Leitus, G.; Diskin-Posner, Y.; Shimon, L.J.W.; Ben David, Y.; Milstein, D. CobaltCatalyzed Hydrogenation of Esters to Alcohols: Unexpected Reactivity Trend Indicates Ester Enolate Intermediacy. Angew. Chem. Int. Ed. 2015, 54, 12357-12360. [CrossRef]

128. Van Der Vlugt, J.I.; Lutz, M.; Pidko, E.A.; Vogt, D.; Spek, A.L. Cationic and neutral Ni ${ }^{\mathrm{II}}$ complexes containing a non-innocent PNP ligand: Formation of alkyl and thiolate species. Dalton Trans. 2009, 1016-1023. [CrossRef]

129. Xiang, W.; Luo, Q.; Jiang, H.; Meng, X.; Li, R.; Zhang, J.; Peng, T. New Ni(II) complexes based on $\mathrm{N}^{\prime} \mathrm{NN}^{\prime}$ pincer ligands: Syntheses, structures and B-F cleavage of BF4- promoted by a di-cationic Ni(II) center. J. Coord. Chem. 2016, 69, 2353-2363. [CrossRef]

130. Lansing, R.B.; Goldberg, K.I.; Kemp, R.A. Unsymmetrical RPNPR' pincer ligands and their group 10 complexes. Dalton Trans. 2011, 40, 8950-8958. [CrossRef]

131. Liang, L.-C.; Chien, P.-S.; Lee, P.-Y. Phosphorus and Olefin Substituent Effects on the Insertion Chemistry of Nickel(II) Hydride Complexes Containing Amido Diphosphine Ligands. Organometallics 2008, 27, 3082-3093. [CrossRef]

132. Liang, L.-C.; Li, C.-W.; Lee, P.-Y.; Chang, C.-H.; Lee, H.M. A terminal nickel(II) anilide complex featuring an unsymmetrically substituted amido pincer ligand: Synthesis and reactivity. Dalton Trans. 2011, 40, 9004-9011. [CrossRef] [PubMed]

133. Liang, L.-C.; Hung, Y.-T.; Huang, Y.-L.; Chien, P.-S.; Lee, P.-Y.; Chen, W.-C. Divergent Carbonylation Reactivity Preferences of Nickel Complexes Containing Amido Pincer Ligands: Migratory Insertion versus Reductive Elimination. Organometallics 2011, 31, 700-708. [CrossRef]

134. Wilson, D.J.D.; Couchman, S.A.; Dutton, J. Are N-Heterocyclic Carbenes “Better" Ligands than Phosphines in Main Group Chemistry? A Theoretical Case Study of Ligand-Stabilized E2 Molecules, L-E-E-L (L = NHC, phosphine; E = C, Si, Ge, Sn, Pb, N, $\mathrm{P}, \mathrm{As}, \mathrm{Sb}, \mathrm{Bi})$. Inorg. Chem. 2012, 51, 7657-7668. [CrossRef] [PubMed]

135. Sun, Y.; Li, X.; Sun, H. [CNN]-pincer nickel(ii) complexes of N-heterocyclic carbene (NHC): Synthesis and catalysis of the Kumada reaction of unactivated C-Cl bonds. Dalton Trans. 2014, 43, 9410-9413. [CrossRef] [PubMed]

136. Wang, Z.; Zheng, T.; Sun, H.; Li, X.; Fuhr, O.; Fenske, D. Sonogashira reactions of alkyl halides catalyzed by NHC [CNN] pincer nickel(ii) complexes. New J. Chem. 2018, 42, 11465-11470. [CrossRef] 
137. Wang, Z.; Li, X.; Sun, H.; Fuhr, O.; Fenske, D. Synthesis of NHC Pincer Hydrido Nickel Complexes and Their Catalytic Applications in Hydrodehalogenation. Organometallics 2018, 37, 539-544. [CrossRef]

138. Wang, Z.; Li, X.; Xie, S.; Zheng, T.; Sun, H. Transfer hydrogenation of ketones catalyzed by nickel complexes bearing an NHC [CNN] pincer ligand. Appl. Organomet. Chem. 2019, 33, e4932. [CrossRef]

139. Yan, J.; Wang, Y.-B.; Zhu, Z.-H.; Li, Y.; Zhu, X.; Hao, X.-Q.; Song, M.-P. Synthesis, Characterization, and Catalytic Studies of Unsymmetrical Chiral NCC Pincer Pd(II) and Ni(II) Complexes Bearing (Imidazolinyl)aryl NHC Ligands. Organometallics 2018, 37, 2325-2334. [CrossRef]

140. Gu, S.; Du, J.; Huang, J.; Guo, Y.; Yang, L.; Xu, W.; Chen, W. Unsymmetrical NCN-pincer mononuclear and dinuclear nickel(ii) complexes of N-heterocyclic carbene (NHC): Synthesis, structure and catalysis for Suzuki-Miyaura cross-coupling. Dalton Trans. 2016, 46, 586-594. [CrossRef] [PubMed]

141. Gafurov, Z.N.; Kantyukov, A.O.; Kagilev, A.A.; Sakhapov, I.F.; Luconi, L.; Rossin, A.; Giambastiani, G.; Babaev, V.M.; Islamov, D.R.; Usachev, K.S.; et al. Electrochemical Generation of Pyrazolyl-Pyridyl N-Heterocyclic Carbene Complexes of Nickel. Russ. J. Electrochem. 2021, 57, 134-140. [CrossRef]

142. Gafurov, Z.N.; Kantyukov, A.O.; Kagilev, A.A.; Sinyashin, O.G.; Yakhvarov, D.G. Electrochemical methods for synthesis and in situ generation of organometallic compounds. Coord. Chem. Rev. 2021, 442, 213986. [CrossRef]

143. Vabre, B.; Canac, Y.; Duhayon, C.; Chauvin, R.; Zargarian, D. Nickel(II) complexes of the new pincer-type unsymmetrical ligands PIMCOP, PIMIOCOP, and NHCCOP: Versatile binding motifs. Chem. Commun. 2012, 48, 10446-10448. [CrossRef]

144. Serrano-Becerra, J.M.; Valdés, H.; Canseco-González, D.; Gomez-Benitez, V.; Hernández-Ortega, S.; Morales-Morales, D. C-S cross-coupling reactions catalyzed by a non-symmetric phosphinito-thiophosphinito PSCOP-Ni(II) pincer complex. Tetrahedron Lett. 2018, 59, 3377-3380. [CrossRef]

145. Shi, R.; Wodrich, M.D.; Pan, H.; Tirani, F.F.; Hu, X. Functional Models of the Nickel Pincer Nucleotide Cofactor of Lactate Racemase. Angew. Chem. Int. Ed. 2019, 58, 16869-16872. [CrossRef]

146. Nevarez, J.L.; Turmo, A.; Hu, J.; Hausinger, R.P. Biological Pincer Complexes. ChemCatChem 2020, 12, 4242-4254. [CrossRef]

147. Liu, X.; Qiu, B.; Yang, X. Bioinspired Design and Computational Prediction of SCS Nickel Pincer Complexes for Hydrogenation of Carbon Dioxide. Catalysts 2020, 10, 319. [CrossRef]

148. Qiu, B.; Wang, W.; Yang, X. Computational Design of SCS Nickel Pincer Complexes for the Asymmetric Transfer Hydrogenation of 1-Acetonaphthone. Catalysts 2019, 9, 101. [CrossRef]

149. Scheerder, A.R.; Lutz, M.; Broere, D.L.J. Unexpected reactivity of a PONNOP 'expanded pincer' ligand. Chem. Commun. 2020, 56, 8198-8201. [CrossRef] [PubMed]

150. Favela-Mendoza, R.; Rufino-Felipe, E.; Valdés, H.; Toscano, R.A.; Hernandez-Ortega, S.; Morales-Morales, D. Synthesis and characterization of non-symmetric Ni(II)- and Pd(II)-POCOP pincer complexes derived from 1,7-naphthalenediol. Evaluation of their catalytic activity in Suzuki-Miyaura couplings. Inorg. Chim. Acta 2020, 512, 119920. [CrossRef]

151. Estudiante-Negrete, F.; Hernández-Ortega, S.; Morales-Morales, D. Ni(II)-POCOP pincer compound $\left.\left[\mathrm{NiCl}_{2} \mathrm{C}_{10} \mathrm{H}_{5}-2,10-(\mathrm{OPPh})_{2}\right\}\right]$ an efficient and robust nickel catalyst for the Suzuki-Miyaura coupling reactions. Inorg. Chim. Acta 2012, 387, 58-63. [CrossRef]

152. Wang, C.; Huang, K.; Ye, J.; Duan, W.-L. Asymmetric Synthesis of P-Stereogenic Secondary Phosphine-Boranes by an Unsymmetric Bisphosphine Pincer-Nickel Complex. J. Am. Chem. Soc. 2021, 143, 5685-5690. [CrossRef] [PubMed]

153. Valderrama-García, B.X.; Rufino-Felipe, E.; Valdés, H.; Hernandez-Ortega, S.; Aguilar-Castillo, B.A.; Morales-Morales, D. Novel and facile procedure for the synthesis of $\mathrm{Ni}(\mathrm{II})$ and $\mathrm{Pd}(\mathrm{II}) \mathrm{PSCOP}$ pincer complexes. Evaluation of their catalytic activity on C-S, C-Se and C-C cross coupling reactions. Inorg. Chim. Acta 2020, 502, 119283. [CrossRef]

154. Li, H.; Gonçalves, T.P.; Zhao, Q.; Gong, D.; Lai, Z.; Wang, Z.-X.; Zheng, J.; Huang, K.-W. Diverse catalytic reactivity of a dearomatized $\mathrm{PN}^{3} \mathrm{P}^{*}$-nickel hydride pincer complex towards $\mathrm{CO}_{2}$ reduction. Chem. Commun. 2018, 54, 11395-11398. [CrossRef] [PubMed] 